\title{
Organ preserving treatment in rectal cancer
}

\author{
Citation for published version (APA):
}

Hupkens, B. J. P. (2019). Organ preserving treatment in rectal cancer: patient selection - quality of life costs. [Doctoral Thesis, Maastricht University]. Optima, Rotterdam.

https://doi.org/10.26481/dis.20191129bh

Document status and date:

Published: 01/01/2019

DOI:

10.26481/dis.20191129bh

Document Version:

Publisher's PDF, also known as Version of record

\section{Please check the document version of this publication:}

- A submitted manuscript is the version of the article upon submission and before peer-review. There can be important differences between the submitted version and the official published version of record.

People interested in the research are advised to contact the author for the final version of the publication, or visit the DOI to the publisher's website.

- The final author version and the galley proof are versions of the publication after peer review.

- The final published version features the final layout of the paper including the volume, issue and page numbers.

Link to publication

\footnotetext{
General rights rights.

- You may freely distribute the URL identifying the publication in the public portal. please follow below link for the End User Agreement:

www.umlib.nl/taverne-license

Take down policy

If you believe that this document breaches copyright please contact us at:

repository@maastrichtuniversity.nl

providing details and we will investigate your claim.
}

Copyright and moral rights for the publications made accessible in the public portal are retained by the authors and/or other copyright owners and it is a condition of accessing publications that users recognise and abide by the legal requirements associated with these

- Users may download and print one copy of any publication from the public portal for the purpose of private study or research.

- You may not further distribute the material or use it for any profit-making activity or commercial gain

If the publication is distributed under the terms of Article $25 \mathrm{fa}$ of the Dutch Copyright Act, indicated by the "Taverne" license above, 


\section{Organ preserving treatment in rectal cancer patient selection - quality of life - costs}


(C) Britt Josephina Petrus Hupkens, Maastricht 2019

No part of this book may be reproduced or transmitted in any form or by any means, without prior permission in writing by author, or when appropriate, by the publishers of the publications.

Layout: Tiny Wouters

Cover design: Luuk Beursgens

Production: Optima

ISBN: 978-94-6361-315-6

Printing and disseminations of this theses was financially supported by Maastricht University, de Nederlandse Vereniging voor Gastro-enterologie (NVGE) and Medical Research Data Management B.V. (MRDM) 


\title{
Organ preserving treatment in rectal cancer patient selection - quality of life - costs
}

\author{
PROEFSCHRIFT \\ ter verkrijging van de graad van doctor aan de Universiteit Maastricht, \\ op gezag van de Rector Magnificus, Prof. dr. Rianne M. Letschert, \\ volgens het besluit van het College van Decanen, \\ in het openbaar te verdedigen \\ op vrijdag 29 november om 10.00 uur
}

door

Britt Josephina Petrus Hupkens 


\section{Promotores}

Prof. dr. GL Beets

Prof. dr. RGH Beets-Tan

\section{Copromotores}

Dr. SO Breukink

Dr. M Maas. Antoni van Leeuwenhoek ziekenhuis, Amsterdam

\section{Beoordelingscommissie}

Prof. dr. LPS Stassen (voorzitter)

Prof. dr. LJ Boersma

Dr. C Mihl

Prof. dr. JF Lange, Erasmus Medisch Centrum

Prof. dr. JHW de Wilt, Radboud UMC Nijmegen 


\section{Contents}

$\begin{array}{lll}\text { Chapter } 1 \quad \text { General introduction } & 7\end{array}$

$\begin{array}{lll}\text { PART I } & \text { Patient selection and follow-up } & 21\end{array}$

Chapter 2 Organ preservation in rectal cancer after chemoradiation: 23 should we extend the observation period in patients with a clinical near complete response?

Chapter 3 MRI surveillance for the detection of local recurrence in rectal cancer after Transanal Endoscopic Microsurgery

PART II Quality of life and functional outcome $\quad 57$

Chapter 4 Quality of life in rectal cancer patients after chemoradiation: $\quad 59$ watch-and-wait policy versus standard resection - a matched controlled study

Chapter 5 Impact of radiotherapy on anorectal function in patients with rectal cancer following a watch-and-wait programme

Chapter 6 Dutch validation of the Low Anterior Resection Syndrome 95 Score

PART III Costs

Chapter 7 Oncological outcomes and hospital costs of the treatment in rectal cancer patients: watch-and-wait policy and standard surgical treatment

Chapter 8 General discussion

Chapter 9 Summary

Chapter 10 Nederlandse samenvatting

Appendix Valorisation

Dankwoord 169

Curriculum Vitae

List of publications 


Chapter 1 


\section{General introduction}

Colorectal cancer is the second most common cancer in the Netherlands, with approximately 15.000 new cases each year, of which one third are located in the rectum $^{1,2}$. One of the main problems after treatment of rectal cancer used to be the high rate of local recurrences, which are notoriously difficult to treat and can cause severe symptoms. Surgical technique was improved in the 90's, with the concept of total mesorectal excision (TME), leading to a reduction in the local recurrence rate to $5-10 \%{ }^{3,4}$.

Another way to reduce the local recurrence rate is by the use of neoadjuvant radiotherapy. The Swedish rectal cancer trial and Dutch TME trial assessed the influence of neoadjuvant short course radiotherapy (5x5Gy), and found a reduction in local recurrence rate with the added $5 \times 5 \mathrm{~Gy}$ from $26-27 \%$ to $9-11 \%, 5$. The Dutch TME trial subgroup analysis showed that patients with stage I rectal cancer (T1-2N0) do not benefit from neoadjuvant radiation, due to an already low local recurrence rate, whereas patients with stage III rectal cancer $(\mathrm{TxN}+)$ showed the largest benefit. The more locally advanced patients still had a relatively high local recurrence rate, and they generally are treated with a more intensive neoadjuvant treatment with a long course of chemoradiation (CRT) followed by a long interval to surgery, which reduced the risk of a local recurrence significantly ${ }^{7}$. In $15-20 \%$ of patients treated with CRT, the definitive histology shows a complete pathological response. The idea behind the new watch-and-wait (W\&W) concept is to identify these patients as so called 'clinical complete responders' and enter them in a stringent follow-up protocol instead of TME surgery ${ }^{8-14}$.

\section{Why consider watch-and-wait instead of the standard TME surgery?}

With optimal MRI staging, neoadjuvant (chemo)radiation (CRT) in high risk patients, and good TME surgery, local recurrence rates are down to $5 \%$. However, this improved oncological outcome comes at a cost. Especially for the elderly and in patients with comorbidity, rectal resections are major procedures with substantial peri-operative morbidity and mortality. Whereas the overall mortality of rectal cancer surgery is $2-3 \%$, mortality rates in the range of $10-15 \%$ have been documented in patients over 80 years of age in a large population 
database $^{15}$. The 6-month mortality can be even as high as $15-25 \%{ }^{15}$. There is also considerable long-term anorectal and urogenital dysfunction in a number of patients, and many patients loath the idea of having a colostomy ${ }^{16}$. Ultralow anastomoses in patients with distal rectal cancer can avoid a stoma, but often leave the patient with a dubious degree of continence ${ }^{17}$. For the frail and elderly patients clinicians can easily balance the decreased morbidity by omitting surgical treatment against the increased oncological risk of $W \& W$ in clinical complete responders. Many clinicians did feel much less comfortable with a fit and healthy patient who desperately wants to avoid a stoma or incontinence, and who were willing to run a small or unknown oncological risk.

\section{Why consider watch-and-wait instead of local excision?}

Local excision of the remaining scar with a good surgical technique (TEM or related technique) offers two main advantages: firstly, it provides histological proof of a complete response, and secondly it clears the bowel wall of a small tumour remnant enabling organ preservation for more patients (i.e. small ypT1 remnant). The main disadvantage is that patients with a local excision after (chemo)radiation have a higher complication rate than non-irradiated patients, with a painful slow healing ulcer as one of the more troublesome complications $^{18,19}$. An additional disadvantage is that follow-up after a local excision is more challenging than after W\&W, both with endoscopy and MRI, especially when there is an extensive inflammatory reaction. It is clear that in patients who have a true complete response, a local excision to obtain histological proof is of no benefit to the patient. The issue whether or not performing a local excision comes down to the accuracy of the clinical assessment of a complete response, together with the consequences of a W\&W approach in a patient with undetected residual tumour. While the exact roles of W\&W and local excision will need to be resolved by further studies, it is our feeling that local excision will eventually be limited to small tumour remnants or equivocal responses.

\section{Who are candidates for a watch-and-wait approach?}

W\&W is generally not considered as standard practice, and is something than can be discussed with patients as an alternative treatment with specific benefits 
and risks. There are two phases in the treatment where the option of "watch and wait" can be considered: first at primary presentation, and second after evaluation of the effect of CRT.

At primary presentation consideration of a "watch and wait" strategy can be complicated. Patients who would benefit the most are the patients with a high operative risk, and/or patients with a distal tumour. The difficulty is that by no means one can predict who will show a very good response and will be amenable to organ preservation by either W\&W or local excision after chemoradiation. Patients with an accepted indication for neoadjuvant treatment should simply start the CRT and take a decision based on the restaging afterwards. The more controversial but also potentially more rewarding group of patients, are those with smaller tumours that can be treated with TME surgery without neoadjuvant therapy. This leads to a dilemma in clinical practice for both clinicians and patients. Although they have a higher response rate with a chance for organ preservation of approaching 50\%, patients who still require TME surgery may end up with a worse functional outcome than if they would have had without neoadjuvant therapy. A number of trials is addressing this question, like the STAR TREC trial and the TESAR trial ${ }^{20}$.

After chemoradiation the consideration of organ preservation is easier. Whether or not neoadjuvant therapy was given with the specific aim for organ preservation, it can be argued that all patients should be re-assessed after an 8-12 week interval ${ }^{21}$. Patients who have an excellent response should be considered possible candidates for organ preservation, even when the primary tumour was relatively large. A meta-analysis showed complete response rates for T1 tumours of around $50 \%$, for T2 tumours 30\%, for T3 tumours $15 \%$ and for T4 tumours $10 \%$. Series that include complete responses of larger tumours suggest that, although the percentage of complete responses is lower, when they do occur, they have the same outcome as in smaller tumours ${ }^{8,11,22}$.

\section{How best to assess the response after (chemo)radiation?}

Traditionally, surgery was performed 6 weeks after CRT, and restaging was considered optional. In order to detect clinical complete responses most centres are now restaging routinely, and because of increasing evidence of a higher rate of complete response a longer interval of 8-12 weeks is now recommended ${ }^{23}$. The more commonly used assessment techniques to evaluate the response are digital rectal examination (DRE), endoscopy and $\mathrm{MRI}$, while endorectal 
ultrasound and PET-scan are less often used ${ }^{24}$. In 2010 Habr-Gama et al. was the first to describe the features of a clinical complete response at DRE and endoscopy ${ }^{25}$. The diagnostic process of assessing the response is rapidly evolving, especially with MRI. Additional to standard MRI T2-weighted imaging functional sequences like diffusion-weighted MRI can improve the accuracy. In our unit we are currently using criteria similar to those of Habr-Gama, supplemented by MRI imaging, summarized in Table $1.1^{9}$. Examples are shown in Figures 1.1-3. A negative biopsy does not exclude the presence of residual tumour, while a positive biopsy taken after a period of at least 8-10 weeks constitutes residual tumour. When the endoscopic picture is clear, a biopsy is not required. The lymph nodes are mainly assessed with standard T2W MRI.

Table 1.1 - Criteria for a clinical complete response after neoadjuvant treatment.

\begin{tabular}{|c|c|c|c|}
\hline Modality & Criteria for CCR & Criteria for near cCR* & $\begin{array}{l}\text { Criteria for } \\
\text { incomplete response }\end{array}$ \\
\hline DRE & $\begin{array}{l}\text { No palpable tumour, } \\
\text { when initially palpable } \\
\text { with DRE }\end{array}$ & Small palpable flexible ridge & $\begin{array}{l}\text { Residual tumour } \\
\text { palpable }\end{array}$ \\
\hline Endoscopy & $\begin{array}{l}\text { No residual tumour } \\
\text { AND white scar }\end{array}$ & $\begin{array}{l}\text { 1. Small residual erythematous } \\
\text { ulcer } \\
\text { OR } \\
\text { 2. Irregular wall thickening }\end{array}$ & Residual tumour \\
\hline Histopathology & $\begin{array}{l}\text { Negative biopsies } \\
\text { from scar (biopsy not } \\
\text { mandatory) }\end{array}$ & Dysplastic changes & Adenocarcinoma \\
\hline \multirow{8}{*}{ MRI } & Standard T2W & Standard T2W & Standard T2W \\
\hline & $\begin{array}{l}\overline{\text { 1. Substantial }} \\
\text { downsizing with no } \\
\text { residual tumour }\end{array}$ & $\begin{array}{l}\text { 1. Obvious downstaging with } \\
\text { residual fibrosis, but heterogeneous } \\
\text { or irregular aspect and signal }\end{array}$ & $\begin{array}{l}\text { 1. Residual tumour, } \\
\text { with or without fibrosis } \\
\text { OR }\end{array}$ \\
\hline & OR & OR & 2. Lymph nodes $\geq 5 \mathrm{~mm}$ \\
\hline & $\begin{array}{l}\text { 2. Residual fibrosis } \\
\text { OR }\end{array}$ & $\begin{array}{l}\text { 2. Obvious downstaging of lymph } \\
\text { nodes, but remaining node }(\mathrm{s}) \geq 5 \mathrm{~mm}\end{array}$ & \\
\hline & $\begin{array}{l}\text { 3. Residual wall } \\
\text { thickening due to } \\
\text { edema } \\
\text { AND }\end{array}$ & & \\
\hline & $\begin{array}{l}\text { no suspicious lymph } \\
\text { nodes }\end{array}$ & & \\
\hline & DWI MRI** & $\underline{\text { DWI MRI }}$ & $\underline{\text { DWI MRI }}$ \\
\hline & $\begin{array}{l}\text { Low signal on high b- } \\
\text { value }\end{array}$ & $\begin{array}{l}\text { Small focal area of high signal on } \\
\text { high b-value }\end{array}$ & $\begin{array}{l}\text { Area of high signal on } \\
\text { high b-value }\end{array}$ \\
\hline
\end{tabular}

\footnotetext{
* patient have a clinical near complete response if they missed only one or two criteria of a clinical complete response, but matched the other criteria for a clinical near complete response; ** available since 2006. cCR: clinical complete response; DRE: digital rectal examination; T2W: T2-weighted MRI; DWI: diffusion weighted imaging; MRI: magnetic resonance imaging.
} 


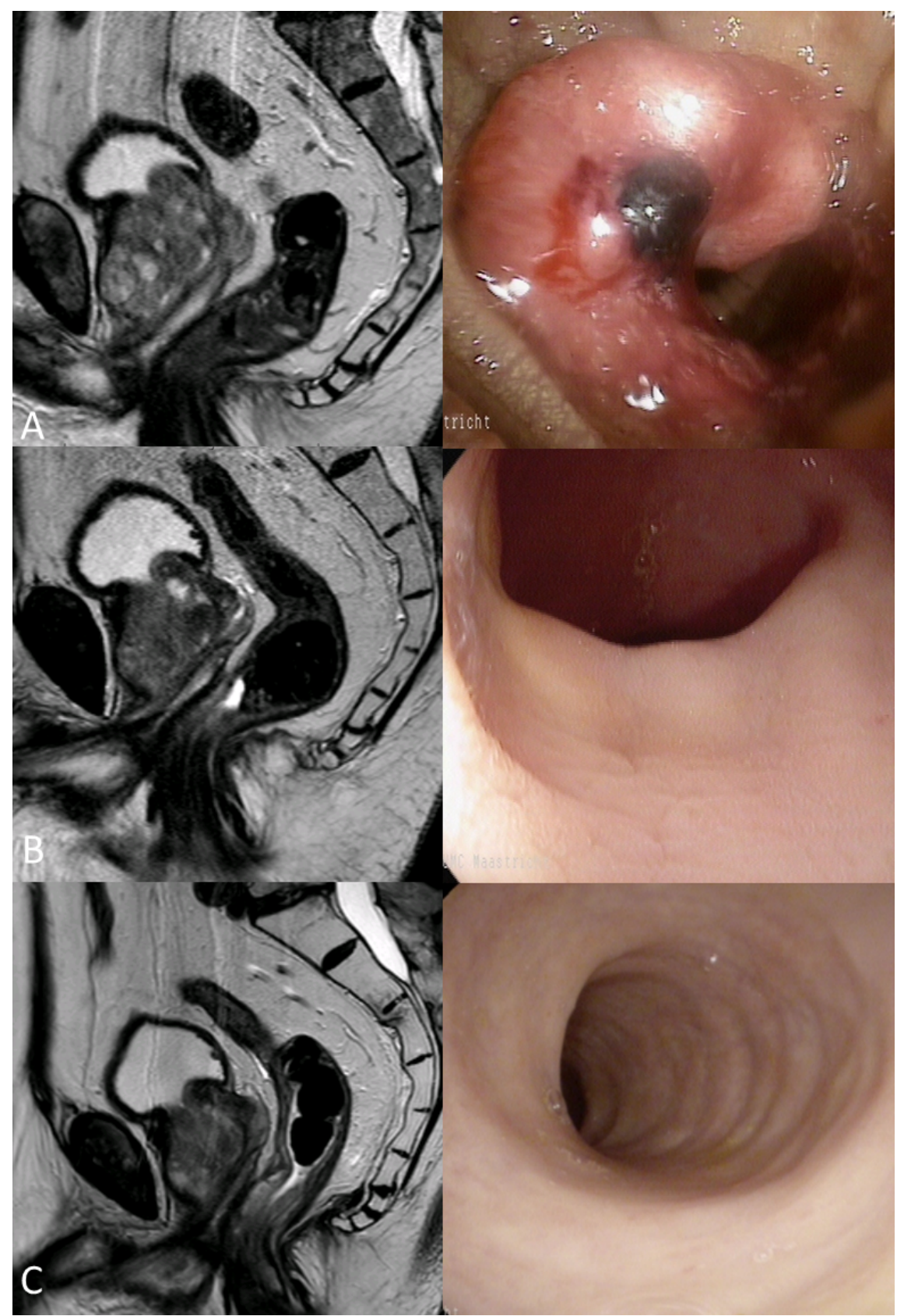

Figure 1.1 - Typical complete response. A: pre-CRT, cT3N1 rectal cancer at 3,5cm of the anorectal verge; B: post-CRT, typical complete response; C: follow-up after 4 years. 


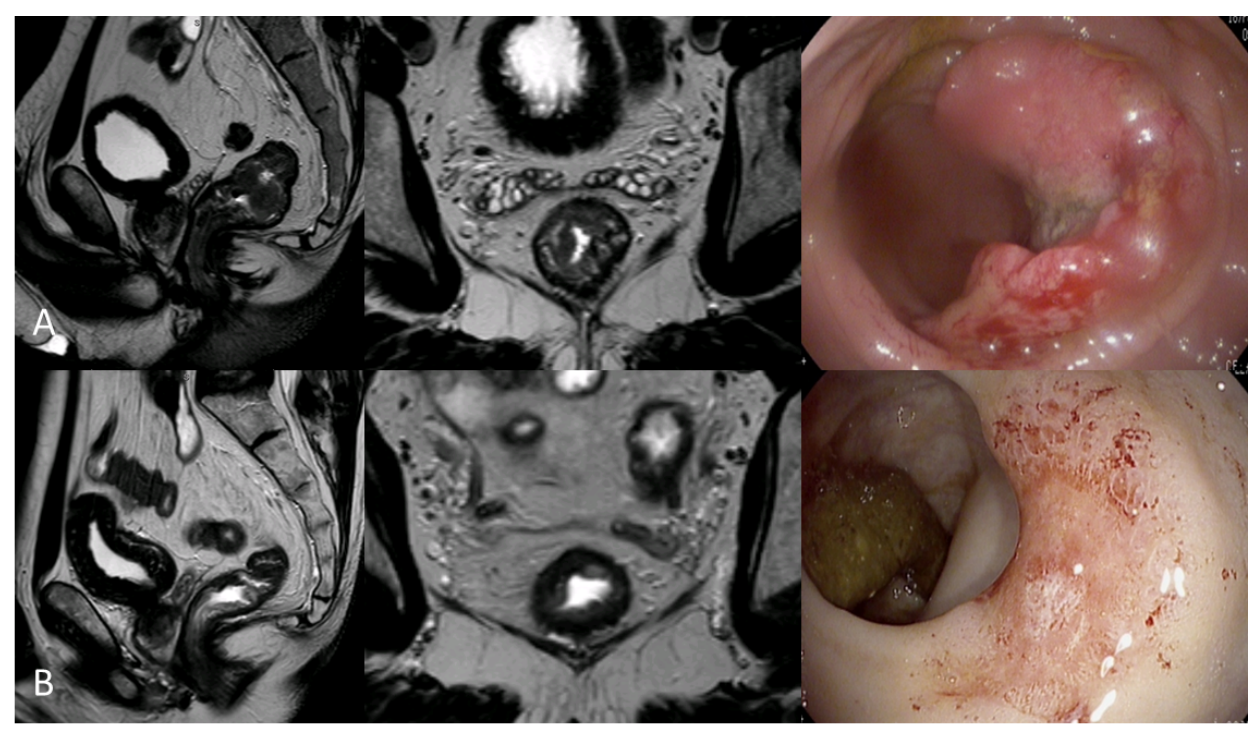

Figure 1.2 - Incomplete response. A: pre-CRT, cT3N2 rectal cancer at $4 \mathrm{~cm}$ of the anorectal verge; B: post-CRT, residual tumour on MRI and endoscopy.

\section{How to discuss the option of watch-and-wait with the patient?}

When discussing the option of W\&W at primary presentation, it should be made clear to the patient that this is not a standard treatment option yet. When there is a standard indication for neoadjuvant therapy patients should start the treatment and the decision should be based on the restaging afterwards, knowing that only a minority will develop a complete response. When a tumour can be treated with surgery only the patient should have a good understanding of the pro's and cons of starting with neoadjuvant treatment aiming at organ preservation, as the patient might end up with a worse functional outcome if good response is not obtained and TME surgery is still required. Participation in a trial that addresses this issue should be encouraged. 


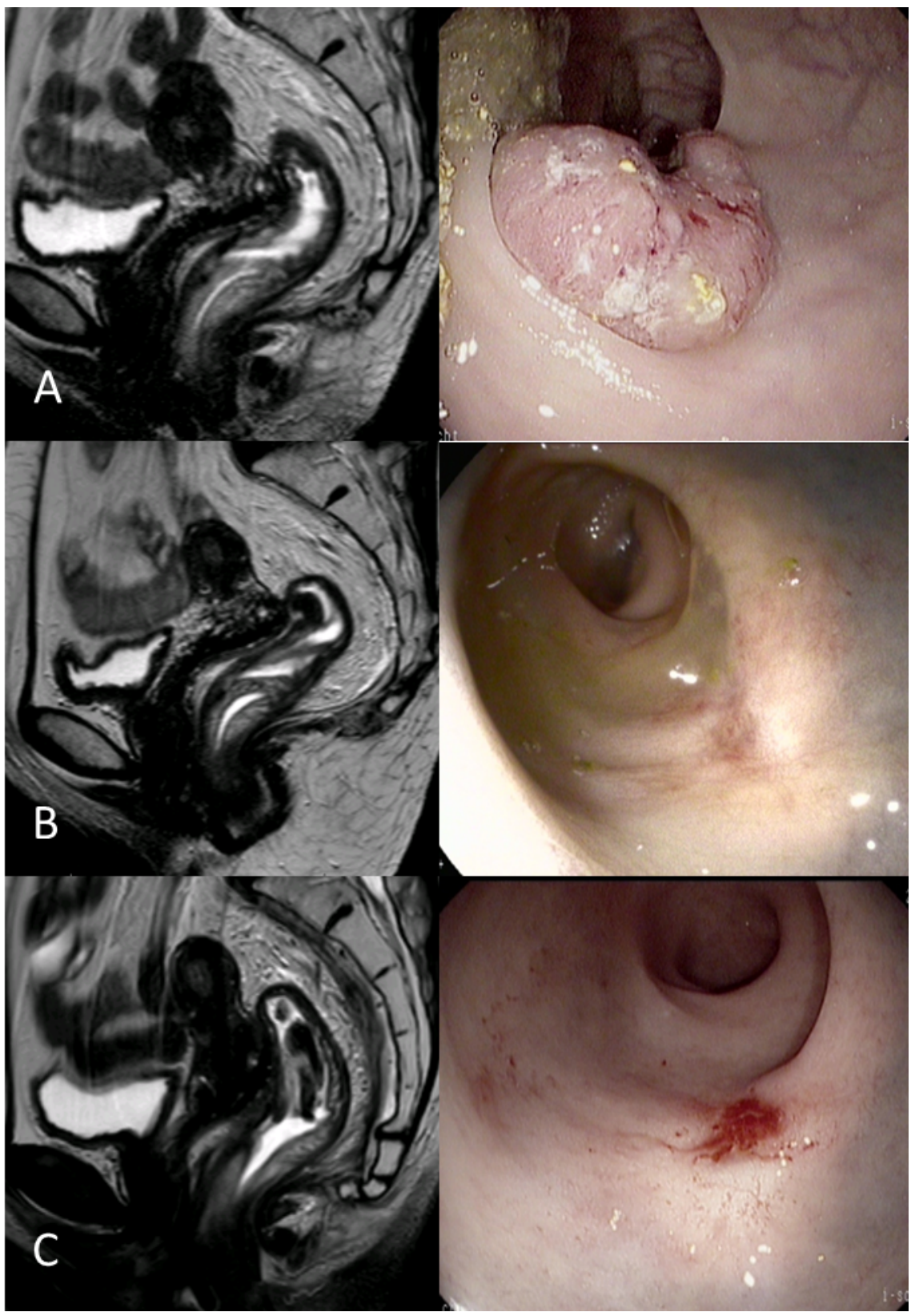

Figure 1.3 - Regrowth in follow-up after complete response. A: pre-CRT, cT3N0 rectal cancer at $4,5 \mathrm{~cm}$ of the anorectal verge; $\mathbf{B}$ : post-CRT, clinical complete response after CRT; $\mathbf{C}$ : regrowth in follow-up. 
When after restaging the patient has a very good response that is amenable to either W\&W or local excision, the patient should have a good understanding of the pro's and cons of the standard accepted TME surgery and organ preservation as an alternative. The patient should understand that TME surgery offers a well-documented oncological safety, and that after organ preservation an estimated $10-25 \%$ of patients will experience a regrowth that requires salvage TME surgery. The survival disadvantage that is associated with this regrowth is in all likelihood very low (0-5\%). However, it has to be discussed thoroughly with the patients that this aspect of organ preservation is still unclear. Additionally, the patient has to understand that a more intense follow-up programme is required to detect regrowth as early as possible. In this process of shared decision making the patient and the doctor will have to come to a wellbalanced decision. This usually requires some time and more than a single visit, but a very good response does allow for more time to take a decision.

\section{How to perform adequate follow-up?}

Inherently a part of a W\&W approach is the acceptance of a $10-25 \%$ risk for regrowth, due to residual disease not detected at restaging. In addition to the standard follow-up after treatment of rectal cancer aimed at detection of metastases, follow-up in a W\&W programme is also aiming at early detection of local regrowth. The vast majority of local regrowths are located intraluminally and occur within 12-18 months ${ }^{9}$. Therefore, frequent examination by DRE and endoscopy during the first two years is the backbone of the luminal follow-up. This should be supplemented by MRI to detect the less frequently occurring regrowths deeper in the bowel wall or lymph nodes ${ }^{26}$. The best schedule is yet to be determined, our own schedule is shown in Table 1.2.

Table 1.2 - Follow-up schedule in W\&W approach. ${ }^{8}$

\begin{tabular}{l|lllll}
\hline & Year 1 & Year 2 & Year 3 & Year 4 & Year 5 \\
\hline CT thorax/liver & 2/year & 1/year & 1/year & 1/year & 1/year \\
CEA & 4/year & 4/year & 4/year & 2/year & 2/year \\
MRI & 3/year & 2/year & 2/year & 2/year & 2/year \\
DRE & 4/year & 2/year & 2/year & 2/year & 2/year \\
Endoscopy * & 4/year & 2/year & 2/year & 2/year & 2/year \\
\hline
\end{tabular}

* In the first year of follow-up, we perform a colonoscopy at 9 months. All other moments sigmoidoscopy is performed. 


\section{How can we provide more evidence on a watch-and-wait approach?}

The highest quality of evidence would be provided by randomized trials comparing standard TME surgery with organ preservation. Such a trial is feasible in small mid-high rectal tumours where the choice is between a straightforward low anterior resection and CRT specifically aiming at organ preservation. Because a number of patients will still require a low anterior resection after CRT many clinicians and well-informed patients would be uncertain as to which is the best treatment, a status of clinical equipoise. A randomized trial is less likely to succeed in patients with distal tumours who are facing a rectal amputation and in patients who already had neoadjuvant treatment that resulted in an apparent clinical complete response. In these situations, many patients have a preference for the option that avoids a permanent colostomy or major surgery, even when informed about the potential risks involved. This causes an ethical dilemma for the surgeon who both wants to respect the patients' wishes and wants to provide evidence.

Another way to provide evidence is to pool all retrospective and prospective data of series of organ preservation by W\&W and local excision. This would provide an opportunity to study important issues like the optimal methods and criteria for selection and follow-up, and the exact risk of a potential inferior oncological outcome. Although the individual series are heterogeneous regarding selection and inclusion criteria, neoadjuvant therapy schedules, timing of inclusion and follow-up schedules, the increased statistical power of pooling allows subgroup analyses on comparable patients and clinical situations. Recently a network of interested clinicians from expert centres have set up an international registry the International Watch \& Wait Database (www.iwwd.org) under the umbrella of EURECCA (European Registration of Cancer Care) and the Champalimaud Foundation in Lisbon with the main goal to pool all available data to provide better information on the risks and benefits of organ preserving strategies. 


\section{Aims of this thesis}

As described above, the watch-and-wait (W\&W) policy seems an oncological safe option in patients with locally advanced rectal cancer. Although a lot of research is already performed, there are several questions remaining in the W\&W-policy. The following objectives are addressed in this thesis:

- Evaluation of the oncological outcome of patients entering the W\&Wprotocol after an extra waiting period (second restaging), compared to patients entering the W\&W-protocol after the first restaging;

- Evaluation of the diagnostic performance of follow-up MRI for the detection of local recurrences of rectal cancer after transanal endoscopic microsurgery (TEM);

- Comparison of quality of life between patients following a W\&W-strategy to patients treated with CRT and TME (standard treatment);

- Assessment of the impact of chemoradiotherapy on anorectal function in patients following a rectal W\&W-strategy;

- Dutch translation and validation of the LARS-score;

- Assessment of the cost-effectiveness of the W\&W-policy.

\section{Outline of this thesis}

In chapter 2 the results of the oncological outcome in a watch-and-wait strategy are shown. We compared the oncological outcome of patients entering the W\&W-strategy after first restaging 6-10 weeks after CRT to the oncological outcome of patients entering the W\&W-strategy after a second restaging after an extra 6 to 12 weeks. Chapter 3 will discuss the results of a retrospective analysis of the diagnostic performance of MRI to detect recurrence in the follow-up of rectal cancer patients after transanal endoscopic microsurgery. In chapter 4 we compared the quality of life of patients treated in a W\&W-strategy after CRT with patients treated with TME surgery after CRT. Chapter 5 discusses the correlation between quality of life, anorectal manometric results and radiotherapy doses and fields in W\&W-patients. In chapter 6 the Dutch translation of the LARS-score was validated in patients who underwent surgery for rectal cancer. Finally, in Chapter 7 a cost-effectiveness analysis was performed of the treatment of locally advanced rectal cancer, where we analysed the hospital costs of a TME subgroup and a W\&W subgroup. 


\section{References}

1. Landelijke_Werkgroep_Gastro-Intestinale_Tumouren. Landelijke Richtlijn Rectumcarcinoom (version 3.0). wwwoncolinenl. 2016.

2. Nederland IK. Cijfers over kanker. http://wwwcijfersoverkankernl/nkr/index. 2016.

3. Quirke P, Durdey P, Dixon MF, Williams NS. Local recurrence of rectal adenocarcinoma due to inadequate surgical resection. Histopathological study of lateral tumour spread and surgical excision. Lancet. 1986;2(8514):996-9.

4. Heald RJ, Ryall RD. Recurrence and survival after total mesorectal excision for rectal cancer. Lancet. 1986;1(8496):1479-82.

5. Kapiteijn E, Marijnen CA, Nagtegaal ID, Putter H, Steup WH, Wiggers T, et al. Preoperative radiotherapy combined with total mesorectal excision for resectable rectal cancer. $\mathrm{N}$ Engl $\mathrm{J}$ Med. 2001;345(9):638-46.

6. Improved survival with preoperative radiotherapy in resectable rectal cancer. Swedish Rectal Cancer Trial. N Engl J Med. 1997;336(14):980-7.

7. Sauer R, Becker H, Hohenberger W, Rodel C, Wittekind C, Fietkau R, et al. Preoperative versus postoperative chemoradiotherapy for rectal cancer. N Engl J Med. 2004;351(17): $1731-40$.

8. Maas M, Beets-Tan RG, Lambregts DM, Lammering G, Nelemans PJ, Engelen SM, et al. Waitand-see policy for clinical complete responders after chemoradiation for rectal cancer. J Clin Oncol. 2011;29(35):4633-40.

9. Martens MH, Maas M., Heijnen, L.A., Lambregts, D.M., Leijtens, J.W., Stassen, L.P., Breukink, S.O., Hoff, C., Belgers, E.J., Melenhorst, J., Jansen, R., Buijsen, J., Hoofwijk, T.G., Beets-Tan, R.G., Beets, G.L. Long-term outcome of an organ preservation program after neoadjuvant treatment for rectal cancer. J Natl Cancer Inst. 2016;108(12).

10. Habr-Gama A, Perez RO, Nadalin W, Sabbaga J, Ribeiro U, Jr., Silva e Sousa AH, Jr., et al. Operative versus nonoperative treatment for stage 0 distal rectal cancer following chemoradiation therapy: long-term results. Ann Surg. 2004;240(4):711-7; discussion 7-8.

11. Smith JD, Ruby JA, Goodman KA, Saltz LB, Guillem JG, Weiser MR, et al. Nonoperative management of rectal cancer with complete clinical response after neoadjuvant therapy. Ann Surg. 2012;256(6):965-72.

12. Appelt AL, Ploen J, Harling H, Jensen FS, Jensen LH, Jorgensen JC, et al. High-dose chemoradiotherapy and watchful waiting for distal rectal cancer: a prospective observational study. Lancet Oncol. 2015;16(8):919-27.

13. Ayloor SR KS, Jayanand SB, et al. Complete clinical response to neoadjuvant chemoradiation in rectal cancers: can surgery be avoided? Hepatogastroenterology. 2013;60(123):410-4.

14. Renehan AG, Malcomson L, Emsley R, Gollins S, Maw A, Myint AS, et al. Watch-and-wait approach versus surgical resection after chemoradiotherapy for patients with rectal cancer (the OnCoRe project): a propensity-score matched cohort analysis. Lancet Oncol. 2016;17(2): 174-83.

15. Rutten HJ, den Dulk M, Lemmens VE, van de Velde CJ, Marijnen CA. Controversies of total mesorectal excision for rectal cancer in elderly patients. Lancet Oncol. 2008;9(5):494-501.

16. Neuman HB, Patil S, Fuzesi S, Wong WD, Weiser MR, Guillem JG, et al. Impact of a temporary stoma on the quality of life of rectal cancer patients undergoing treatment. Ann Surg Oncol. 2011;18(5):1397-403.

17. Sturiale A, Martellucci J, Zurli L, Vaccaro C, Brusciano L, Limongelli P, et al. Long-term functional follow-up after anterior rectal resection for cancer. Int J Colorectal Dis. 2017;32(1): 83-8.

18. Verseveld M, de Graaf EJ, Verhoef C, van Meerten E, Punt CJ, de Hingh IH, et al. Chemoradiation therapy for rectal cancer in the distal rectum followed by organ-sparing transanal endoscopic microsurgery (CARTS study). Br J Surg. 2015;102(7):853-60. 
19. Lezoche E, Guerrieri M, Paganini AM, D'Ambrosio G, Baldarelli M, Lezoche G, et al. Transanal endoscopic versus total mesorectal laparoscopic resections of T2-NO low rectal cancers after neoadjuvant treatment: a prospective randomized trial with a 3-years minimum follow-up period. Surg Endosc. 2005;19(6):751-6.

20. Borstlap WA, Tanis PJ, Koedam TW, Marijnen CA, Cunningham C, Dekker E, et al. A multicentred randomised trial of radical surgery versus adjuvant chemoradiotherapy after local excision for early rectal cancer. BMC Cancer. 2016;16:513.

21. Heald RJ, Beets G, Carvalho C. Report from a consensus meeting: response to chemoradiotherapy in rectal cancer - predictor of cure and a crucial new choice for the patient: on behalf of the Champalimaud 2014 Faculty for 'Rectal cancer: when NOT to operate'. Colorectal Dis. 2014;16(5):334-7.

22. Habr-Gama A, Perez RO, Wynn G, Marks J, Kessler H, Gama-Rodrigues J. Complete clinical response after neoadjuvant chemoradiation therapy for distal rectal cancer: characterization of clinical and endoscopic findings for standardization. Dis Colon Rectum. 2010;53(12):1692-8.

23. Wasserberg N. Interval to surgery after neoadjuvant treatment for colorectal cancer. W J Gastroenterol. 2014;20(15):4256-62.

24. Beets GL, Figueiredo NF, Beets-Tan RG. Management of rectal cancer without radical resection. Annu Rev Med. 2017;68:169-82.

25. Habr-Gama A, Perez R, Proscurshim I, Gama-Rodrigues J. Complete clinical response after neoadjuvant chemoradiation for distal rectal cancer. Surg Oncol Clin N Am. 2010;19(4):829-45.

26. Lambregts DM, Maas M, Bakers FC, Cappendijk VC, Lammering G, Beets GL, et al. Long-term follow-up features on rectal MRI during a wait-and-see approach after a clinical complete response in patients with rectal cancer treated with chemoradiotherapy. Dis Colon Rectum. 2011;54(12):1521-8. 



\section{Chapter 2}

Organ preservation in rectal cancer after chemoradiation: should we extend the observation period in patients with a clinical near complete response?

BJP Hupkens, M Maas, MH Martens, ME van der Sande, DMJ Lambregts, SO Breukink, J Melenhorst, JB Houwers, C Hoff, MN Sosef, JWA Leijtens, $M$ Berbee, RGH Beets-Tan, GL Beets Ann Surg Oncol. 2018;25(1):197-203 


\section{Abstract}

Background: To assess whether extending the observation period in patients with a near clinical complete response (near cCR) after chemoradiation (CRT) leads to an impaired oncological outcome.

Methods: Patients who had a clinical complete response (cCR) 8-10 weeks after CRT restaging with MRI and endoscopy were offered a watch-and-wait strategy (W\&W1). Patients with a near CCR were offered to undergo local excision or a second restaging 6-12 weeks later. Patients who achieved a CCR at the second restaging were offered a watch-and-wait strategy (W\&W2).

Results: 102 patients with a $\mathrm{CCR}$ at the first restaging immediately entered the W\&W1. The remaining 68 patients had a near CCR: 19 underwent TEM-surgery and 49 patients opted for a second restaging. $44 / 49$ (90\%) patients showed a $\mathrm{CCR}$ at the second restaging and entered the W\&W2. The patients in the W\&W1-group had a 2-year local regrowth-free rate (LRFR) of $84 \%$, and 2-year overall survival (OS) of $99 \%$. Patients in the W\&W2-group had a 2-year LRFR of $73 \%$ and OS of $98 \%(p>0.05)$. Multivariable Cox-regression analyses showed that late inclusion was not significant predictive for a higher risk of LR or lower disease-free survival (DFS).

Conclusions: $90 \%$ of the patients with a near CCR 8-10 weeks after CRT will proceed to a CCR 6-12 weeks later. Therefore, it seems logical to extend the observation period rather than to proceed to surgery. Although there is a nonsignificant increase in local regrowth rate in these patients, it does not seem to impact the oncological outcome. 


\section{Introduction}

Patients with locally advanced rectal cancer are treated with neoadjuvant chemoradiation (CRT) followed by total mesorectal excision (TME), typically after 6-10 weeks. In 15-20\% of these patients, histopathology shows no residual tumour $^{1}$. Organ-preservation (watch-and-wait (W\&W) policy) could be offered to clinical complete responders (cCR) after neoadjuvant CRT as an alternative for resection, mainly because of an improved quality of life and good oncological outcome $^{2-9}$. The interest in this approach is increasing, and there is a shift from a very strict selection strategy, including only patients when all diagnostic procedures show an unequivocal complete response, towards a less strict approach in which organ preservation is also considered in the so-called clinical near complete responders (near cCR). These patients have on endoscopy and MRI still some minor or equivocal findings and a local excision is often advocated to determine the final response. Although the oncological results of local excision after CRT in near $\mathrm{CCR}$ are reported to be good, substantial morbidity is associated with the procedure ${ }^{10-14}$. Another approach to determine whether or not these near cCRs are in reality complete responders is to extend the observation period. A longer interval after CRT has been shown to result in more patients with a cCR15. With a second assessment after another 6-12 weeks interval in patients with a near CCR an additional number of patients are expected to show a cCR that can be managed by a W\&W-policy, while patients with residual abnormalities can undergo additional treatment ${ }^{15}$.

A question is whether patients who achieve a complete response after a prolonged interval between CRT and response assessment have a higher risk for local regrowth and/or distant metastasis in a W\&W-policy than patients who immediately have a complete response. Therefore, the aim of this study was to compare the outcome of patients selected for a W\&W-policy at restaging 8-10 weeks after CRT to that of patients selected after a second restaging after an additional 6-12 weeks observation.

\section{Methods}

\section{Patients}

This study included a highly selected group of all rectal cancer patients who were evaluated as potential candidates for a W\&W-strategy after neoadjuvant 
CRT between January 2005 and August 2015, including both patients who were primarily treated at our institute and patients who were referred. Organpreservation was offered in a prospective cohort study, approved by the local IRB and registered in clinicaltrials.gov since 2009 (NCT00939666 and NCT02278653). Inclusion criteria were: non-metastatic biopsy proven rectal cancer; neoadjuvant treatment (long course of CRT or 5x5Gy radiotherapy with long waiting interval); and evidence of a $\mathrm{CCR}$ or near CCR (definitions described below). Follow-up data was available for a period of $\geq 12$ months after inclusion for W\&W.

\section{Post-chemoradiotherapy evaluation}

All patients underwent post-CRT restaging 8-10 weeks after the last radiation, with digital rectal examination (DRE), endoscopy, and MRI (including diffusionweighted (DWI-)MRI). This was either primarily performed in our hospital or repeated in our hospital in referred patients. DRE and endoscopy were performed by surgeons with expertise in response evaluation. A typical CCR on endoscopy was defined as a white scar with telangiectasia without palpable abnormalities ${ }^{3,8}$. Biopsy was not mandatory, but when performed should be negative. A clinical near complete response (near $\mathrm{cCR}$ ) was defined as a superficial soft irregularity at DRE, a small residual flat ulcer, or irregular wall thickening at endoscopy and/or dysplasia at histopathology. A cCR on (DWI)MRI was defined, as absence of residual tumour on T2W-MRI, with low signal at the former tumour location on b1000 DWI-MRI and absence of suspicious nodes on T2W-MRI.3, 8 A near CCR was defined as obvious downstaging with/without residual fibrosis, but with a heterogeneous or irregular aspect on MRI and/or a small focal area of high signal on b1000 DWI-MRI. All MRIs were evaluated by radiologists with $\geq 5$ years of specific expertise in rectal cancer imaging.

\section{Decision for watch-and-wait policy}

From 2005-2009 patients were restaged after 8-10 weeks after CRT. The patients who had an unequivocal CCR were offered a watch-and-wait policy. During 2009-2011 this approach shifted and besides patients with an immediate cCR 8-10 weeks after CRT (W\&W1), also patients with a near CCR were offered to undergo either a local excision, or a second restaging after an additional 6-12 weeks waiting interval. Initially, we used a 6-week interval, but only minor change in the clinical image was observed, so we changed this interval to 12 weeks later on. Patients who achieved a $\mathrm{CCR}$ at the second restaging were 
then offered a W\&W-policy (W\&W2). All patients who did not obtain a cCR at the second restaging underwent a TME. The patient flow chart is shown in Figure 2.1. All patients eligible for W\&W policy were also offered TME as the standard treatment.

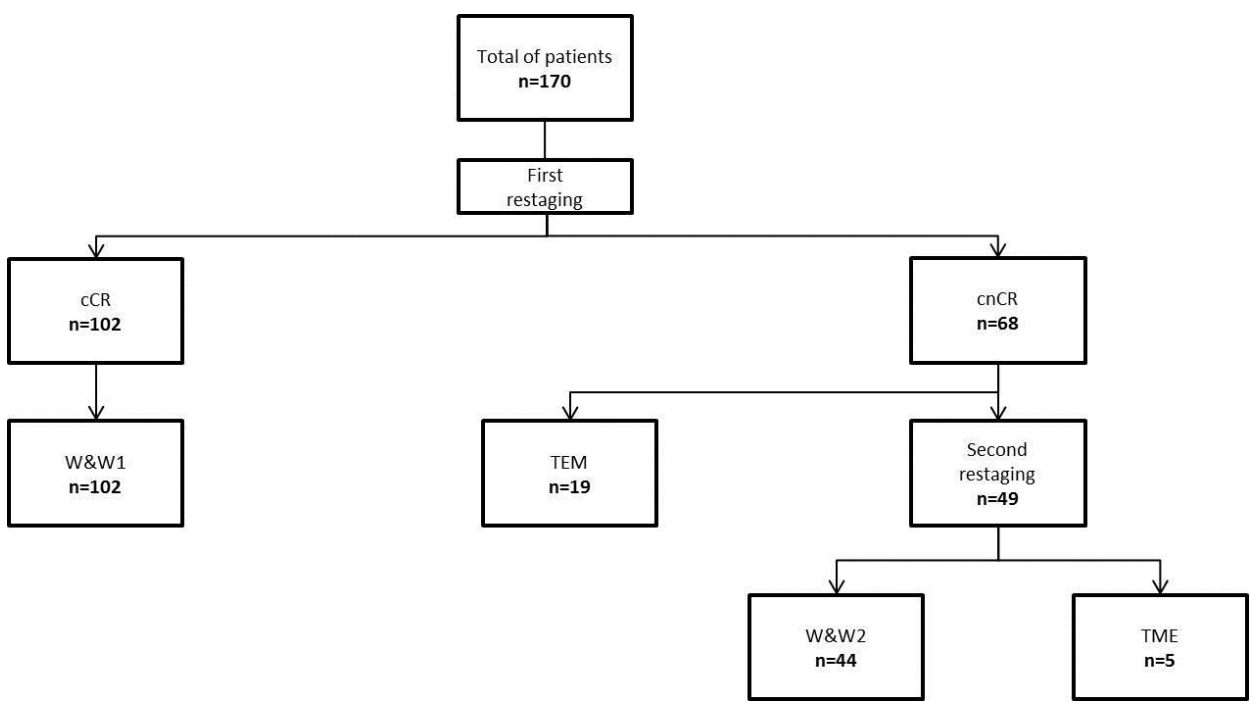

Figure 2.1 - Flow chart. First restaging: MRI and endoscopy, 8-10 weeks after the end of chemoradiation therapy; Second restaging: MRI and endoscopy, 6-12 weeks after the first restaging; $\mathrm{cCR}=$ clinical complete response; $\mathrm{cnCR}=$ clinical near complete response; $\mathrm{W} \& \mathrm{~W} 1$ = entering watch-and-wait protocol after first restaging; $W \& W 2$ = entering watch-and-wait protocol after second restaging; TEM = transanal endoscopic microsurgery; TME = total mesorectal excision.

\section{Follow-up}

Additional to standard follow-up according to national guidelines for colorectal cancer (consisting of CEA and CT of thorax and abdomen), patients underwent follow-up examinations specific for organ preservation: DRE, flexible sigmoidoscopy and MRI 3-monthly in the first year and 6-monthly thereafter, as described previously ${ }^{3,8}$.

\section{Statistical analysis}

Baseline characteristics were compared between groups by the independent samples t-test for continuous variables and Chi-square test for categorical variables. The interval between CRT and restaging was calculated from the last 
day of CRT to the first restaging in patients in W\&W1 group and to the second restaging in the $\mathrm{W} \& \mathrm{~W} 2$ group.

Two-year local regrowth-free survival (LRFS), disease-free survival (DFS), and overall survival (OS) were calculated using Kaplan-Meier survival methods. Differences in survival between groups were tested by the log-rank test. OS was defined as the absence of death, LRFS as absence of luminal or nodal regrowth, and disease-free-survival as the absence of regrowth, death, and distant metastasis. Duration of follow-up was calculated from the last date of radiotherapy to the event of interest or the last follow-up date.

A multivariable Cox proportional hazards analysis was performed with the following factors: primary stage, age, sex, W\&W1 vs. W\&W2, and adjuvant chemotherapy. Analyses were performed with IBM SPSS Statistics (version 22.0). P-values $\leq 0.05$ were considered as statistically significant.

\section{Results}

\section{Baseline characteristics}

Baseline patient characteristics are shown in Table 2.1. 170 patients had a CCR or near cCR after CRT. 141/170 patients (83\%) were referred from 32 other hospitals.

\section{Clinical complete responders}

102 patients $(60 \%)$ had a cCR at first restaging 8-10 weeks after CRT and opted for a W\&W strategy (W\&W1-group). The median time between CRT restaging was 9 weeks (range 4-21 weeks).

\section{Clinical near complete responders}

Sixty-eight patients (40\%) had a near cCR. Of these 68 patients, twenty-eight $(41 \%)$ had a near cCR because suspected small residual tumour on both MRI and endoscopy; 11 patients (16\%) had suspected residual tumour at endoscopy with a complete response on MRI; in 19 patients (28\%) suspected residual tumour was seen on MRI with a complete response at endoscopy; the remaining ten patients $(15 \%)$ had suspicious or uncertain nodes on MRI.

Of the 68 near cCR patients, 19 (28\%) underwent TEM: 10 patients had ypT0, 3 had ypT1 and 6 had ypT2. The 6 patients with ypT2 tumours in the TEM 
specimen were offered completion TME but refused. The other 49 near cCR patients chose to wait longer and undergo a second restaging. This second restaging was performed after a median total interval of 23 weeks (range 13-49 weeks) from the final radiation dose. After this second restaging, 44/49 patients $(90 \%)$ had a cCR and opted for a W\&W-policy (W\&W2 group). The remaining five patients with clinical residual tumour underwent $T M E$, with an ypTONO in one patient, ypT1N0 in 2 patients and ypT3N1 in the other patients.

Table 2.1 - Baseline characteristics.

\begin{tabular}{lcccc}
\hline & Total & W\&W1 & near cCR & W\&W2 \\
\hline $\mathrm{n}$ & 170 & 102 & 68 & 44 \\
mean age (SD) & $64 \mathrm{y}(9.8)$ & $64 \mathrm{y}(10.5)$ & $65 \mathrm{y}(8.8)$ & $65 \mathrm{y}(9.1)$ \\
median time CRTx-inclusion & 12wks (4-49) & 9wks $(4-21)$ & 22wks $(11-49)$ & 22wks $(13-45)$ \\
cT & & & & \\
$\quad$ cT1-2 & $44(25.9 \%)$ & $26(25.5 \%)$ & $17(25.0 \%)$ & $11(25.0 \%)$ \\
cT3 & $113(66.5 \%)$ & $67(65.7 \%)$ & $47(69.1 \%)$ & $30(68.2 \%)$ \\
cT4 & $13(7.6 \%)$ & $9(8.8 \%)$ & $4(5.9 \%)$ & $3(6.8 \%)$ \\
cN & & & \\
$\quad$ CN0 & $44(25.9 \%)$ & $29(28.4 \%)$ & $15(22.1 \%)$ & $7(15.9 \%)$ \\
cN+ & $126(74.1 \%)$ & $73(71.6 \%)$ & $53(77.9 \%)$ & $37(84.1 \%)$ \\
Tumour height & & & & \\
$\quad$ 0-5cm & $140(82.4 \%)$ & $84(82.4 \%)$ & $56(82.4 \%)$ & $38(86.4 \%)$ \\
$>5$ cm & $30(17.6 \%)$ & $18(17.6 \%)$ & $12(17.6 \%)$ & $6(13.6 \%)$ \\
Adjuvant CTx & $44(25.9 \%)$ & $30(29.4 \%)$ & $14(20.6 \%)$ & $10(22.7 \%)$ \\
\hline
\end{tabular}

Total: All patients included in this study. W\&W1: entering watch and wait protocol after first restaging; near cCR: near complete responders, all patients in the TEM, W\&W2, and TME-group; W\&W2: entering watch and wait protocol after second restaging; $\mathrm{n}$ : number of patients; SD: standard deviation; CRTx: chemoradiotherapy; CTx: chemotherapy.

\section{Local regrowth and survival}

The median follow-up of patients in the W\&W1-group was 26 months (5-136 months). 2-year LRFR was $84 \%(95 \% \mathrm{Cl} 74.9-90.2)$. 2-year DFS was $97 \%(95 \% \mathrm{Cl} 89.4-99.3)$. Two-year OS was $99 \%(95 \% \mathrm{Cl} 91.6-99.8)$ for the W\&W1-group. The patients in the W\&W2-group had a median follow-up of 19.5 months (6-103 months). Two-year LRFR is $73 \%(95 \% \mathrm{Cl} 54.6-84.8)$; a DFS of $93 \%(95 \% \mathrm{Cl} 78.6-97.5)$; and an OS of 98\% (95\%Cl 84.6-99.7) (Figure 2.2 and Table 2.2). Although LRFR was lower in the W\&W2-group, there were no significant differences regarding long-term outcome $(p=0.237)$. The multivariate Cox-regression analysis showed an increased hazard ratio for W\&W2 for local regrowth $(\mathrm{HR} 1.43,95 \% \mathrm{Cl} \quad 0.64-3.22)$ although this was not statistically significant (Table 2.3). 
Fifteen patients in the W\&W1-group had a local regrowth: twelve had a luminal regrowth (after mean 11 $\pm 5,7$ months, two a nodal regrowth (after mean 9,5 $\pm 5,0$ months), and one patient had both a luminal and nodal regrowth (after 7 months). In the W\&W2-group ten patients had a local regrowth, all intraluminal (after mean 12,8 $\pm 5,3$ months). All patients, in both groups, could be salvaged with a TME (all RO resections): the same surgical procedure that would have been performed if they would not have participated in W\&W. Three patients had postoperative complications from TME and one patient developed a recurrence after salvage TME.

In the nineteen patients who underwent TEM, four patients had a luminal regrowth and two patients had lung metastasis. None of the ypT0 patients had a recurrence. From 3 ypT1 patients, one patient developed a luminal regrowth, and one patient lung metastasis. From 6 ypT2 patients, three patients (50\%) had a luminal regrowth and one patient had lung metastasis.
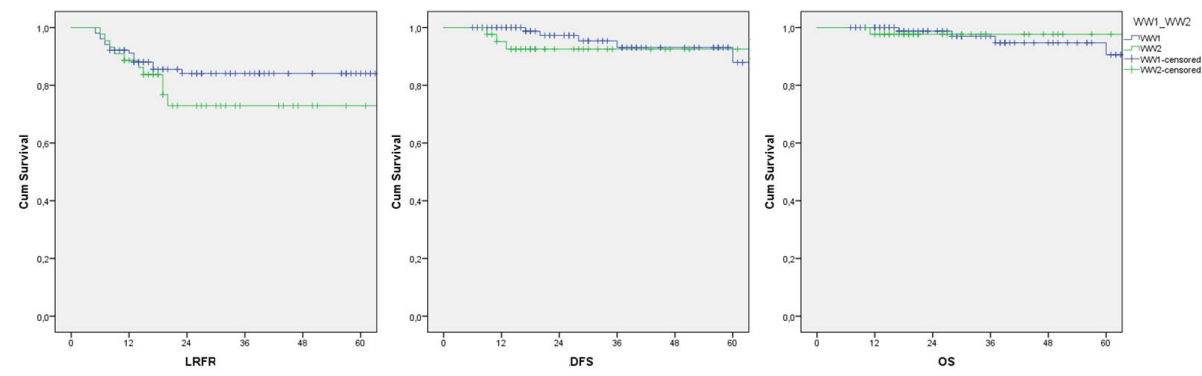

Figure 2.2 - Oncological outcome. LRFR = local regrowth free survival; DFS = disease free survival; OS = overall survival; W\&W1 = entering watch-and-wait protocol after first restaging; W\&W2 = entering watch-and-wait protocol after second restaging.

Table 2.2 - 2-year survival data.

\begin{tabular}{lcccc}
\hline & Total & W\&W1 & W\&W2 & $p$-value \\
\hline LRFR & $79.9 \%$ & $84.1 \%$ & $72.9 \%$ & 0.237 \\
& $(95 \% \mathrm{Cl} 72.5-85.5)(\mathrm{n}=31)$ & $(95 \% \mathrm{Cl} 74.9-90.2)(\mathrm{n}=15)$ & $(95 \% \mathrm{Cl} 54.6-84.8)(\mathrm{n}=10)$ \\
DFS & $95.2 \%$ & $97.3 \%$ & $92.6 \%$ & 0.515 \\
& $(95 \% \mathrm{Cl} 90.0-97.7)(\mathrm{n}=7)$ & $(95 \% \mathrm{Cl} 89.4-99.3)(\mathrm{n}=2)$ & $(95 \% \mathrm{Cl} 78.6-97.5)(\mathrm{n}=3)$ & \\
OS & $98.6 \%$ & $98.8 \%$ & $97.7 \%$ & 0.750 \\
& $(95 \% \mathrm{Cl} 94.6-99.7)(\mathrm{n}=2)$ & $(95 \% \mathrm{Cl} 91.6-99.8)(\mathrm{n}=1)$ & $(95 \% \mathrm{Cl} 84.6-99.7)(\mathrm{n}=1)$ & \\
\hline
\end{tabular}

Total: all patients with $\mathrm{CCR}$ and $\mathrm{nCR}(\mathrm{W} \& \mathrm{~W} 1+\mathrm{TEM}+\mathrm{W} \& \mathrm{~W} 2+\mathrm{TME})$. W\&W1: entering watch and wait protocol after first restaging; W\&W2: entering watch and wait protocol after second restaging; LRFR: local regrowth free rate; DFS: disease-free survival; OS: overall survival; n: number of events. 
Table 2.3 - Cox regression analysis.

\begin{tabular}{lcccc}
\hline & \multicolumn{1}{c}{ LR } & & NRD & $\mathrm{p}$ \\
\cline { 2 - 5 } & $\mathrm{HR}(95 \% \mathrm{Cl})$ & $\mathrm{p}$ & $\mathrm{HR}(95 \% \mathrm{Cl})$ & 0.607 \\
Late inclusion & $1.431(0.637-3.215)$ & 0.385 & $1.455(0.348-6.075)$ & 0.071 \\
Adjuvant treatment & $0.425(0.143-1.260)$ & 0.123 & $0.166(0.024-1.168)$ & 0.361 \\
LARC & $1.624(0.714-3.697)$ & 0.248 & $1.930(0.471-7.902)$ & 0.070 \\
Male sex & $0.619(0.246-1.558)$ & 0.309 & $0.114(0.011-1.196)$ & 0.008 \\
Age & $1.011(0.968-1.055)$ & 0.627 & $1.133(1.033-1.244)$ & 0.007 \\
\hline
\end{tabular}

LR: local regrowth; NRD: non-regrowth disease (death and metastasis); HR: hazard ratio; Late inclusion: inclusion after second re-assessment; LARC: locally advanced rectal cancer.

\section{Discussion}

This study shows that the majority of patients $(90 \%)$ with a near CCR response 8-10 weeks after CRT of rectal cancer will evolve into a CCR at a second reassessment 6-12 weeks later. Allowing a longer interval for near CCR will increase the number of patients who can be offered W\&W, avoiding unnecessary surgery in more patients. There is an increase in local regrowth rate in these patients, but this does not seem to lead to worse disease-free and overall survival.

The initial selection strategy for complete responders for W\&W was very strict, leading to a low number of regrowths, but many complete responses were missed $^{3,16}$. The 'test of time concept' in the current study increased the number of patients eligible for W\&W by $43 \%$. This 'test of time' approach was also proposed by Smith et al. who evaluated patients first 6-7 weeks after CRT followed by a second evaluation at 12 weeks for patients with major responses that fell slightly short of criteria for a typical $\mathrm{CCR}^{4}$. The one-year observation period as applied in early reports of Habr-Gama can also be seen as extended observation period, as is the 'deferral of surgery' concept of the Royal Marsden UK trial ${ }^{2,17}$. The goal of these different approaches is to maximize the detection of complete responders. The underlying idea is that our current diagnostic techniques are insufficiently accurate to show a true complete response because the rectal mucosa and wall can still be healing. The patients in the present study who were labelled as near CCR had presumed residual disease on MRI in approximately $84 \%$, and residual mucosal abnormalities at endoscopy in $57 \%$. Appearance of residual mucosal abnormalities is an important reason for missed cCR was also reported by Nahas et al. ${ }^{18}$. In a study on TME specimens, $74 \%$ of the ypT0 tumours showed mucosal lesions, mostly ulcers ${ }^{4}$. Our study 
showed that in the large majority of patients these features suggestive of residual disease disappeared after an extended interval. Several studies showed that the ability to detect a $\mathrm{CCR}$ is low for MRI as a single diagnostic modality $(18-35 \%)^{18,19}$ and moderate for endoscopy $(53 \%)^{20-22}$. Combining both increases sensitivity to $71 \%$, meaning that still $29 \%$ of the complete responses are missed $^{18}$. The diagnostic performance of the modalities to predict whether a near cCR might become a cCR is yet to be determined.

Many retrospective studies have evaluated the impact of the interval after CRT on the $\mathrm{pCR}$ rate after surgery. A recent meta-analysis showed that the percentage of pCR after surgery increases by $6 \%$ when comparing intervals $<6-8$ weeks with intervals of $>6-8$ weeks $^{23}$. Sloothaak et al. reported an initial steep increase in response from 4 weeks after CRT, levelling off and reaching a plateau at 10-11 weeks ${ }^{15}$. The single randomized trial (GRECCAR 6), reported only a very small and non-significant difference in pCR between an interval of 7 versus 11 weeks $^{24}$. Although it seems there is little to gain with regard to increasing the pCR rate by extending the interval any longer, the clinical image of cCR lags behind and can lead to performing surgery while actually the patient will achieve a CR. This is confirmed by the observation that after an additional interval of only 6 weeks only minor change in the clinical image was seen.

From a practical point of view, the traditional assessment 6-8 weeks after completion of CRT is a good starting point. Most patients will have obvious residual tumour that requires surgery. A local excision can be considered in special circumstances or in patients with substantial comorbidity. Some patients will present with a $\mathrm{CCR}$, and the option of $\mathrm{W} \& \mathrm{~W}$ can be offered as an alternative to TME for patients with a near CCR, it is a reasonable option to extend the observation period with another 12 weeks, because the majority of these patients proceed to a cCR. One of the main concerns with extending the observation period is the risk of local tumour progression and the development of distant metastases in patients who will not reach a cCR. So far, the experience is that rapid local tumour progression in this short time span is virtually non-existent in patients with a near $\mathrm{CCR}$, and that the originally planned TME is possible when eventually required. Although the current study is underpowered to draw conclusions in this respect, no statistically significant negative impact of a second observation period was noted on distant recurrence. The meta-analysis of studies comparing short and long intervals to surgery does not suggest any detrimental effect on survival of prolonging the 
interval $^{25}$. Overall the risk for additional metastatic disease during a 12-week period in patients with a near CCR is expected to be very small.

The alternative to an additional observation period in near $\mathrm{CCR}$ is a local excision. This may however result in postoperative morbidity, wound dehiscence and pain $^{12}$. Additionally, there are reports that functional results are inferior compared to patients in a W\&W-strategy ${ }^{22}$. A local excision does provide a definitive answer regarding the presence of residual tumour and enables organ preservation in patients with a small tumour remnant ${ }^{26}$.

Another approach is to use the interval for so called 'consolidation chemotherapy'. This approach has two potential advantages: (1) early chemotherapy could improve prognosis by tackling potential distant micro metastases and (2) systemic chemotherapy combined with the prolonged interval may lead to a higher number of cCRs. This approach is supported by studies that have shown an increased pCR rate of $31-38 \%$ when chemotherapy is administered after neoadjuvant $\mathrm{CRT}^{1,27,28}$.

\section{Limitations}

This study had some limitations. First, the follow-up is rather short to provide reliable long-term estimates of disease-free survival and overall survival. Second, the sample size is small and therefore, it is impossible to draw any definite conclusions about a difference in the potential risk for distant recurrence between the two groups with different observation intervals. Third, the population consists of a highly selected patient group, who were referred to our unit for further management with an already established good clinical response at the referring hospital. In an effort to correct for this potential bias the two groups were strictly based on the interval of the post-CRT assessment that led to the decision for a W\&W-policy, irrespective of whether this was done at the referring centre or our own centre. This, however, has led to overlap in intervals to restaging between groups.

\section{Conclusions}

The large majority of patients with a near CCR 8-10 weeks after chemoradiation will evolve into a cCR by extending the observation period after CRT and can be 
included in a W\&W-policy. These patients may have a higher local regrowth rate compared to initially clinical complete responders, but without an apparent impact on overall survival. All regrowths could be easily salvaged. Therefore, it appears to be safe to extend the interval in near cCRs in order to increase the number of patients who can benefit from organ preservation. 


\section{References}

1. Maas M, Nelemans PJ, Valentini V, et al. Long-term outcome in patients with a pathological complete response after chemoradiation for rectal cancer: a pooled analysis of individual patient data. Lancet Oncol. 2010;11(9):835-44.

2. Habr-Gama A, Perez RO, Nadalin W, et al. Operative versus nonoperative treatment for stage 0 distal rectal cancer following chemoradiation therapy: long-term results. Ann Surg. 2004; 240(4):711-7; discussion 717-8.

3. Maas M, Beets-Tan RG, Lambregts DM, et al. Wait-and-see policy for clinical complete responders after chemoradiation for rectal cancer. J Clin Oncol. 2011;29(35):4633-40.

4. Smith JD, Ruby JA, Goodman KA, et al. Nonoperative management of rectal cancer with complete clinical response after neoadjuvant therapy. Ann Surg. 2012;256(6):965-72.

5. Ayloor SR KS, Jayanand SB, et al. Complete clinical response to neoadjuvant chemoradiation in rectal cancers: can surgery be avoided? . Hepatogastroenterology. 2013;60(123):410-414.

6. Appelt AL, Ploen J, Harling $\mathrm{H}$, et al. High-dose chemoradiotherapy and watchful waiting for distal rectal cancer: a prospective observational study. Lancet Oncol. 2015;16(8):919-27.

7. Renehan AG, Malcomson L, Emsley R, et al. Watch-and-wait approach versus surgical resection after chemoradiotherapy for patients with rectal cancer (the OnCoRe project): a propensity-score matched cohort analysis. Lancet Oncol. 2016;17(2):174-83.

8. Martens MH, Maas M, Heijnen LA, Lambregts DM, Leijtens JW, Stassen LP, Breukink SO, Hoff C, Belgers EJ, Melenhorst J, Jansen R, Buijsen J, Hoofwijk TG, Beets-Tan RG, Beets GL. Long-term outcome of an organ preservation program after neoadjuvant treatment for rectal cancer. J Natl Cancer Inst. 2016;108(12).

9. Beets GL, Figueiredo NF, Beets-Tan RG. Management of rectal cancer without radical resection. Annu Rev Med. 2017;68:169-182.

10. Lezoche G, Baldarelli M, Guerrieri M, et al. A prospective randomized study with a 5-year minimum follow-up evaluation of transanal endoscopic microsurgery versus laparoscopic total mesorectal excision after neoadjuvant therapy. Surg Endosc. 2008;22(2):352-8.

11. Perez RO, Habr-Gama A, Sao Juliao GP, et al. Transanal Endoscopic Microsurgery (TEM) following neoadjuvant chemoradiation for rectal cancer: Outcomes of salvage resection for local recurrence. Ann Surg Oncol. 2016;23(4):1143-8.

12. Perez RO, Habr-Gama A, Sao Juliao GP, et al. Transanal endoscopic microsurgery for residual rectal cancer after neoadjuvant chemoradiation therapy is associated with significant immediate pain and hospital readmission rates. Dis Colon Rectum. 2011;54(5):545-51.

13. Coco C, Rizzo G, Mattana C, et al. Transanal endoscopic microsurgery after neoadjuvant radiochemotherapy for locally advanced extraperitoneal rectal cancer: short-term morbidity and functional outcome. Surg Endosc. 2013;27(8):2860-7.

14. Garcia-Aguilar J, Renfro LA, Chow OS, et al. Organ preservation for clinical T2N0 distal rectal cancer using neoadjuvant chemoradiotherapy and local excision (ACOSOG Z6041): results of an open-label, single-arm, multi-institutional, phase 2 trial. Lancet Oncol. 2015;16(15):1537-46.

15. Sloothaak DA, Geijsen DE, van Leersum NJ, et al. Optimal time interval between neoadjuvant chemoradiotherapy and surgery for rectal cancer. Br J Surg. 2013;100(7):933-9.

16. Maas M, Lambregts DM, Nelemans PJ, et al. Assessment of clinical complete response after chemoradiation for rectal cancer with digital rectal examination, Endoscopy, and MRI: Selection for organ-saving treatment. Ann Surg Oncol. 2015;22(12):3873-80.

17. West MA, Dimitrov BD, Moyses HE, et al. Timing of surgery following neoadjuvant chemoradiotherapy in locally advanced rectal cancer - A comparison of magnetic resonance imaging at two time points and histopathological responses. Eur J Surg Oncol. 2016;42(9): 1350-8.

18. Nahas SC, Rizkallah Nahas CS, Sparapan Marques CF, et al. Pathologic complete response in rectal cancer: Can we detect it? Lessons learned from a proposed randomized trial of watchand-wait treatment of rectal cancer. Dis Colon Rectum. 2016;59(4):255-63. 
19. Hughes R, Harrison M, Glynne-Jones R. Could a wait and see policy be justified in T3/4 rectal cancers after chemo-radiotherapy? Acta Oncol. 2010;49(3):378-81.

20. Nakagawa WT, Rossi BM, de OFF, et al. Chemoradiation instead of surgery to treat mid and low rectal tumours: is it safe? Ann Surg Oncol. 2002;9(6):568-73.

21. Lim L, Chao M, Shapiro J, et al. Long-term outcomes of patients with localized rectal cancer treated with chemoradiation or radiotherapy alone because of medical inoperability or patient refusal. Dis Colon Rectum. 2007;50(12):2032-9.

22. Habr-Gama A, Lynn PB, Jorge JM, et al. Impact of organ-preserving strategies on anorectal function in patients with distal rectal cancer following neoadjuvant chemoradiation. Dis Colon Rectum. 2016;59(4):264-9.

23. Habr-Gama A, de Souza PM, Ribeiro U, Jr., et al. Low rectal cancer: impact of radiation and chemotherapy on surgical treatment. Dis Colon Rectum. 1998;41(9):1087-96.

24. Lefevre $\mathrm{JH}$, Mineur L, Kotti S, et al. Effect of interval (7 or 11 weeks) between neoadjuvant radiochemotherapy and surgery on complete pathologic response in rectal cancer: A multicentre, randomized, controlled trial (GRECCAR-6). J Clin Oncol. 2016;34(31):3773-80.

25. Petrelli F, Sgroi G, Sarti E, et al. Increasing the interval between neoadjuvant chemoradiotherapy and surgery in rectal cancer: A meta-analysis of published studies. Ann Surg. 2016;263(3):458-64.

26. Creavin B, Ryan E, Martin ST, et al. Organ preservation with local excision or active surveillance following chemoradiotherapy for rectal cancer. Br J Cancer. 2017;116(2):169-74.

27. Huang CM, Huang MY, Tsai $\mathrm{HL}$, et al. An observational study of extending FOLFOX chemotherapy, lengthening the interval between radiotherapy and surgery, and enhancing pathological complete response rates in rectal cancer patients following preoperative chemoradiotherapy. Therap Adv Gastroenterol. 2016;9(5):702-12.

28. Garcia-Aguilar J, Chow OS, Smith DD, et al. Effect of adding mFOLFOX6 after neoadjuvant chemoradiation in locally advanced rectal cancer: a multicentre, phase 2 trial. Lancet Oncol. 2015;16(8):957-66. 



\section{Abstract}

Objectives: To evaluate diagnostic performance of follow-up MRI for detection of local recurrence of rectal cancer after transanal endoscopic microsurgery (TEM).

Methods: Between January 2006 and February 2014, 81 patients who underwent TEM were included. Two expert readers (R1 and R2), independently evaluated MRI on T2-weighted (T2W) and diffusion-weighted (DWI) MRI for the detection of local recurrence, retrospectively and recorded on a five-point scale for the confidence. Diagnostic performance of follow-up MRI was assessed using ROC-curve analysis and kappa statistics for the reproducibility between readers.

Results: 293 MRls were performed, 203 included DWI. 18 (22\%) patients developed a local recurrence: luminal 11, nodal 2 and both 5 . Areas under the curve (AUCs) for local recurrence detection were 0.72 (R1) and 0.80 (R2) for T2W-MRI. For DWI, AUCs were 0.70 (R1) and 0.89 (R2). For nodal recurrence AUCs were 0.72 (R1) and 0.80 (R2) for T2W-MRI. Reproducibility was good for T2W-MRI ( $\mathrm{k} 0.68$ for luminal and $\mathrm{k} 0.71$ for nodal recurrence) and moderate for DWI (K0.57). AUCs and reproducibility for recurrence detection increased during follow-up.

Conclusions: Follow-up with MRI after TEM for rectal cancer is feasible. Postoperative changes can be confusing at the first postoperative MRI, but during follow-up diagnostic performance and reproducibility increase. 


\section{Introduction}

Transanal endoscopic microsurgery (TEM) is used for the treatment of early rectal cancer, e.g. resection of adenomas and T1sm1 tumours ${ }^{1,2}$. Recently, TEM has been proposed as an alternative for total mesorectal excision (TME) in small residual tumours after neoadjuvant treatment, in line with the increasing interest for organ preservation after neoadjuvant treatment ${ }^{3,4}$. Reported recurrence rates are in the range of $0-24 \%$ for early rectal cancer treated by local excision or TEM $^{5-11}$ and $7-14 \%$ for TEM after neoadjuvant treatment ${ }^{4}$. Recurrence of early rectal cancer after TEM depends on the primary features of the tumour, e.g. tumour stage, Sm-invasion and differentiation grade 1. Recurrences in patients after chemoradiation usually occur within the first 18 months of follow-up and consist of luminal rather than nodal recurrences ${ }^{3,12,13}$.

The increased use of TEM stresses the need for an accurate follow-up tool to assess local status and to identify both luminal and nodal recurrences. The mainstay of follow-up has been endoscopy with endorectal ultrasound (ERUS). MRI can assess both the lumen and the mesorectum and is less operator dependent than ERUS ${ }^{14,15}$. Therefore, MRI is expected to be of additional value for follow-up after TEM ${ }^{16}$. However, so far, no literature exists on the value of MRI in follow-up after TEM.

Therefore, the aim of this study was to evaluate MRI for follow-up after TEM (in patients with and without neoadjuvant treatment) with regard to diagnostic performance for detection of a luminal or nodal recurrence and inter-observer agreement.

\section{Materials and methods}

\section{Patients}

Institutional review board approval and informed consent were waived for this retrospective study. In total 378 patients were treated between January 2006 and February 2014 with TEM in a regional tertiary referral centre. Patients were included when they met the following inclusion criteria: (1) histologically proven rectal cancer, (2) RO resection and (3) follow-up with MRI. Patients with histology other than adenocarcinoma were excluded. In total 81 patients fulfilled these criteria. All TEMs were performed in one regional, tertiary TEM referral hospital, according to regional guidelines ${ }^{17}$. The population consisted of two 
patient groups: (1) patients with small rectal tumours (up to cT2) without (neo)adjuvant therapy and (2) patients with a small residual tumour after neoadjuvant therapy (up to ycT2).

\section{Follow-up}

Follow-up was combined in two hospitals: a regional hospital in which the TEMs were performed, and a university hospital with specific expertise in rectal cancer MRI. Follow-up consisted of three MRIs (at 3,6 and 12 months of follow-up) and 3-4 endoscopies in the first year, and two MRIs and two endoscopies (every 6 months) in year $2-5^{18}$.

MRI consisted of T2-weighted (T2W) sequences in three orthogonal directions. All scans that were performed at the university hospital included a DWI sequence. MR sequences per centre are shown in Appendix 3.1.

\section{MRI evaluation}

All MRls were evaluated by two independent expert readers (RGHB and MM). Reader 1 (RGHB) (R1) has 20 years of experience and reader 2 (MM) (R2) has 8 years of experience in reading rectal cancer MRI and post-TEM MRI. Presence of a local and/or nodal recurrence was evaluated by means of a 5-point confidence level scale (CL0: definitely no recurrence; CL1: probably no recurrence; CL2: indeterminate presence of recurrence; CL3: probable recurrence; CL4: definite recurrence). First, T2W-MRI was evaluated and then - in the same reading session - DWI was evaluated (T2W + DWI). The readers were blinded for endoscopy, histopathology and each other's results. The imaging criteria used to define the confidence level scores are shown in Table 3.1. Additionally, readers evaluated morphology (normal rectal wall, scar tissue, fibrosis (massive or minimal), edema), and signal intensity (high, intermediate or low signal) of the rectal wall and the mesorectal tissue on T2WMRI (Figure 3.1). Change in morphology and signal intensity during follow-up were noted. 
Table 3.1 - Definitions of confidence level scores for luminal and nodal recurrences.

\begin{tabular}{|c|c|c|c|}
\hline Confidence level & $\begin{array}{l}\text { Luminal recurrence on } \\
\text { T2W-MRI }\end{array}$ & $\begin{array}{l}\text { Luminal recurrence on } \\
\text { DWI-MRI }\end{array}$ & $\begin{array}{l}\text { Nodal recurrence on } \\
\text { T2W-MRI (26) }\end{array}$ \\
\hline $\begin{array}{l}\text { CL0: Definitely no } \\
\text { recurrence }\end{array}$ & $\begin{array}{l}\text { - Normal/intact rectal wall } \\
\text { - No intermediate signal } \\
\text { at TEM location }\end{array}$ & $\begin{array}{l}\text { Absence of high signal } \\
\text { in scar at b1000 images }\end{array}$ & $\begin{array}{l}\text { - Normal size }(<5 \mathrm{~mm}) \\
\text { - Homogeneity of the nodal } \\
\text { signal } \\
\text { - Oval shape } \\
\text { - Regular border }\end{array}$ \\
\hline $\begin{array}{l}\text { CL1: Probably no } \\
\text { recurrence }\end{array}$ & $\begin{array}{l}\text { - Minimal fibrotic wall } \\
\text { thickening }\end{array}$ & $\begin{array}{l}\text { No circumscribed foci of } \\
\text { high signal in scar at } \\
\text { b1000 images }\end{array}$ & $\begin{array}{l}\text { Normal size }(<5 \mathrm{~mm}) \text { with } \\
\text { one of following criteria: } \\
\text { Heterogeneous signal in } \\
\text { node } \\
\text { Round shape } \\
\text { Irregular border }\end{array}$ \\
\hline \multirow[t]{3}{*}{$\begin{array}{l}\text { CL2: Intermediate } \\
\text { presence of } \\
\text { recurrence }\end{array}$} & $\begin{array}{l}\text { Interrupted or defect rectal } \\
\text { wall with mesorectal } \\
\text { spiculation }\end{array}$ & $\begin{array}{l}\text { Small foci of high signal } \\
\text { in scar at b1000 images }\end{array}$ & $\begin{array}{l}\text { Normal size }(<5 \mathrm{~mm}) \text { with } \\
\text { two of before mentioned } \\
\text { criteria, }\end{array}$ \\
\hline & $\begin{array}{l}\text { Heterogeneous signal in } \\
\text { the scar }\end{array}$ & & OR \\
\hline & $\begin{array}{l}\text { Closed rectal wall with } \\
\text { massive fibrosis and } \\
\text { mesorectal spiculation }\end{array}$ & & $\begin{array}{l}\text { Intermediate size }(5-9 \mathrm{~mm}) \\
\text { with one of before } \\
\text { mentioned criteria }\end{array}$ \\
\hline \multirow[t]{2}{*}{$\begin{array}{l}\text { CL3: Probably } \\
\text { recurrence }\end{array}$} & $\begin{array}{l}\text { Mixed signal intensity, but } \\
\text { predominantly } \\
\text { intermediate signal }\end{array}$ & $\begin{array}{l}\text { A small, but obvious } \\
\text { area of high signal in } \\
\text { scar at b1000 images }\end{array}$ & $\begin{array}{l}\text { Normal size }(<5 \mathrm{~mm}) \text { with } \\
\text { three out of three criteria }\end{array}$ \\
\hline & & & $\begin{array}{l}\text { OR } \\
\text { Intermediate size }(5-9 \mathrm{~mm}) \\
\text { with two of } \\
\text { abovementioned criteria }\end{array}$ \\
\hline \multirow[t]{2}{*}{$\begin{array}{l}\text { CL4: Definitely } \\
\text { recurrence }\end{array}$} & $\begin{array}{l}\text { Massive intermediate } \\
\text { signal of rectal wall or } \\
\text { mesorectal tissue }\end{array}$ & $\begin{array}{l}\text { Marked high signal in } \\
\text { scar or mesorectal } \\
\text { tissue at b1000 images }\end{array}$ & $\begin{array}{l}\text { Size }>9 \mathrm{~mm} \\
\text { OR }\end{array}$ \\
\hline & & & $\begin{array}{l}\text { Intermediate size }(5-9 \mathrm{~mm}) \\
\text { with three out of three } \\
\text { criteria }\end{array}$ \\
\hline
\end{tabular}

\section{Reference standard}

The reference standard consisted of histopathology in case of a suspected local (luminal or nodal) recurrence. For a luminal recurrence the histopathological diagnosis was obtained either with a biopsy or with the resection specimen of the re-TEM or TME. In case of a nodal recurrence the reference standard was the TME specimen. For patients without a recurrence follow-up was the reference standard, with a minimal disease-free follow-up time of 15 months 
considered as absence of recurrence as calculated from the last follow-up MRI that was performed.

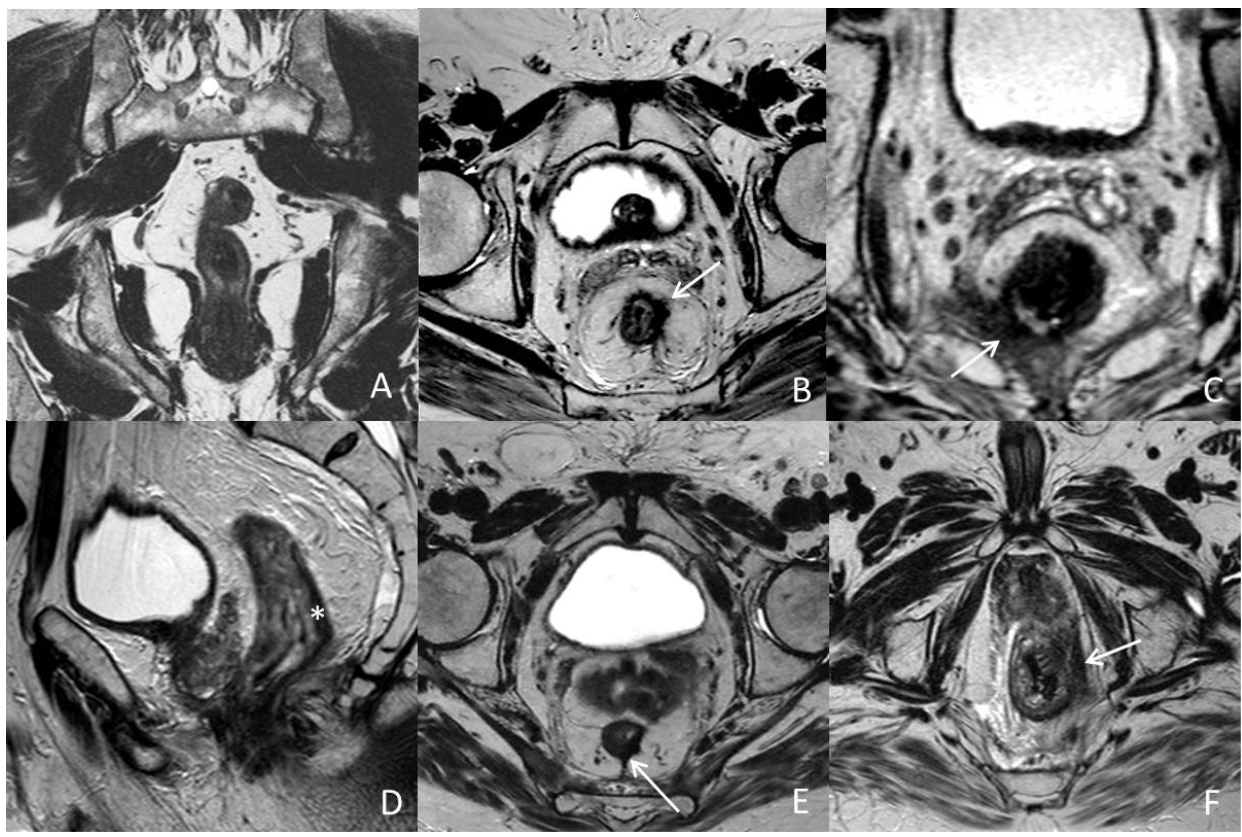

Figure 3.1 - Examples of morphological changes in the rectal wall and mesorectal tissue after TEM. A: normal rectal wall and mesorectal tissue; B: intact rectal wall with fibrosis; C: interrupted rectal wall with mass effect; D: edema of rectal wall as a result of chemoradiation ( ${ }^{*}$ ); $\mathbf{E}$ : spicular fibrosis in the mesorectal tissue and extending to the MRF; F: fibrosis into mesorectal tissue with massive spread to the MRF.

\section{Statistical analysis}

Statistical analyses were performed with IBM SPSS version 22 (Chicago, IL) and Stata, Statacorp Stata version 11.0 (College Station, TX: Statacorp LP 2009). Descriptive analyses were used to assess baseline characteristics. The confidence level scores for luminal and nodal recurrence were used to construct receiver operator characteristics $(R O C)$.

curves and areas under the curve (AUCs) were calculated to evaluate diagnostic performance. Cut-off for confidence level score was determined before onset of the study between 2 and 3. AUCs were compared by the method of Hanley et al. ${ }^{19}$. Because patients underwent several MRIs during follow-up, results from the individual MRIs are not independent observations. Therefore, robust 
variance estimates which adjust for correlation of data within patients were used for calculation of $95 \%$ confidence intervals for sensitivities and specificities ${ }^{20}$. Interobserver agreement was analysed by using quadratic weighted kappa coefficients. The degree of agreement was interpreted as follows: poor agreement as $\mathrm{K}$ value $0.00-0.20$; fair agreement as $\mathrm{K}$ value $0.21-0.40$; moderate agreement as $\mathrm{k}$ value $0.41-0.60$; good agreement as $\mathrm{K}$ value $0.61-0.80$, and excellent agreement as $\mathrm{K}$ value $0.81-1.00^{21}$.

For the analyses of the agreement between readers with regard to the predictive morphological factors, the proportion of specific agreement was calculated for positive and negative outcome by the method as proposed by de Vet et al. ${ }^{22}$ This method was chosen as an alternative for the Cohen's $\mathrm{K}$, as the prevalence of recurrence is very low, leading to an underestimation of the agreement when using Cohen's $\mathrm{K}^{22}$.

Diagnostic performance and agreement were calculated for the total group, but also for the first postoperative MRI and subsequent MRIs separately, to evaluate whether diagnostic performance increases during follow-up. With logistic regression analyses imaging factors (based on scoring of morphology and signal intensity of the rectal wall and mesorectum) predictive of recurrence were identified. Odds ratios (ORs) with 95\% confidence intervals are reported. $P$-values $\leq 0.05$ are considered statistically significant.

\section{Results}

\section{Demographics}

81 patients were included, $53(65 \%)$ underwent TEM as the primary treatment and $28(35 \%)$ underwent a TEM after neoadjuvant CRT. One of the patients had adjuvant CRT because of suspicious lateral nodes on MRI after TEM. Baseline characteristics are shown in Table 3.2. The median follow-up of the patients without recurrence as measured from the date of primary surgery was 50.5 months (range: 16-113 months). The median number of follow-up MRIs per patient was 3 (range 1-9), with a total number of 293 MRIs available for this study. 203/293 (69\%) MRIs were performed with a DWI-sequence. Six MRIs (in 2 patients) were excluded from the evaluation because of inadequate visualization of the former tumour location $(n=5)$ or artefacts $(n=1)$. So, in total 287 MRIs were available for evaluation, of which 203 with DWI (71\%). 
Eighteen patients $(22 \%)$ developed a recurrence (11 luminal, 2 nodal, 5 had both a luminal and nodal recurrence). In five patients a recurrence was already seen at the first post-TEM MRI. The median size of recurrences on MRI was $25 \mathrm{~mm}(9-130 \mathrm{~mm})$. Half of the recurrences had the largest maximal size in the axial plane, e.g. in the direction of the resection plane of the TEM.

Table 3.2 - Patient characteristics of 81 patients.

\begin{tabular}{lccc}
\hline Characteristics & No recurrence $(\mathbf{n}=\mathbf{6 3})$ & Recurrence $(\mathbf{n = 1 8})$ & Total $(\mathbf{n}=\mathbf{8 1})$ \\
\hline Age $(\mathrm{y})^{*}$ & & & \\
Mean & 64 & 64 & 64 \\
SD & \pm 11 & \pm 10 & \pm 10 \\
Sex & & & \\
Male & $47(74.6 \%)$ & $7(61.1 \%)$ & $58(71.6 \%)$ \\
Female & $16(25.4 \%)$ & & $23(28.4 \%)$ \\
Tumour stage & & $3(16.7 \%)$ & \\
(y)pT0 & $19(30.2 \%)$ & 0 & $22(27.2 \%)$ \\
(y)pTis & $1(1.6 \%)$ & $9(50.0 \%)$ & $1(1.2 \%)$ \\
(y)pT1 & $27(42.9 \%)$ & $6(33.3 \%)$ & $36(44.4 \%)$ \\
(y)pT2 & $13(20.6 \%)$ & & $19(23.5 \%)$ \\
(y)pT3 & $3(4.7 \%)$ & & $3(3.7 \%)$ \\
\hline
\end{tabular}

* Age at moment of TEM.

\section{Diagnostic performance}

\section{Luminal recurrence}

Based on all MRI exams, AUCs for luminal recurrence detection on standard T2W-MRI was $0.72(95 \% \mathrm{Cl}: 0.54-0.89)$ for reader 1 and $0.80(95 \% \mathrm{Cl}$ : $0.64-0.96)$ for reader 2 . AUC for detection of a luminal recurrence on DWI was 0.70 (95\% Cl: 0.53-0.88) for reader 1 and 0.89 (95\% Cl: 0.76-1.00) for reader 2. For reader 1 , addition of DWI to T2W-MRI increased performance compared to T2W-MRI for the first postoperative scan only, but not for the subsequent followup MRIs. For reader 2, addition of DWI increased performance both for the first postoperative MRI and for subsequent MRIs, by increasing confidence of the reader. In 5/16 (31\%) luminal recurrences DWI detected the recurrence earlier than T2W-MRI (Figure 3.2). Confidence of the readers in assessing recurrence increased during follow-up (Figure 3.3). All results are shown in Figure 3.4 and Table 3.3. 


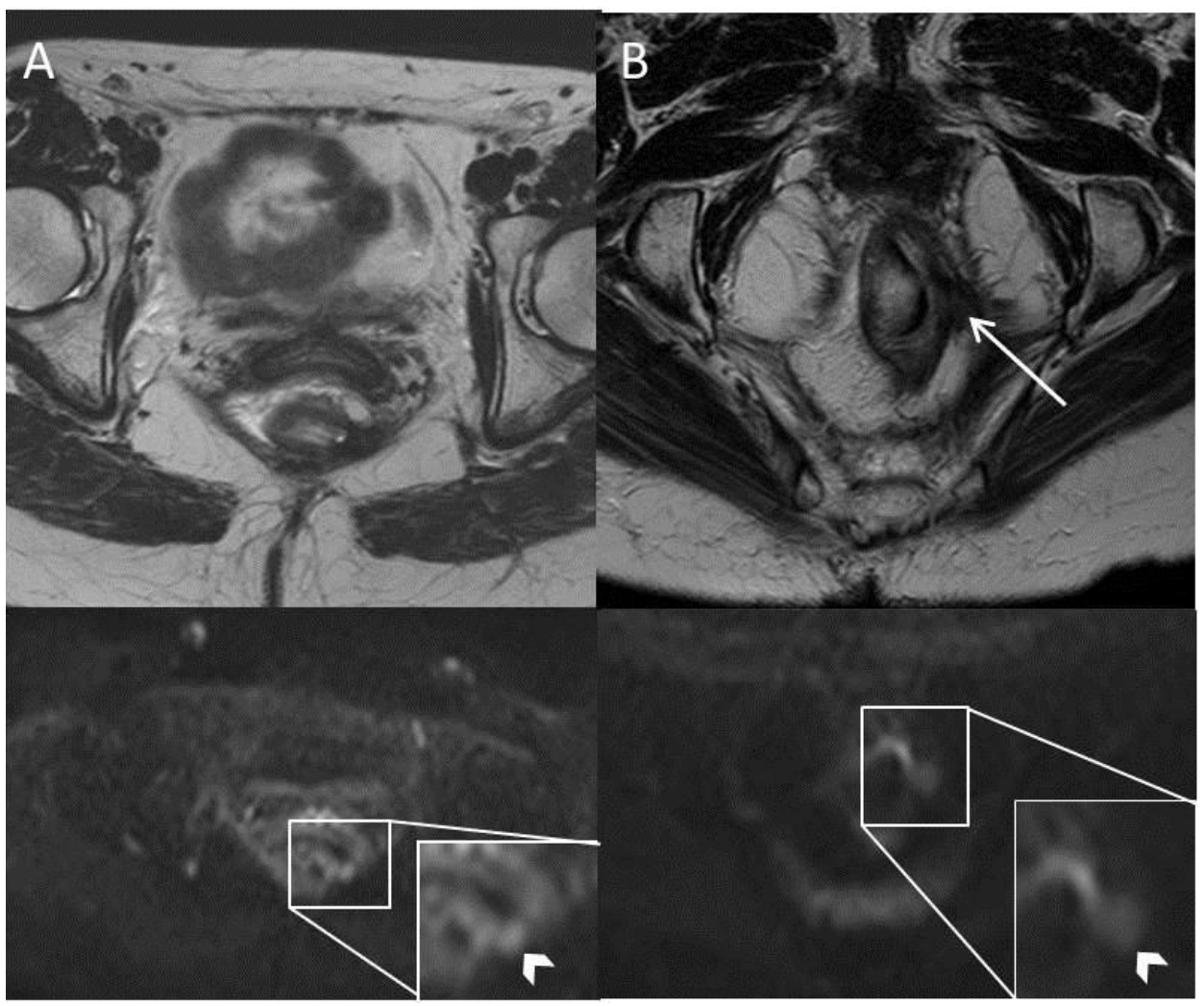

Figure 3.2 - Detection of a recurrence on DWI, before it was visible on T2W-MRI. A: MRI 6 months after TEM: no signs of recurrence on T2W, but small focus (arrowhead) of high signal on b1000DWI. B: MRI 9 months after TEM: recurrence visible on both T2W- and DWI-MR (arrow).

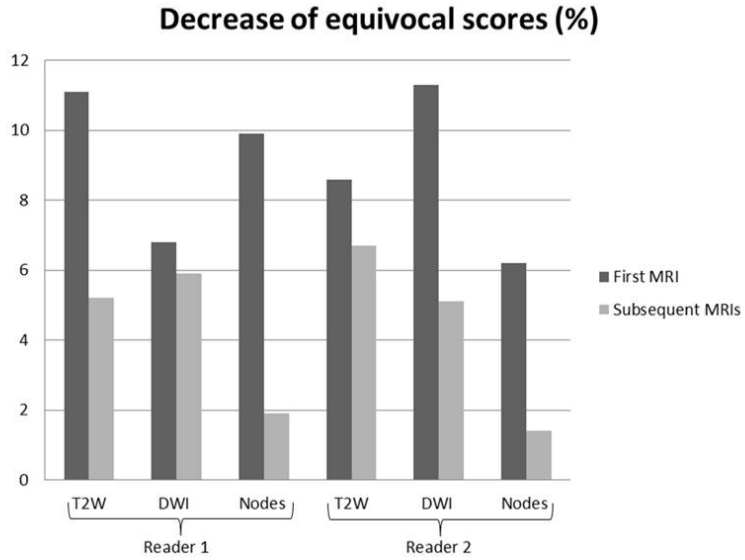

Figure 3.3 - The number of equivocal scores (CL2) decreased during follow-up in \%. 


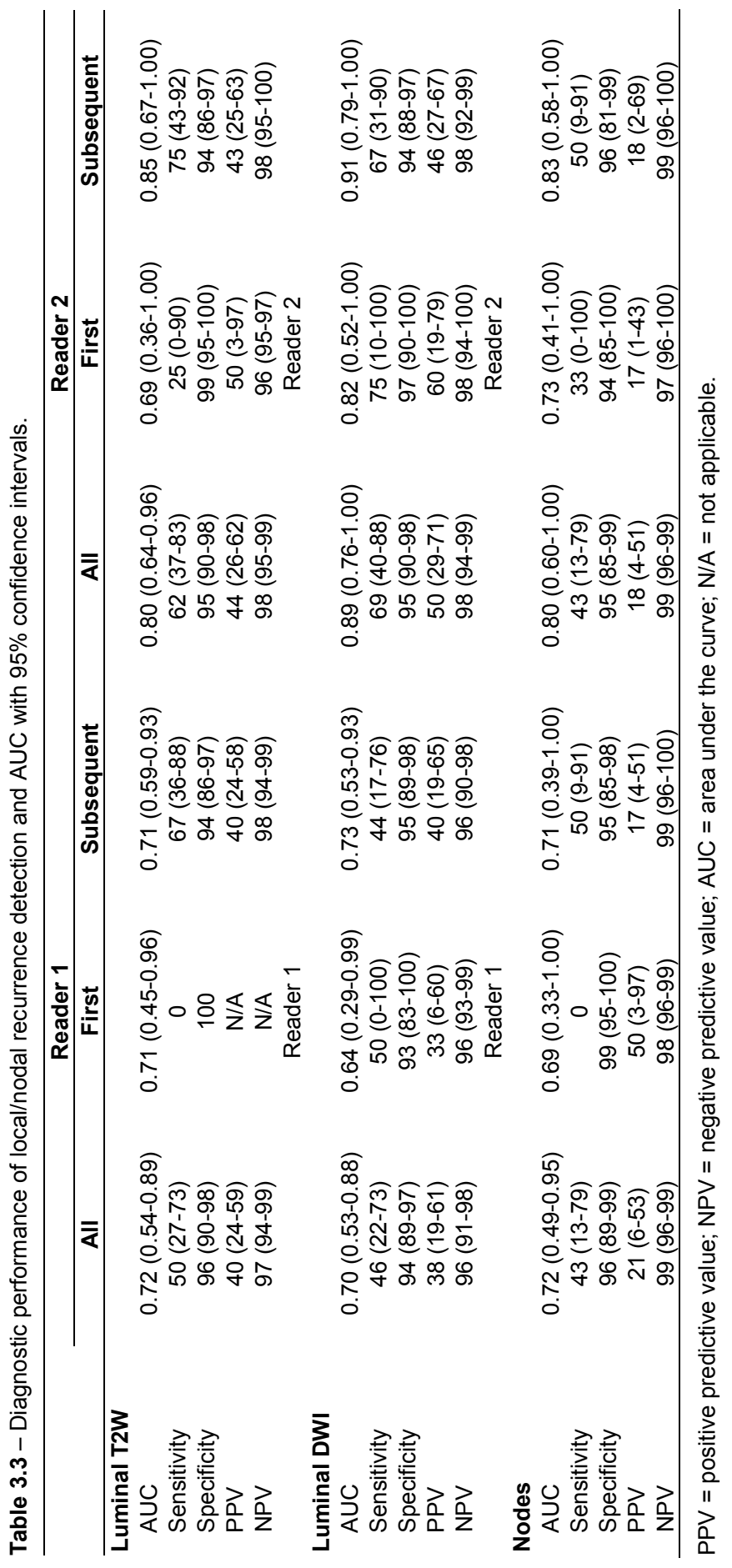



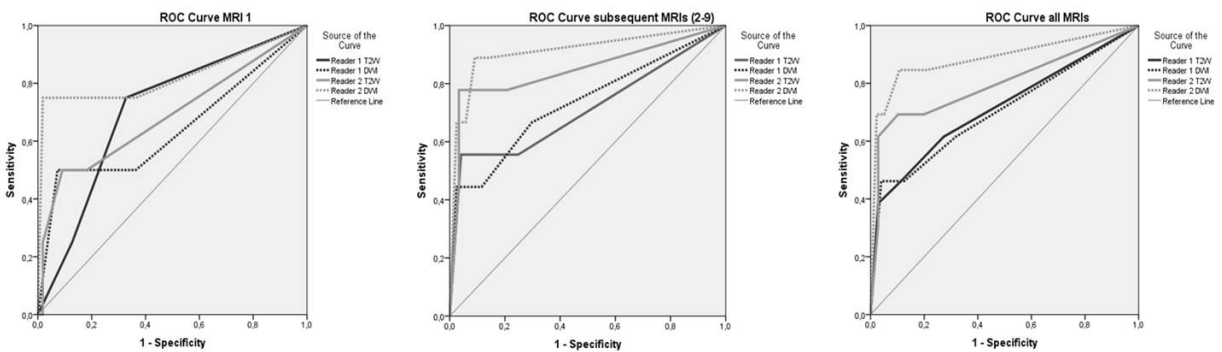

Figure 3.4 - Receiver operator characteristics (ROC) curves for the diagnostic performance for the detection of a luminal recurrence for standard T2W-MRI and DWI for both readers. A: ROC curve for first MRI; B: ROC curve for subsequent MRIs; C: ROC curve for all MRIs.

\section{Predictive factors on MRI for luminal recurrence}

Appearance of intermediate signal of the rectal wall and mesorectal tissue were statistically significant predictive factors for local recurrence (Figure 3.5) with odds ratios between $6.8(95 \% \mathrm{Cl}: 2.4-19.8, \mathrm{p}<0.001)$ and $8.0(95 \% \mathrm{Cl}: 2.7-23.4$, $\mathrm{p}<0.001)$. The results of the regression analyses are shown in Table 3.4.

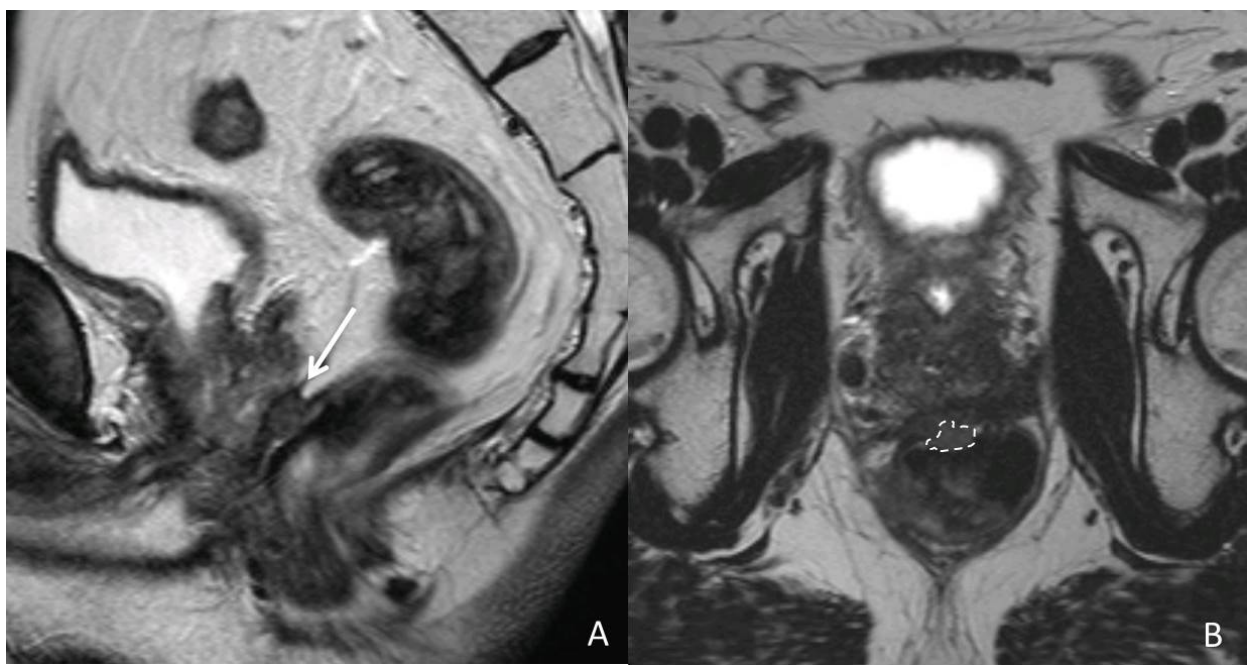

Figure 3.5 - Intermediate signal in rectal wall and mesorectum as a predictive factor of local recurrence. 


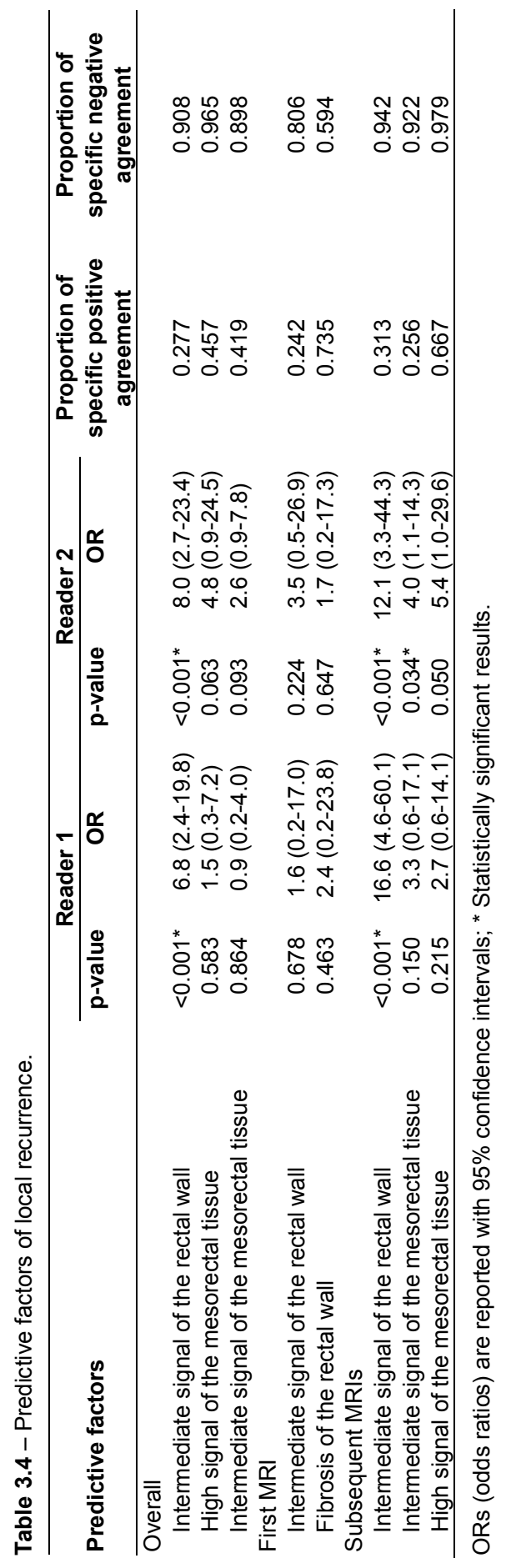




\section{Nodal recurrence}

For nodal recurrence detection the AUC was $0.72(95 \% \mathrm{Cl}: 0.49-0.95)$ for reader 1 and $0.80(95 \% \mathrm{Cl}: 0.60-1.00)$ for reader 2 . The sensitivity of nodal recurrence detection on the first MRI is low for both readers, with a high specificity. An increase in AUC was seen during follow-up (Table 3.3).

\section{Interobserver agreement}

Interobserver agreement based on all MRIs was good for standard T2W-MRI for detecting luminal recurrence ( $\mathrm{\kappa} 0.68$ ) and for detecting nodal recurrence (к 0.71). Interobserver agreement was moderate for detecting luminal recurrence with DWI ( $\mathrm{k}$ 0.57). For both T2W-MRI and DWI, interobserver agreement increased during follow-up (T2W-MRI luminal: $\mathrm{k} 0.09$ to $\mathrm{k} 0.78$; T2W-MRI nodal: $\mathrm{k} 0.36$ to $\kappa$ 0.84; and DWI luminal: $\mathrm{k} 0.49$ to $\mathrm{k} 0.61$ ).

\section{Differences in morphology between patients with and without chemoradiation}

There were some differences in morphology between patients with and without chemoradiation. Patients treated with neo-adjuvant CRT had more fibrosis in the rectal wall, more edema of the rectal wall, and a more intermediate signal of the mesorectum. These morphologic differences were most prominent on the first and second MRI after TEM and the difference decreased after longer follow-up (Table 3.4).

\section{Discussion}

The present study shows that MRI is a feasible technique for follow-up after TEM for rectal cancer, both in a primary and in a post-CRT setting. Serial followup imaging allows readers to become more confident, shown by an increase in AUC and an increase in agreement for T2W-MRI and DWI when follow-up scans are compared to the first postoperative MRI scan. DWI can help in identifying recurrences earlier. Patients who had CRT showed more morphological abnormalities during follow-up after TEM than patients without CRT. At T2W$\mathrm{MRI}$, intermediate signal intensity of the rectal wall was the most robust predictive factor for luminal recurrence. Identification of a nodal recurrence is more challenging, reflected by the low sensitivity for both readers.

There is limited evidence on follow-up after TEM for early rectal cancer and small tumours after chemoradiation. Studies published so far mainly focus on 
long-term outcome and used a heterogeneous strategy for follow-up, relying mainly on endoscopy $y^{4,23-25}$. No studies have been published about the most suitable imaging modality and/or the most adequate follow-up schedule. The current results show that MRI can be considered as an imaging modality for follow-up after TEM, as an adjunct to the endoscopic follow-up. The first postoperative scan after TEM is difficult to interpret because of a heterogeneous signal at the TEM location, massive fibrosis and substantial edema in the rectal wall and mesorectal fat, which leads to uncertainty in readers. This uncertainty is reflected in a relatively high number of equivocal scores (CL2), a lower interobserver agreement compared to follow-up MRIs and low sensitivities for both readers when evaluating the first postoperative MRI. When looking at follow-up scans, readers become more confident, probably because of the ability to compare with earlier scans. The one factor that helped both readers the most in identifying luminal recurrences was the appearance of intermediate signal in the scar (Figure 3.5).

The appearance of intermediate signal in the dark fibrosis is rather easy to appreciate and the use of this sign can be of help when radiologists are evaluating post-TEM MRI in clinical practice. Strikingly, at the first postoperative MRI at 3 months after TEM five recurrences were already found. This finding points out the need for early imaging of the TEM scar in order not to miss early recurrences and to furthermore provide a baseline scan to compare with during further follow-up.

We found that DWI is helpful in the follow-up after TEM. Overall, DWI outperforms T2W-MRI for the detection of luminal recurrences. At the first postoperative MRI, DWI was more accurate compared to T2-weighted MRI, suggesting that DWI is less influenced by post-TEM changes, which is supported by the higher interobserver agreement at the first postoperative MRI for DWI compared to T2W-MRI. Addition of DWI mainly led to an increase in sensitivity compared to T2W-MRI when evaluating the first postoperative MRI, which leads to a lower risk of missing an early luminal recurrence. Also, DWI could identify a recurrence earlier during follow-up than T2W-MRI in several patients, where appearance of diffusion restriction was noted before changes on T2W-MRI were seen. Probably, DWI helps in differentiating tumour tissue from fibrosis, similarly to its use in response evaluation of rectal cancer after chemoradiation and therefore has a higher diagnostic performance than T2WMRI only ${ }^{26-28}$. The higher sensitivity with DWI comes at the expense of a slightly lower specificity and a low PPV. This can be explained by the small foci of high 
signal that were sometimes found at post-TEM DWI, which disappeared during follow-up (Figure 3.6) and can be misinterpreted as residual tumour or recurrence. Probably, these are small foci of T2 shine through because of edema, which - due to the small size of the foci - are difficult to appreciate on the ADC map.

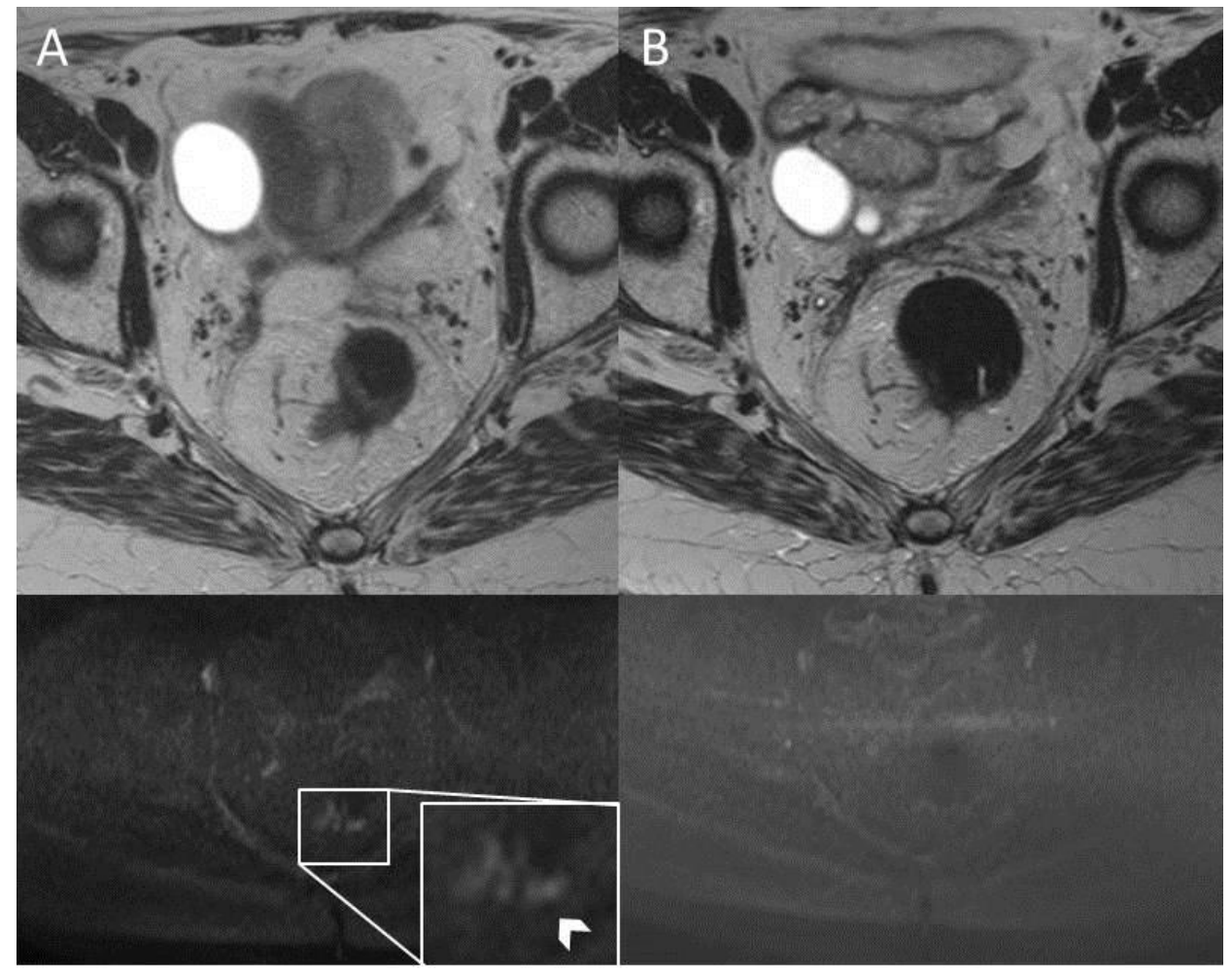

Figure 3.6 - False-positive high signal on DWI-MRI. A: High signal on b1000 DWI at first post-TEM follow-up scan B: 3 months later no signs of recurrence on T2W- and DWI-MRI. The patient remained recurrence free during follow-up. 
Detection of a nodal recurrence remains a challenge - just as in primary staging of rectal cancer and given the very few nodal recurrences in this population it is difficult to draw any robust conclusions on nodal evaluation after TEM. The same difficulties regarding size and morphology apply during follow-up after TEM as when nodes are evaluated at primary staging and at restaging after chemoradiation. In our experience, the major difference in post-TEM MRI is that at the first post-operative scan many reactive enlarged nodes are found which can confuse the radiologist (Figure 3.7).

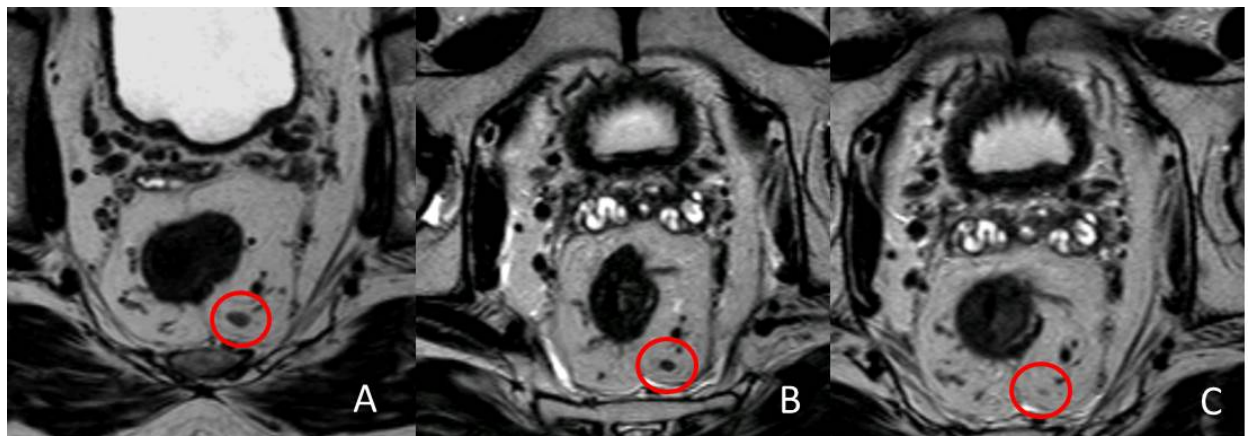

Figure 3.7 - Reactive nodes. A: MRI post-TEM, B: MRI 5 months post-TEM, C: MRI 8 months post TEM. The major difference in post-TEM MRI is that at the first post-operative scan many reactive enlarged nodes are found which can confuse the radiologist.

Interobserver agreement was moderate to good for all modalities and outcomes. However, interobserver agreement was relatively low for the presence of predictive morphological features for luminal recurrence (e.g. appearance of intermediate signal in the scar/rectal wall). Given the low prevalence of recurrence we calculated the proportion of specific agreement for either the presence or absence of a morphological feature, rather than using Cohen's $\mathrm{K}$ $(\text { Table } 3.4)^{22}$. This shows that mainly the agreement on presence of intermediate signal in the rectal wall and of the mesorectum is relatively low, even though it does increase during follow-up (from 0.24 at the first post-TEM MRI to 0.31 during follow-up). However, the fact that these features were predictive for luminal recurrence in the logistic regression analyses, supports that these features are reproducible and robust, even though agreement is relatively low. For all other morphological features agreement is moderate to excellent and specifically, agreement on the absence of features is excellent. 


\section{Limitations}

This study has several limitations. First, the study is retrospective and a part of the patients underwent (neo)adjuvant chemoradiation, while others did not. However, we observed that the aspect of the morphological changes is similar between both groups, but in patients who had CRT changes were more profound and frequently encountered. After longer follow-up this difference decreased. Also, several patients refused salvage surgery, while based on histopathology salvage surgery was indicated. Second, follow-up was performed in two hospitals and MR protocols differed to some extent (Appendix 3.1). Third, only expert readers were involved, so it is unsure whether the results are applicable to the general reader. Last, there is no comparison with standard follow-up after TEM (endoscopy usually combined with CT/ERUS), so no recommendation can be made regarding cost-effectiveness of implementing $\mathrm{MRI}$ in the follow-up compared to regular follow-up.

\section{Conclusions}

MRI (including DWI) is feasible for follow-up after TEM for rectal cancer. At the first postoperative scan the postoperative changes can be confusing, but during follow-up diagnostic performance and interobserver agreement increase. Therefore, we recommend to use the first post-TEM MRI as a baseline scan for further follow-up. Because early recurrence can occur, the baseline scan can be performed approximately 4-6 weeks after TEM. The factors on post-TEM MRI that are most suspicious for a recurrence are: (appearance of) intermediate signal and/or appearance of high signal at b1000 DWI-MRI in the scar tissue at the former tumour location. Nodal staging remains a challenge. 
Appendix 3.1 - MRI sequences per centre.

T2W Regional Hospital (tertiary TEM referral) - Siemens Magnetom Aera 1,5 Tesla

Up to Sep 2013 T2 SAG: TR/TE 7500/113ms, 0.8x0.8x5.0mm voxel size, 24 slices T1 TRA: TR/TE $601 / 11 \mathrm{~ms}, 0.8 \times 0.8 \times 3.0 \mathrm{~mm}$ voxel size, 26 slices T2 TRA: TR/TE $5300 / 74 \mathrm{~ms}, 1.0 \times 1.0 \times 6.0 \mathrm{~mm}$ voxel size, 30 slices T2 COR: TR/TE $8730 / 113 \mathrm{~ms}, 0.8 \times 0.8 \times 3.0 \mathrm{~mm}$ voxel size, 30 slices T1 COR: TR/TE $7420 / 108 \mathrm{~ms}, 0.8 \times 0.8 \times 3.0 \mathrm{~mm}$ voxel size, 26 slices

Since Sep 2013 T2 SAG: TR/TE 4400/120ms, $1.56 \times 1.56 \times 5.0 \mathrm{~mm}$ voxel size, 18 slices T1 TRA: TR/TE $574 / 12 \mathrm{~ms}, 1.04 \times 1.17 \times 3.0 \mathrm{~mm}$ voxel size, 24 slices T2 TRA: TR/TE $6000 / 120 \mathrm{~ms}, 1.04 \times 1.17 \times 3.0 \mathrm{~mm}$ voxel size, 24 slices T2 COR: TR/TE $6000 / 120 \mathrm{~ms}, 1.04 \times 1.17 \times 3.0 \mathrm{~mm}$ voxel size, 24 slices

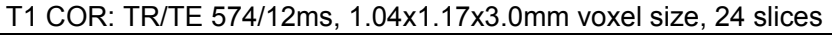

T2W University Hospital - Philips Interna and Philips Ingenia

T2 SAG: TR/TE 3427/150ms, 3NSA, 0.8x1.1x4.0mm voxel size, 22 slices T2 TRA: TR/TE 9558/130ms, 3NSA, 0.8x1.1×3.0mm voxel size, 30 slices T2 COR: TR/TE 9558/130ms, 3NSA, 0.8x1.1×3.0mm voxel size, 30 slices

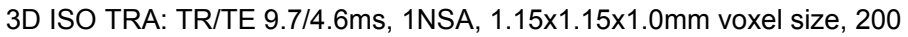
slices

DWI University Hospital - Philips Interna and Philips Ingenia

Up to Dec 2011 DWIBS b0-b100-b500-b1000: TR/TE 4829/70ms, EPI factor 53-64, 5NSA, $1.8 \times 2.3 \times 5.0 \mathrm{~mm}$ voxel size, $24-50$ slices, $5.33-10.37 \mathrm{~min}$ acquisition time Jan 2012-June 2012 DWI SPIR b0-500-1000: TR/TE 4829/70ms, EPI factor 53-64, 5NSA, $1.8 \times 2.3 \times 5.0 \mathrm{~mm}$ voxel size, $24-50$ slices, $5.33-10.37 \mathrm{~min}$ acquisition time

July 2012-Oct 2012 DWI SPAIR b0-500-1000: TR/TE 4829/70ms, EPI factor 53-64, 5NSA, $1.8 \times 2.3 \times 5.0 \mathrm{~mm}$ voxel size, $24-50$ slices, $5.33-10.37 \mathrm{~min}$ acquisition time Nov 2012-Mar 2013 DWI SPAIR b0-25-50-100-500-1000: TR/TE 4147/66ms, EPI factor 77, 5NSA, $1.8 \times 2.3 \times 5.0$ voxel size, 20 slices

Since March 2013 DWI SPAIR b0-25-50-100-500-1000-2000: TR/TE 4499/80ms, EPI factor 87, $5 \mathrm{NSA}, 1.8 \times 2.3 \times 5.0 \mathrm{~mm}$ voxel size, 20 slices 


\section{References}

1. Tytherleigh MG, Warren BF, Mortensen NJ. Management of early rectal cancer. Br J Surg. 2008;95(4):409-23.

2. Borschitz T, Gockel I, Kiesslich R, Junginger T. Oncological outcome after local excision of rectal carcinomas. Ann Surg Oncol. 2008;15(11):3101-8.

3. Verseveld M, de Graaf EJ, Verhoef C, van Meerten E, Punt CJ, de Hingh IH, et al. Chemoradiation therapy for rectal cancer in the distal rectum followed by organ-sparing transanal endoscopic microsurgery (CARTS study). Br J Surg. 2015;102(7):853-60.

4. Lezoche E, Guerrieri M, Paganini AM, D'Ambrosio G, Baldarelli M, Lezoche G, et al. Transanal endoscopic versus total mesorectal laparoscopic resections of T2-N0 low rectal cancers after neoadjuvant treatment: a prospective randomized trial with a 3-years minimum follow-up period. Surg Endosc. 2005;19(6):751-6.

5. Restivo A, Zorcolo L, D'Alia G, Cocco F, Cossu A, Scintu F, et al. Risk of complications and long-term functional alterations after local excision of rectal tumours with transanal endoscopic microsurgery (TEM). Int J Colorectal Dis. 2015.

6. Serra-Aracil X, Vallverdu H, Bombardo-Junca J, Pericay-Pijaume C, Urgelles-Bosch J, Navarro-Soto S. Long-term follow-up of local rectal cancer surgery by transanal endoscopic microsurgery. W J Surg. 2008;32(6):1162-7.

7. Steinhagen E, Chang G, Guillem JG. Initial experience with transanal endoscopic microsurgery: the need for understanding the limitations. J Gastrointest Surg. 2011;15(6): 958-62.

8. Buess G. Review: transanal endoscopic microsurgery (TEM). J R Coll Surg Edinb. 1993;38(4): 239-45.

9. Allaix ME, Arezzo A, Caldart M, Festa F, Morino M. Transanal endoscopic microsurgery for rectal neoplasms: experience of 300 consecutive cases. Dis Colon Rectum. 2009;52(11): 1831-6.

10. De Graaf EJ, Doornebosch PG, Tollenaar RA, Meershoek-Klein Kranenbarg E, de Boer AC, Bekkering FC, et al. Transanal endoscopic microsurgery versus total mesorectal excision of T1 rectal adenocarcinomas with curative intention. Eur J Surg Oncol. 2009;35(12):1280-5.

11. Lebedyev A, Tulchinsky H, Rabau M, Klausner JM, Krausz M, Duek SD. Long-term results of local excision for T1 rectal carcinoma: the experience of two colorectal units. Tech Coloproctol. 2009;13(3):231-6.

12. Junginger T, Goenner $U$, Hitzler M, Trinh TT, Heintz A, Wollschlaeger D, et al. Long-term oncologic outcome after transanal endoscopic microsurgery for rectal carcinoma. Dis Colon Rectum. 2016;59(1):8-15.

13. Perez RO, Habr-Gama A, Sao Juliao GP, Proscurshim I, Fernandez LM, de Azevedo RU, et al. Transanal Endoscopic Microsurgery (TEM) Following Neoadjuvant Chemoradiation for Rectal Cancer: Outcomes of Salvage Resection for Local Recurrence. Ann Surg Oncol. 2016;23(4): 1143-8.

14. Burdan F, Sudol-Szopinska I, Staroslawska E, Kolodziejczak M, Klepacz R, Mocarska A, et al. Magnetic resonance imaging and endorectal ultrasound for diagnosis of rectal lesions. Eur $\mathrm{J}$ Med Res. 2015;20:4.

15. Engelen SM, Beets GL, Beets-Tan RG. Role of preoperative local and distant staging in rectal cancer. Onkologie. 2007;30(3):141-5.

16. Lambregts DM, Lahaye MJ, Heijnen LA, Martens MH, Maas M, Beets GL, et al. MRI and diffusion-weighted MRI to diagnose a local tumour regrowth during long-term follow-up of rectal cancer patients treated with organ preservation after chemoradiotherapy. Eur Radiol. 2016; 26(7):2118-25.

17. Landelijke_Werkgroep_Gastro-Intestinale_Tumouren. Landelijke Richtlijn Rectumcarcinoom (version 3.0). www.oncoline.nl. 2016. 
18. Maas M, Beets-Tan RG, Lambregts DM, Lammering G, Nelemans PJ, Engelen SM, et al. Waitand-see policy for clinical complete responders after chemoradiation for rectal cancer. J Clin Oncol. 2011;29(35):4633-40.

19. Hanley JA, McNeil BJ. A method of comparing the areas under receiver operating characteristic curves derived from the same cases. Radiology. 1983;148(3):839-43.

20. Rogers $\mathbf{W H}$. Regression standard errors in clustered samples. Stata Technical Bulletin Reprints. 1993;3:88-94.

21. Cohen J. Weighted kappa: nominal scale agreement with provision for scaled disagreement or partial credit. Psychol Bull. 1968;70(4):213-20.

22. de Vet HC, Mokkink LB, Terwee CB, Hoekstra OS, Knol DL. Clinicians are right not to like Cohen's kappa. BMJ. 2013;346:f2125.

23. Guerrieri M, Gesuita R, Ghiselli R, Lezoche G, Budassi A, Baldarelli M. Treatment of rectal cancer by transanal endoscopic microsurgery: experience with 425 patients. W J Gastroenterol. 2014;20(28):9556-63.

24. Doornebosch PG, Ferenschild FT, de Wilt JH, Dawson I, Tetteroo GW, de Graaf EJ. Treatment of recurrence after transanal endoscopic microsurgery (TEM) for T1 rectal cancer. Dis Colon Rectum. 2010;53(9):1234-9.

25. Sylla $P$, Rattner DW, Delgado S, Lacy AM. NOTES transanal rectal cancer resection using transanal endoscopic microsurgery and laparoscopic assistance. Surg Endosc. 2010;24(5): 1205-10.

26. van der Paardt MP, Zagers MB, Beets-Tan RG, Stoker J, Bipat S. Patients who undergo preoperative chemoradiotherapy for locally advanced rectal cancer restaged by using diagnostic MR imaging: a systematic review and meta-analysis. Radiology. 2013;269(1): 101-12.

27. Lambregts DM, Vandecaveye $\mathrm{V}$, Barbaro $\mathrm{B}$, Bakers FC, Lambrecht $\mathrm{M}$, Maas $\mathrm{M}$, et al. Diffusion-weighted MRI for selection of complete responders after chemoradiation for locally advanced rectal cancer: a multicentre study. Ann Surg Oncol. 2011;18(8):2224-31.

28. Lambregts DM, Maas M, Bakers FC, Cappendijk VC, Lammering G, Beets GL, et al. Long-term follow-up features on rectal MRI during a wait-and-see approach after a clinical complete response in patients with rectal cancer treated with chemoradiotherapy. Dis Colon Rectum. 2011;54(12):1521-8. 



\section{Chapter 4}

Quality of life in rectal cancer patients after chemoradiation: watch-and-wait policy versus standard resection - a matched controlled study

BJP Hupkens, MH Martens, JH Stoot, M Berbee, J Melenhorst, RG Beets-Tan, GL Beets, SO Breukink 


\section{Abstract}

Background: $15-20 \%$ of patients with locally advanced rectal cancer have a clinical complete response after chemoradiation therapy. These patients can be offered non-operative organ-preserving treatment, the so-called watch-and-wait policy. The main goal of this watch-and-wait policy is an anticipated improved quality of life and functional outcome compared to a total mesorectal excision, while maintaining a good oncological outcome. The aim of this study was to compare quality of life of W\&W-patients with a matched-controlled group of patients who underwent chemoradiation and surgery (TME-group).

Methods: The study population consisted of two groups: 41 patients after a watch-and-wait policy, and 41 matched patients after chemoradiation and surgery. Patients were matched on sex, age, tumour-stage and tumour height. All patients were disease-free at the moment of recruitment after a minimal follow-up of two years. Quality of life was measured by validated questionnaires covering general QoL (SF-36, EORTC QLQ-C30), disease specific QoL (EORTC-QLQ-CR38), defecation problems (Vaizey- and LARS-score), sexual problems (IIEF and FSFI) and urinary dysfunction (IPSS).

Results: The watch-and-wait-group showed better physical and cognitive function, better physical and emotional role and better global health status compared to the TME-group. The watch-and-wait-patients showed less problems with defecation, sexual and urinary tract function. Limitations: This study only focused on watch-and-wait-patients who achieved a sustained complete response for two years. Additionally, this is a study with a limited number of patients and with quality of life measurements on non-predefined and variable intervals after surgery.

Conclusions: After a successful watch-and-wait approach the quality of life was better than after chemoradiation and surgery on several domains. However, chemoradiation therapy on its own is not without long term side-effects, as one third of the watch-and-wait-patients suffered from major LARS-symptoms, compared to $66.7 \%$ of the patients in the TME-group. 


\section{Introduction}

Patients with locally advanced rectal cancer are usually treated with neoadjuvant chemoradiation therapy (CRT) and surgery (total mesorectal excision (TME)). In approximately $15-20 \%$ of the patients no residual tumour is reported after standard resection, this is called a pathologic complete response $(\mathrm{pCR})^{1}$. Based on this phenomenon the watch-and-wait policy (W\&W) has been developed ${ }^{2,3}$. The W\&W-policy was meant to provide less functional problems in patients with rectal cancer. Previous studies showed already promising oncological results for the W\&W-patients with disease-free survival rates of $81-92 \%$ and overall survival rates of $97-100 \%^{2-5}$. Given this good oncological outcome, focus has shifted towards quality of life and functional outcome in studies that evaluate a watch-and-wait policy in patients with a complete response.

TME has been shown to have a negative influence on quality of life of patients with rectal cancer, with anorectal, sexual and urinary dysfunction as common long-term sequela ${ }^{6-8}$. Additional radiotherapy can increase the long-term risk for functional problems, probably because of fibrosis of the rectal wall, anal sphincter and urogenital organs ${ }^{9}$.

It looks like patients who are treated in a W\&W-policy will have better functional outcomes and a better QoL. However, the effect of radiotherapy alone is not clear yet.

The hypothesis of this study was that W\&W-patients with a sustained complete response after CRT have a better QoL and functional outcome compared to patients with rectal cancer who were treated by neoadjuvant CRT followed by TME.

\section{Materials and methods}

\section{Patient selection}

The study was approved by the Committee on Medical Research Ethics and all patients provided written informed consent. This study population consisted of two groups: W\&W-patients (W\&W-group) with a sustained clinical complete response after CRT, and patients that underwent CRT followed by TME (TMEgroup), without recurrences. The inclusion criteria for the watch-and-wait policy were described in previous papers ${ }^{3,5}$. Patients were included in the W\&Wapproach when they had a clinical complete response after CRT. A clinical 
complete response (cCR) was described as no palpable tumour at digital rectal examination (DRE), no residual tumour and a white scar at endoscopy, negative biopsies from scar at histopathology (biopsy was not mandatory), and no residual tumour and no suspicious lymph nodes on MRI, including diffusionweighted MRI (DWI). After two years the late side effects of CRT were expected to have reached their plateau phase, which is why only patients with at least two year follow-up were included ${ }^{10}$. All patients were disease-free at the moment of recruitment. Patients were matched on sex, age, tumour-stage, and tumour height defined as distance from anorectal junction to the lower edge of the tumour on sagittal MRI.

Exclusion criteria were: pre-existent functional problems of the pelvic floor, more extensive surgery than TME for locally advanced rectal cancer (e.g. pelvic exenteration), Crohn's disease or ulcerative colitis and pregnancy.

\section{Questionnaires}

QoL and pelvic functional outcome were assessed with the Short Form 36 (SF36) health survey ${ }^{11}$, the European Organization for Research and Treatment of Cancer (EORTC) QLQ-30 questionnaire, version 3.0, Global Quality of Life Score $^{12}$, the EORTC-QLQ-CR38 ${ }^{13}$, the Vaizey-score ${ }^{14}$, the LARS-score ${ }^{15}$, the International Index of Erectile Function (IIEF) ${ }^{16}$, the Female Sexual Function Index $(\mathrm{FSFI})^{17}$, and the International Prostate Symptom Score (IPSS) ${ }^{18}$.

\section{General health}

The SF-36 ${ }^{11}$, is a generic QoL questionnaire (Dutch version of the Medical Outcomes Study Short-Form (SF-36)) consisting of 36 questions organized in nine multi-item scales: physical functioning, physical role functioning, pain, general well-being, vitality, social functioning, emotional role functioning, mental functioning and health change.

The EORTC-QLQ-C30 ${ }^{12}$, is a cancer specific instrument to measure quality of life. This questionnaire is subdivided into five functional levels (i.e. physical, role, emotional, cognitive, and social), three symptom scales (fatigue, nausea and vomiting, and pain) and six single items (dyspnoea, insomnia, appetite loss, constipation, diarrhoea, and financial difficulties) and one global quality of life scale. The scores are calculated into a score range from 0 to 100 . A high score for a functional scale represents a high level of functioning. A high score in the symptom scale represents a high level of symptomatology and problems. A high 
score for the global health status and quality of life represents a high quality of life.

The EORTC-QLQ-CR38 ${ }^{13}$, is a colorectal specific QoL questionnaire and consists of 38 questions. Validity and reliability have been described in Dutch patients with colorectal cancer. The questionnaire is subdivided into four functional scales (i.e. body image, sexual functioning, sexual enjoyment and future perspective) and eight symptom scales (micturition problems, gastrointestinal tract symptoms, chemotherapy side effects, defecation problems, stoma-related problems, male and female sexual problems and weight loss). Half of the questions are completed by all patients, while the remaining 19 questions are divided into groups of questions relevant for subsamples of patients only (i.e., male or female, patient with or without a stoma). These scores are also calculated into a score range from 0 to 100.

\section{Defecation problems}

The Vaizey-score ${ }^{14}$, is a score to assess faecal incontinence. In this questionnaire patients are asked to evaluate their defecation pattern of the previous four weeks, including questions regarding consistency of stool lost, frequency and its effect on lifestyle. Patients with high scores have more incontinence problems.

The LARS-score ${ }^{15}$, is a relatively new score evaluating bowel dysfunction after low anterior resection for rectal cancer. The questionnaire consists of five questions including questions about incontinence for flatus and liquid stool, frequency, clustering and urgency. The range of this score is 0-42 and is divided into no LARS (0-20 points), minor LARS (21-29 points) and major LARS (30-42 points).

\section{Sexual dysfunction}

The IIEF and FSFI were used to indicate sexual problems. The IIEF ${ }^{16}$, was used to assess male sexual function. In this questionnaire fifteen items are assessed. The questionnaire is subdivided into five response domains (erectile function, orgasmic function, intercourse satisfaction, sexual desire, and overall satisfaction). The domain scores are calculated by cumulating the scores of individual items in each domain. Complete erectile dysfunction (ED) is defined as an erectile function domain score $<10$ and partial ED as a score between 10 and 17 . 
The $\mathrm{FSFI}^{17}$, is a questionnaire consisting of 19 items, and has been developed as a brief, multidimensional self-report instrument for assessing the key dimensions of sexual function in women. A higher score is related to more sexual problems.

\section{Urinary dysfunction}

The IPSS ${ }^{18}$, is a validated questionnaire to assess problems of the urinary tract. Officially this score is used for patients with benign prostate hypertrophy to assess bladder function, but because of lack of an alternative, this questionnaire seems the best option. The IPSS is subdivided into seven items: which include incomplete bladder emptying, frequency, intermittency, urgency, weak stream, straining, and nocturia. Also, QoL is evaluated in this questionnaire. The range of this score is $0-35$ and is divided into mild symptoms (0-7 points), moderate symptoms (8-19 points), and severe symptoms (20-35 points).

According to all questionnaire manuals, the missing values were dealt with as follow: if there was a missing value, the scale was considered missing.

\section{Statistical analysis}

Baseline characteristics for all groups were calculated and compared by use of descriptive analysis. Independent sample t-test were used for continuous variables, Chi-square test was used for categorical variables.

Differences in QoL between the two groups were analysed with the MannWhitney $U$ tests. We considered $p$-values $<0.05$ as statistically significant. Data were analysed in SPSS for windows (version 22.0, SPSS, Chicago, IL, USA).

\section{Results}

\section{Study population}

Of the 56 eligible W\&W-patients, 41 signed a written informed consent. This resulted in a response rate of $73.2 \%$, see Figure 4.1. These $41 \mathrm{~W} \& \mathrm{~W}$-patients were matched with 41 patients who underwent CRT and TME (TME-group). Patient characteristics are shown in Table 4.1. 


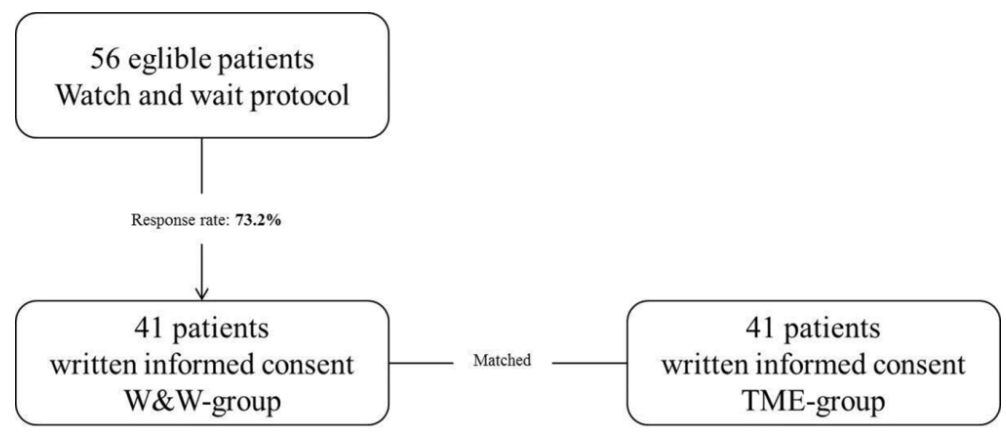

Figure 4.1 - Study population.

Table 4.1 - Patient characteristics.

\begin{tabular}{lcc}
\hline & CRT +TME & CRT + W\&W \\
\hline$n$ & 41 & 41 \\
Sex & & $29(70.7 \%)$ \\
$\quad$ Male & $28(68.3 \%)$ & $12(29.3 \%)$ \\
$\quad$ Female & $13(31.7 \%)$ & $64.1(11.8)$ \\
Mean age (y) (SD) & $63.8(20.2)$ & $3.5(3.1)$ \\
Mean tumour height (cm) (SD) & $3.6(3.4)$ & \\
T-stage & & $8(19.5 \%)$ \\
$\quad$ cT2 & $7(17.1 \%)$ & $32(78.0 \%)$ \\
cT3 & $33(80.5 \%)$ & $1(2.4 \%)$ \\
$\quad$ CT4 & $1(2.4 \%)$ & \\
Type of surgery & & \\
$\quad$ LAR & $35(85.4 \%)$ & \\
APR & $6(14.6 \%)$ & \\
\hline
\end{tabular}

CRT: chemoradiation therapy; TME: total mesorectal excision; W\&W: watch and wait; SD: standard deviation; APR: abdominal peritoneal resection (type of TME).

\section{General health}

Questions of the SF-36 were completed for all items in $93 \%$ of the responders. The W\&W-group reported better physical function (W\&W: 46.6 vs. TME: 34.13, $p=0.02$ ), physical role (W\&W: 47.4 vs. TME: $34.5, p=0.01)$ and emotional role (W\&W: 45.3 vs. TME: $36.6, p=0.004$ ) compared to the TME-group. However, the TME-group reported a significant better general health (W\&W: 34.9 vs. TME: $46.9, \quad p=0.02$ ) compared to the W\&W-group according to the SF36questionnaire. All results are shown in Figure 4.2. 


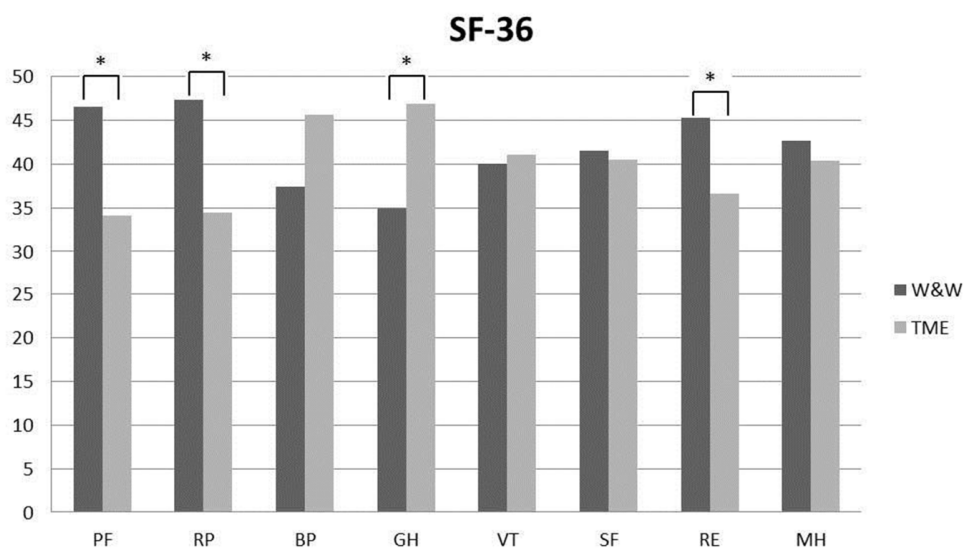

Figure 4.2 - SF-36. * significant result | PF: physical functioning | RP: role physical | BP: bodily pain | GH: general health | VT: vitality | SF: social functioning | RE: role emotional | MH: mental health.

Questions of the EORTC-QLQ-C30 were completed for all items in $95 \%$ of the responders. The W\&W-group showed better physical functioning (W\&W: 46.3 vs. TME: $35.8, p=0.04$ ), role functioning (W\&W: 46.4 vs. TME: $35.7, p=0.04$ ) and cognitive function (W\&W: 47.5 vs. TME: $35.5, p=0.02$ ) compared to the TMEgroup according to the EORTC-QLQ-C30 questionnaire. Also, the W\&W-group had significantly less financial difficulties (W\&W: 34.7 vs. TME: 48.6, $p=0.001$ ) and a better global health status (W\&W: 45.9 vs. TME: 35.9, $\mathrm{p}=0.05$ ). The W\&W-group had a lower pain score compared to the TME-group (36.8 vs. 44.2 points, $\mathrm{p}=0.08$ ).

Questions of the EORTC-QLQ-CR38 were completed for all items in $92 \%$ of the responders. On the EORTC-QLQ-CR38, the W\&W-group showed a significant better body image (W\&W: 36.0 vs. TME: $46.1, p=0.05$ ) compared to the TMEgroup. The W\&W-group had a better quality of life in the last week (W\&W 45.8 vs. TME 36.1, $p=0.05$ ) compared to the TME-group. All results are shown in Figure 4.3 and Figure 4.4. 


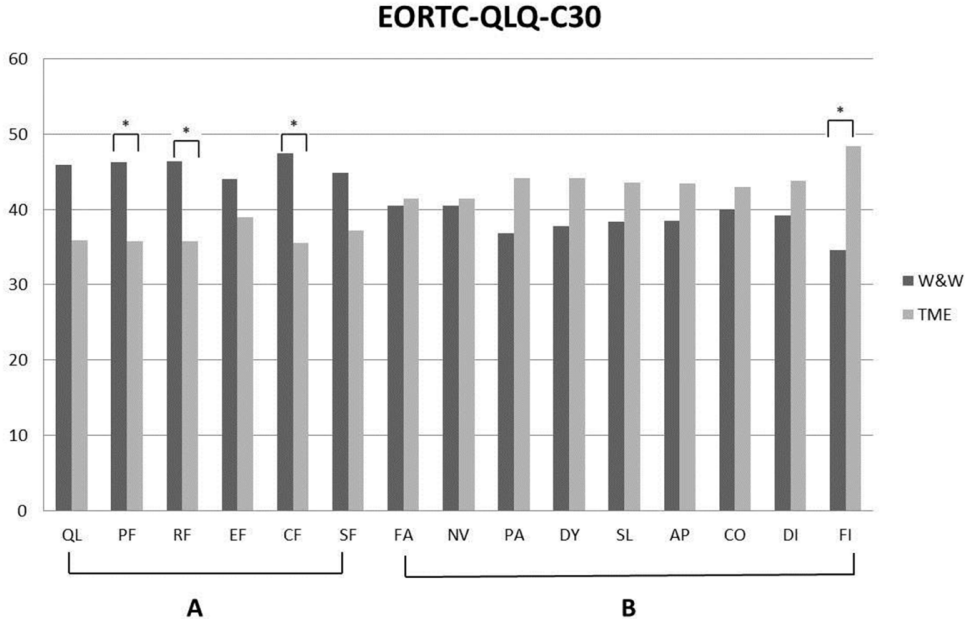

Figure 4.3 - EORTC-QLQ-C30 * significant result | A: functional scale (higher scores mean better results) | B: symptom scale (lower scores mean better results) | QL: global health status | PF: physical functioning | RF: role functioning | EF: emotional functioning | CF: cognitive functioning | SF: social functioning | FA: fatigue | NV: nausea and vomiting | PA: pain | DY: dyspnoea | SL: insomnia | AP: appetite loss | CO: constipation | DI: diarrhoea | FI: financial difficulties.

\section{EORTC-QLQ-CR38}

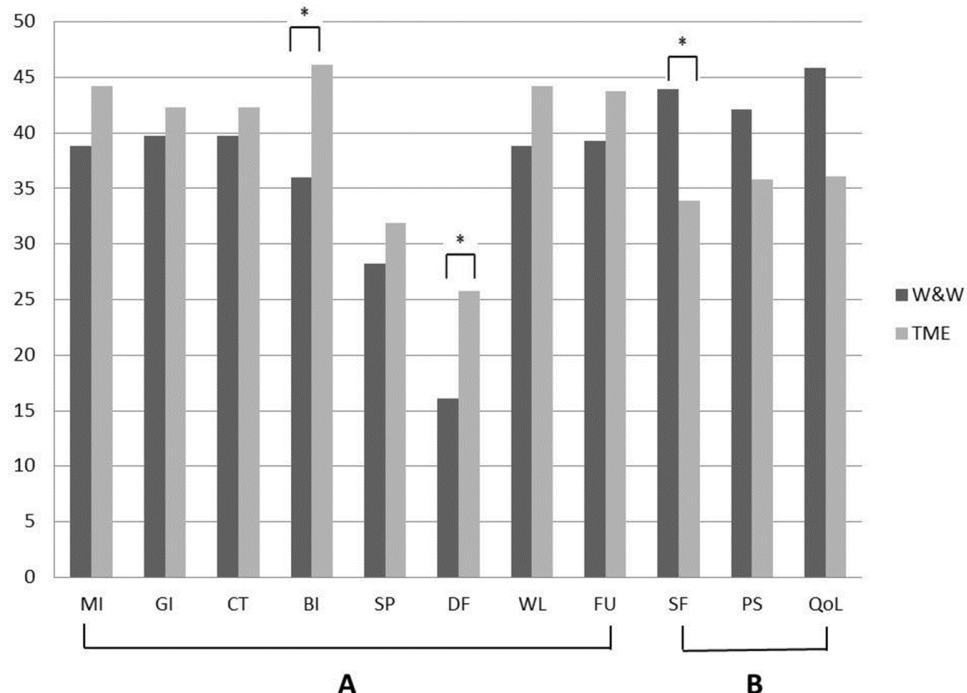

Figure 4.4 - EORTC-QLQ-CR38. * significant result | A: lower scores mean better results | B: higher scores mean better results | MI: micturition problems | GI: gastro-intestinal problems | CT: chemotherapy side effects | BI: body image | SP: sexual problems | DF: defecation problems | WL: weight loss | FU: future | SF: sexual function | PS: pleasure in sex | QoL: quality of life in last month. 


\section{Defecation problems}

The Vaizey- and LARS-score were completed for all items in resp. $81 \%$ and $70 \%$ of the responders. Patients treated with an abdominal perineal resection (APR) were not able to fill in these questionnaires. The TME-group reported significantly more faecal incontinence according to the Vaizey-score (W\&W: 28.8 vs. TME: $39.8, p=0.02$ ) and LARS-score (W\&W: 26.0 vs. TME: $35.5, p=0.04$ ). All results are shown in Figure 4.5. In both groups there are patients with major LARS-symptoms (W\&W: $35.9 \%$ vs. TME: $66.7 \%$ ).

Based on the EORTC-QLQ-CR38, the W\&W-group had significant less defecation problems (W\&W: 16.1 vs. TME: 25.8, $p=0.01$ ).

\section{Defecation problems}

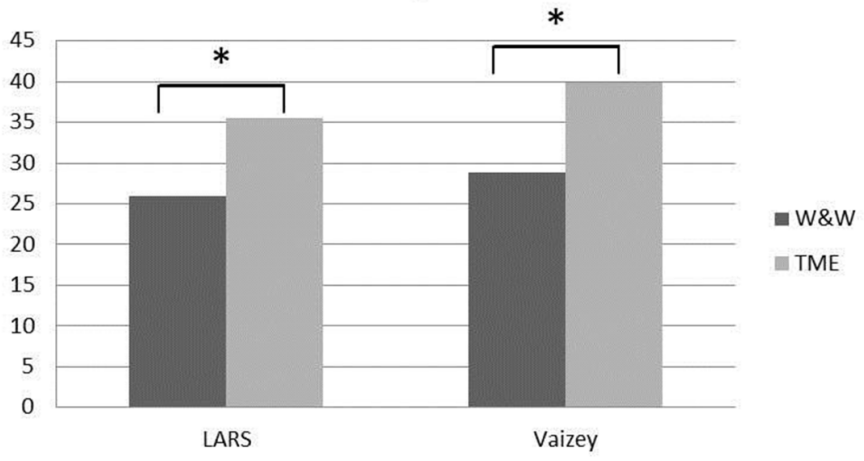

Figure 4.5 - Defecation problems. * significant result.

\section{Sexual dysfunction}

The FSFI and IIEF were completed for all items in respectively. $40 \%$ and $97 \%$ of the responders. There were no significant differences between the W\&W- and TME-group regarding sexual function in both male and female patients based on the IIEF and FSFI respectively.

The EORTC-QLQ-CR38 showed a better sexual function in W\&W-patients (W\&W 44.0 vs. TME: 33.9, $p=0.04$ ) compared to the TME-group.

\section{Urinary tract dysfunction}

The IPSS questionnaires were completed for all items in $98 \%$ of the responders. The W\&W-group reported less intermittency-problems (W\&W: 22.7 vs. TME: $34.8, p=0.002$ ) and had a better quality of life (W\&W: 22.1 vs. TME: 34.1, 
$p=0.003)$. A trend was seen in two subgroups of the IPSS-questionnaire. Patients in the TME-group had more complains of a weak stream (W\&W: 24.9 vs. TME: $32.4, p=0.07$ ) and strain (W\&W: 25.2 vs. TME: 32.0, $p=0.06$ ). Patients in the W\&W-group had mild symptoms (mean: 5.8), the TME-group had moderate symptoms (mean: 10.6). All results are shown in Figure 4.6.

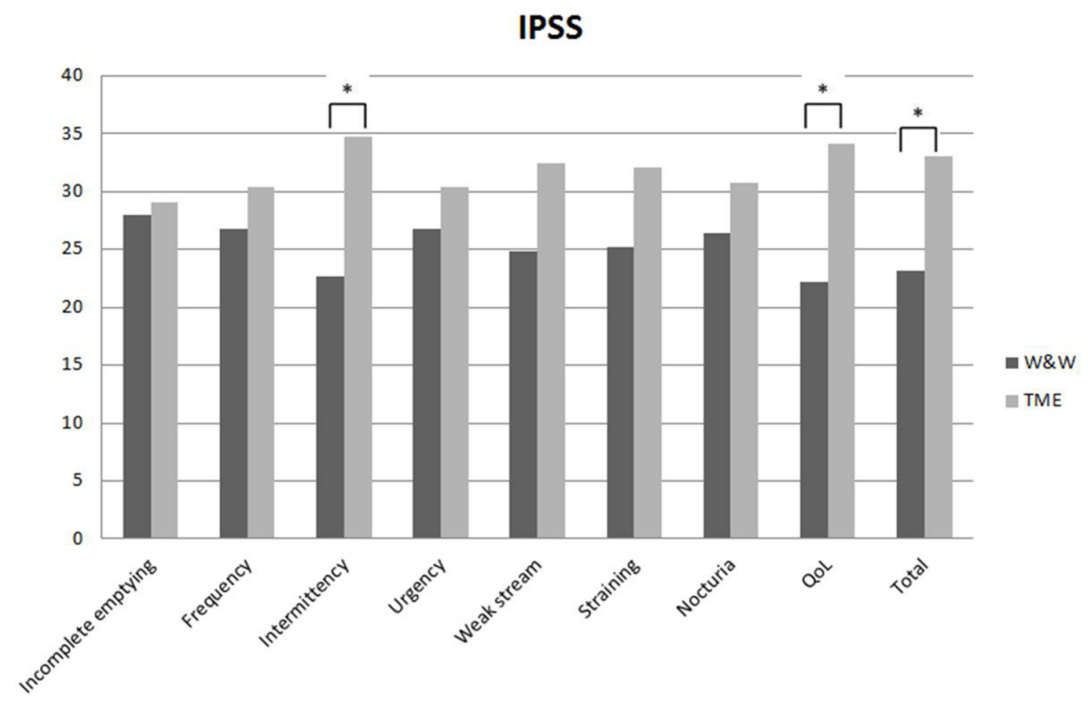

Figure 4.6 - IPSS. * significant result.

\section{Discussion}

This matched controlled study showed that watch-and-wait patients with a sustained clinical response after chemoradiation had a better quality of life than patients who underwent CRT and total mesorectal excision. W\&W-patients had better scores regarding physical function, general health, cognitive function and their financial situation. Additionally, the W\&W-group reported a better body image score, less defecation problems and less urinary tract problems compared to the TME-group.

Regarding general quality of life, W\&W-patients scored better in almost every subgroup, except for the general health according to the SF36-questionnaire. A possible explanation is that patients in the W\&W group might feel more insecure because the rectum has not been resected. As a result, these patients might still experience a regrowth, a fact of which they are reminded at the more frequent 
and intensive follow-up visits and exams compared to the less frequent follow-up of TME-patients.

Until now, limited studies are known regarding QoL in W\& W patients ${ }^{1,3,5,19}$. In the study of Habr-Gama W\&W-patients were compared with patients treated with CRT followed by local excision ${ }^{19}$. On manometric assessment W\&Wpatients had better resting pressure and maximal squeeze pressure compared to patients who underwent local excision. On all domains of the questionnaires there were fewer defecation problems in the W\&W-group compared to the local excision-group. To our knowledge there are no studies comparing QoL between patients in a W\&W-policy and 'standard treatment' with CRT and TME.

In the present study, W\&W-patients had fewer defecation problems compared to TME-patients. $66.7 \%$ of the patients in the TME-group had major LARS symptoms. This finding is in line with the literature showing a relatively high incidence of defecation problems after neoadjuvant CRT followed by TME, compared to TME only ${ }^{9,20-23}$. Although they did not undergo a resection, still a third of the patients in the W\&W-group reported major LARS-problems. This result can be explained by the fact that pelvic radiotherapy may induce long term gastro-intestinal morbidity. Studies have shown that up to half of all patients undergoing pelvic radiotherapy for various tumours will develop late radiationinduced gastro-intestinal changes which impairs their $\mathrm{QOL}^{24}$. As some symptoms overlap, either caused by TME or pelvic radiation ${ }^{25}$, high LARSscores may be partially due to radiation-induced changes.

Sexual dysfunction is a common problem after rectal cancer surgery ${ }^{8,26}$. Our study showed no significant differences between the two groups regarding sexual function in both male and female patients based on the IIEF and FSFI. In male patients a trend is seen of less erectile function problems in the W\&Wgroup. No differences were seen in female patients. Because of the low response rate on both questionnaires no meaningful conclusions regarding sexual function after W\&W can be drawn yet. The low response rate of female patients is in accordance with previous studies who reported on sexual function after rectal cancer treatment, and is thought to be due to the fact that women are less likely to volunteer information to their physician regarding sexual problems because of anxiety ${ }^{27-30}$.

Regarding urinary dysfunction, patients in the W\&W-group reported mild symptoms, while patients in the TME-group had moderate symptoms. Rectal cancer surgery is associated with long-term urinary dysfunction, like incontinence and difficulty in bladder emptying ${ }^{26,28,31}$. Known risk factors are: 
perioperative blood loss, autonomic nerve damage, low rectal cancer, lymph node involvement, and pre-operative urinary dysfunction ${ }^{31,32}$.

One of the mechanisms for functional problems after surgery is damage to the autonomic nervous system. Even optimal autonomic nerve preserving surgical techniques could lead to sexual dysfunction due to intra-operative stretching or neuropraxia rather than to nerve transection ${ }^{33-35}$. The male sexual function requires an intact sympathetic and parasympathetic nervous systems, for both erection and ejaculation ${ }^{30}$. The female sexual function is much less understood. Theoretically, both the sympathetic and parasympathetic stimulations are responsible for vascular engorgement, which results in vaginal and vulvar lubrication, but the exact mechanism is still unknown ${ }^{30}$. Regarding urinary function, damage to the superior hypogastric plexus and the hypogastric nerves may cause urge incontinence ${ }^{36}$. Adding CRT to surgery may increase the risk of genitourinary dysfunction compared to surgery alone ${ }^{28,37}$. Genitourinary toxicity is a well-known potential result of pelvic irradiation. Late radiation-induced genitourinary toxicity includes symptoms such as dysuria, urgency/frequency, incontinence, erectile dysfunction, infertility and lubrication problems ${ }^{28}$. The exact mechanism behind radiation-induced genitourinary dysfunction remains to be unknown. However, inflammation, fibrosis and vascular changes all appear to be of importance.

Regarding cosmetics, the W\&W-group showed a better body image compared to the TME-group based on the EORTC-QLQ-CR38. Age had no effect on these scores. However, these outcomes are to be expected as all the patients in the TME-group had a temporarily or permanent stoma. Literature shows a lower QoL in patients with a stoma ${ }^{38,39}$. Moreover, the patients who had been operated had to deal with abdominal scars ${ }^{40}$.

\section{Limitations}

There are some limitations to our study. The present study focuses on W\&W patients who achieved a sustained complete response for two years, and therefore misses the $15 \%$ of patients in our entire cohort of W\&W patients who require surgery for a regrowth. For a complete 'intention to treat' understanding of the present QoL results there should be a correction for the W\&W group of approximately $15 \%$. Additionally, this is a study with a limited number of patients and with QoL measurements on non-predefined and variable intervals after surgery. Both these issues of 'intention to treat' and possible selection bias are 
addressed in an ongoing prospective study in our centre with predefined QoL evaluation intervals.

\section{Conclusions}

In conclusion, patients with a sustained clinical complete response after CRT for rectal cancer who are followed with a W\&W policy have a significantly better quality of life score on several domains compared to patients who undergo a TME after CRT. However, CRT on its own is not without long term side-effects, as one third of the W\&W-patients suffered from major LARS-symptoms, compared to $66.7 \%$ of the TME-patients. Together with the oncological data, it is important to discuss functional outcome with patients as well. This information may help patients to cope better with posttreatment recovery after chemoradiation.

A prospective study with emphasis on functional outcome and quality of life at several standard moments during follow-up has been started. 


\section{References}

1. Maas M, Nelemans PJ, Valentini V, Das P, Rodel C, Kuo LJ, Calvo FA, Garcia-Aguilar J, Glynne-Jones R, Haustermans K, Mohiuddin M, Pucciarelli S, Small W, Jr., Suarez J, Theodoropoulos G, Biondo S, Beets-Tan RG, Beets GL. Long-term outcome in patients with a pathological complete response after chemoradiation for rectal cancer: a pooled analysis of individual patient data. Lancet Oncol. 2010;11:835-44.

2. Habr-Gama A, Perez RO, Nadalin W, Sabbaga J, Ribeiro U Jr, Silva e Sousa AH Jr, Campos FG, Kiss DR, Gama-Rodrigues J. Operative versus nonoperative treatment for stage 0 distal rectal cancer following chemoradiation therapy: long-term results. Ann Surg. 2004;240:711-7.

3. Maas M, Beets-Tan RG, Lambregts DM, Lammering G, Nelemans PJ, Engelen SM, van Dam RM, Jansen RL, Sosef M, Leijtens JW, Hulsewe KW, Buijsen J, Beets GL. Wait-and-see policy for clinical complete responders after chemoradiation for rectal cancer. J Clin Oncol. 2011; 29:4633-4640.

4. Glynne-Jones R, Hughes R. Critical appraisal of the 'wait and see' approach in rectal cancer for clinical complete responders after chemoradiation. Br J Surg. 2012;99:897-909.

5. Martens MH, Maas M., Heijnen, L.A., Lambregts, D.M., Leijtens, J.W., Stassen, L.P., Breukink, S.O., Hoff, C., Belgers, E.J., Melenhorst, J., Jansen, R., Buijsen, J., Hoofwijk, T.G., Beets-Tan, R.G., Beets, G.L. Long-term outcome of an organ preservation program after neoadjuvant treatment for rectal cancer. J Natl Cancer Inst 2016;108(12).

6. Harji DP, Griffiths B, Velikova G, Sagar PM, Brown J. Systematic review of health-related quality of life in patients undergoing pelvic exenteration. Eur J Surg Oncol. 2016;42:1132-45.

7. Wiltink LM, Nout RA, van der Voort van Zyp JR, Ceha HM, Fiocco M, Meershoek-Klein Kranenbarg E, Marinelli AW, van de Velde CJ, Marijnen CA. Long-term health-related quality of life in patients with rectal cancer after preoperative short-course and long-course (Chemo) Radiotherapy. Clin Colorectal Cancer. 2016;15:e93-9.

8. Sun V, Grant M, Wendel CS, McMullen CK, Bulkley JE, Herrinton LJ, Hornbrook MC, Krouse RS. Sexual function and health-related quality of life in long-term rectal cancer survivors. J Sex Med. 2016;13:1071-9.

9. Bregendahl S, Emmertsen KJ, Lous J, Laurberg S. Bowel dysfunction after low anterior resection with and without neoadjuvant therapy for rectal cancer: a population-based crosssectional study. Colorectal Dis. 2013;15:1130-9.

10. Zucali R. Radiotherapy and combined chemo-radiotherapy of rectal cancer. Tumouri. 1995;81: 74-7.

11. Ware JE, Jr., Sherbourne CD. The MOS 36-item short-form health survey (SF-36). I. Conceptual framework and item selection. Med Care. 1992;30:473-83.

12. Aaronson NK, Ahmedzai S, Bergman B, Bullinger M, Cull A, Duez NJ, Filiberti A, Flechtner H, Fleishman SB, de Haes JC, et al. The European Organization for Research and Treatment of Cancer QLQ-C30: a quality-of-life instrument for use in international clinical trials in oncology. J Natl Cancer Inst 1993;85:365-76.

13. Sprangers MA, te Velde A, Aaronson NK. The construction and testing of the EORTC colorectal cancer-specific quality of life questionnaire module (QLQ-CR38). European Organization for Research and Treatment of Cancer Study Group on Quality of Life. Eur J Cancer. 1999;35:238-47.

14. Vaizey CJ, Carapeti E, Cahill JA, Kamm MA. Prospective comparison of faecal incontinence grading systems. Gut. 1999;44:77-80.

15. Emmertsen $\mathrm{KJ}$, Laurberg S. Low anterior resection syndrome score: development and validation of a symptom-based scoring system for bowel dysfunction after low anterior resection for rectal cancer. Ann Surg. 2012;255:922-8.

16. Rosen RC, Riley A, Wagner G, Osterloh IH, Kirkpatrick J, Mishra A. The international index of erectile function (IIEF): a multidimensional scale for assessment of erectile dysfunction. Urology. 1997;49:822-30. 
17. Rosen R, Brown C, Heiman J, Leiblum S, Meston C, Shabsigh R, Ferguson D, D'Agostino R, Jr. The Female Sexual Function Index (FSFI): a multidimensional self-report instrument for the assessment of female sexual function. J Sex Marital Ther. 2000;26:191-208.

18. Barry MJ, Fowler FJ, Jr., O'Leary MP, Bruskewitz RC, Holtgrewe HL, Mebust WK, Cockett AT. The American Urological Association symptom index for benign prostatic hyperplasia. The Measurement Committee of the American Urological Association. J Urol. 1992;148:1549-57; discussion 64.

19. Habr-Gama A, Lynn PB, Jorge JM, Sao Juliao GP, Proscurshim I, Gama-Rodrigues J, Fernandez LM, Perez RO. Impact of organ-preserving strategies on anorectal function in patients with distal rectal cancer following neoadjuvant chemoradiation. Dis Colon Rectum 2016;59:264-9.

20. Ozgen Z, Ozden S, Atasoy BM, Ozyurt H, Gencosmanoglu R, Imeryuz N. Long-term effects of neoadjuvant chemoradiotherapy followed by sphincter-preserving resection on anal sphincter function in relation to quality of life among locally advanced rectal cancer patients: a crosssectional analysis. Radiation Oncol 2015;10:168.

21. Maris A, Penninckx F, Devreese AM, Staes F, Moons P, Van Cutsem E, Haustermans K, D'Hoore A. Persisting anorectal dysfunction after rectal cancer surgery. Colorectal Dis. 2013; 15:e672-9.

22. Ekkarat $\mathrm{P}$, Boonpipattanapong $\mathrm{T}$, Tantiphlachiva $\mathrm{K}$, Sangkhathat $\mathrm{S}$. Factors determining low anterior resection syndrome after rectal cancer resection: A study in Thai patients. Asian $\mathrm{J}$ Surg. 2015;39:225-31.

23. Horisberger K, Rothenhoefer S, Kripp M, Hofheinz RD, Post S, Kienle P. Impaired continence function five years after intensified chemoradiation in patients with locally advanced rectal cancer. Eur J Surg Oncol. 2014;40:227-33.

24. Olopade FA, Norman A, Blake P, Darnaley DP, Harrington KJ, Khoo V, Tait D, Hackett C, Andreyev HJ. A modified inflammatory bowel disease questionnaire and the vaizey incontinence questionnaire are simple ways to identify patients with significant gastrointestinal symptoms after pelvic radiotherapy. Br J Cancer. 2005;9:1663-70.

25. Andreyev HJ, Wotherspoon A, Denham JW, Hauer-Jensen M. Defining pelvic-radiation disease for the survivorship era. Lancet Oncol. 2010;11:310-2.

26. Lange MM, van de Velde CJ. Urinary and sexual dysfunction after rectal cancer treatment. Nat Rev Urol. 2011;8:51-7.

27. Breukink SO, van der Zaag-Loonen HJ, Bouma EM, Pierie JP, Hoff C, Wiggers T, Meijerink WJ. Prospective evaluation of quality of life and sexual functioning after laparoscopic total mesorectal excision. Dis Colon Rectum 2007;50:147-55.

28. Bregendahl S, Emmertsen KJ, Lindegaard JC, Laurberg S. Urinary and sexual dysfunction in women after resection with and without preoperative radiotherapy for rectal cancer: a population-based cross-sectional study. Colorectal Dis. 2015;17:26-37.

29. Platell CF, Thompson PJ, Makin GB. Sexual health in women following pelvic surgery for rectal cancer. Br J Surg 2004;91:465-8.

30. Eveno C, Lamblin A, Mariette C, Pocard M. Sexual and urinary dysfunction after proctectomy for rectal cancer. J Visc Surg. 2010;147:e21-30.

31. Lange MM, Maas CP, Marijnen CA, Wiggers T, Rutten HJ, Kranenbarg EK, van de Velde CJ, Cooperative Clinical Investigators of the Dutch Total Mesorectal Excision T. Urinary dysfunction after rectal cancer treatment is mainly caused by surgery. $\mathrm{Br} \mathrm{J}$ Surg. 2008;95:1020-8.

32. Benoist S, Panis Y, Denet C, Mauvais F, Mariani P, Valleur P. Optimal duration of urinary drainage after rectal resection: a randomized controlled trial. Surgery. 1999;125:135-41.

33. Zedan A, Salah T. Total mesorectal excision for the treatment of rectal cancer. Electron Physician. 2015;7:1666-72.

34. Duran E, Tanriseven M, Ersoz N, Oztas M, Ozerhan IH, Kilbas Z, Demirbas S. Urinary and sexual dysfunction rates and risk factors following rectal cancer surgery. Int CJ Colorectal Dis. 2015;30:1547-55. 
35. Beraldo FB, Yusuf SA, Palma RT, Kharmandayan S, Goncalves JE, Waisberg J. Urinary dysfunction after surgical treatment for rectal cancer. Arq Gastroenterol. 2015;52:180-5.

36. Havenga K, Maas CP, DeRuiter MC, Welvaart K, Trimbos JB. Avoiding long-term disturbance to bladder and sexual function in pelvic surgery, particularly with rectal cancer. Sem Surg Oncol. 2000;18:235-43.

37. Jensen PT, Froeding LP. Pelvic radiotherapy and sexual function in women. Transl Androl Urol. 2015;4:186-205.

38. Neuman HB, Patil S, Fuzesi S, Wong WD, Weiser MR, Guillem JG, Paty PB, Nash GM, Temple LK. Impact of a temporary stoma on the quality of life of rectal cancer patients undergoing treatment. Ann Surg Oncol. 2011;18:1397-403.

39. Mrak K, Jagoditsch M, Eberl T, Klingler A, Tschmelitsch J. Long-term quality of life in pouch patients compared with stoma patients following rectal cancer surgery. Colorectal Dis. 2011; 13:e403-10.

40. Benedict C, Rodriguez VM, Carter J, Temple L, Nelson C, DuHamel K. Investigation of body image as a mediator of the effects of bowel and GI symptoms on psychological distress in female survivors of rectal and anal cancer. Support Care Cancer. 2016;24:1795-802. 



\title{
Chapter
}

\begin{abstract}
Impact of radiotherapy on anorectal function in a patients with rectal cancer following a watch-andwait programme
\end{abstract}

ME van der Sande, BJP Hupkens, M Maas, SMJ van Kuijk, M Berbee, J Melenhorst, GL Beets, SO Breukink. 


\section{Abstract}

Background and Purpose: To assess the long-term anorectal function in rectal cancer patients following a watch-and-wait policy after chemoradiotherapy and to investigate the dose-volume effects of radiotherapy on the anorectal function.

Methods and materials: Thirty-three patients with primary rectal cancer who were treated with chemoradiotherapy and a watch-and-wait policy with minimum follow-up of 2 years were included. We assessed the anorectal function using anorectal manometry and patient reported outcomes (Vaizey- and LARS score). Dose-volume histograms were calculated for the rectum and anal sphincter complex, and associations between the dose-volume parameters and anorectal function were assessed.

Results: $D_{\text {mean }}$ to the rectum and anal sphincter complex were $50.5 \mathrm{~Gy}$ and 44.7Gy, respectively. After a median follow-up of 38 (range 23-116) months, $33.3 \%$ of the patients reported major LARS. Mean LARS score was $23.4 \pm 11.3$ and mean Vaizey score was $4.3 \pm 4.1$. The most frequent complaints were clustering of defaecation and faecal urgency. Trends towards a Vaizey and LARS score after higher anal sphincter complex dose were observed, although these associations were not statistically significant.

Conclusions: This is the first study to investigate the late dose-effects of radiotherapy specifically on the anorectal function in rectal cancer patients. Onethird of the patients had major LARS and the most frequent reported complaints were clustering and faecal urgency. Additionally, we observed trends towards worse long-term anorectal function after higher anal sphincter complex radiotherapy dose. However, this should be evaluated on a larger scale. Future efforts to the minimise the dose to the sphincters could possibly reduce the impact of radiotherapy on the anorectal function. 


\section{Introduction}

The standard of care for patients with locally advanced or distal rectal cancer is neoadjuvant chemoradiation therapy (CRT) followed by total mesorectal excision (TME). CRT leads to downsizing and downstaging of the tumour in most patients, may increase the opportunity for sphincter-saving surgery and decreases the risk for local recurrence ${ }^{1}$. However, treatment with neoadjuvant CRT and TME can adversely affect bladder, sexual, and anorectal function in the long term ${ }^{2}$. In patients who achieve a complete response to neoadjuvant $\mathrm{CRT}$, a watch-and-wait policy can be considered to avoid the related morbidity and mortality of $\mathrm{TME}^{3-5}$.

The main goal of a watch-and-wait policy is an anticipated improved functional outcome and quality of life, while maintaining a good oncological outcome. While there is growing evidence supporting the oncological safety, the quality of life and functional outcomes after a watch-and-wait policy remain less explored. In a previous report ${ }^{6}$ we showed that quality of life after a watch-and-wait policy was better than after CRT and TME. Nonetheless, the anorectal function was impaired in the watch-and-wait group, with one third of the patients reporting major bowel dysfunction. This comes as no surprise as irradiation of the rectum is known to cause injury to the rectal wall and related autonomic nerves resulting in impaired long-term functional outcome ${ }^{7}$. Because of the proximity of the anal canal to the tumour, the anal sphincter muscles are often also in the high-dose field of radiation in patients with low rectal cancer. However, very limited data are available on the relationship between radiotherapy dose and anorectal dysfunction in rectal cancer patients. Particularly in rectal cancer patients in whom no resection is performed after CRT, e.g. in patients following a watchand-wait policy, the effects of chemoradiotherapy alone on functional outcomes can be assessed. In this study we assessed the long-term anorectal function in rectal cancer patients following a watch-and-wait policy, using the Vaizey score, LARS (Low Anterior Resection Syndrome) score and anorectal manometry. Additionally, we explored the associations between the radiotherapy dosimetric parameters of the rectum and anal sphincter complex and the anorectal function outcomes. 


\section{Materials and methods}

\section{Study population}

Patients with primary rectal cancer and a complete response after CRT who were treated according to a watch-and-wait policy in our institute between January 2009 and April 2015 and who had a minimum follow-up of two years were included in this cross-sectional study. Follow-up of $\geq$ two years was chosen so long-term effects, which at that time are expected to have reached a plateau phase, could be measured. All patients were part of a prospective cohort study on the watch-and-wait policy (clinicaltrials.gov NCT00939666) and a part was also included in a previous report on quality of life $^{6}$. The inclusion criteria for a watch-and-wait policy in rectal cancer have been described previously ${ }^{4,8}$. Exclusion criteria for the present study were salvage therapy for recurrent disease or having a colostomy. Ethical committee approval was obtained for sending out questionnaires and patients gave a separate informed consent for a manometric evaluation of the anorectal function during routine follow-up.

\section{Chemoradiotherapy}

All patients were treated with chemoradiotherapy. 3D-conformal or intensitymodulated radiotherapy consisted of $50.4 \mathrm{~Gy}$, with daily fractions of $1.8 \mathrm{~Gy}$ on weekdays. Dose specification occurred according to ICRU 50/62. The clinical target volume (CTV) included the gross tumour volume, the mesorectum, presacral and internal iliac node regions, and in case of distal node positive tumours the obturator fossa. A symmetric PTV margin of $1 \mathrm{~cm}$ was applied. Examples are shown in Figure 5.1. No dose limitations were used for the anal sphincter complex during initial treatment planning. Radiotherapy was combined with $825 \mathrm{mg} / \mathrm{m} 2 /$ day capecitabine bid, seven days a week.

\section{Organ delineation and dose calculations}

The rectum and anal sphincter complex were manually delineated on the axial CT images ( $3 \mathrm{~mm}$ slice thickness) of the original radiotherapy planning CT scans, using Focal ${ }^{\mathrm{TM}}$ treatment planning system (XiO, Elekta $A B$, Stockholm, Sweden). Organ contours were defined according to the Pelvic Normal Tissue contouring guidelines by the Radiation Therapy Oncology Group (RTOG) ${ }^{9}$. The rectum was defined as a solid organ including the rectal contents from the lowest slice with a rectal lumen to the rectosigmoid flexure where the rectum 
moves ventrally and loses its round shape. The anal sphincter complex (internal and external sphincter muscle) circumference was delineated as a solid organ from anal verge to the anorectal border. All delineations were performed by one investigator (M.S.) and confirmed by a radiation oncologist specialised in rectal cancer treatment (M.B.). Examples of these delineations are shown in Figure 5.1.

Dose volume histograms (DVH) were calculated with the original treatment plans and were used to measure the radiation dosimetric coverage of the rectum and anal sphincter complex for each patient. The maximum and mean doses were calculated $\left(D_{\max }\right.$ and $\left.D_{\text {mean }}\right)$, as well as the relative volumes receiving a dose of 30-50 Gy or more $\left(\mathrm{V}_{30 \mathrm{~Gy}}-\mathrm{V}_{50 \mathrm{~Gy}}\right)$.

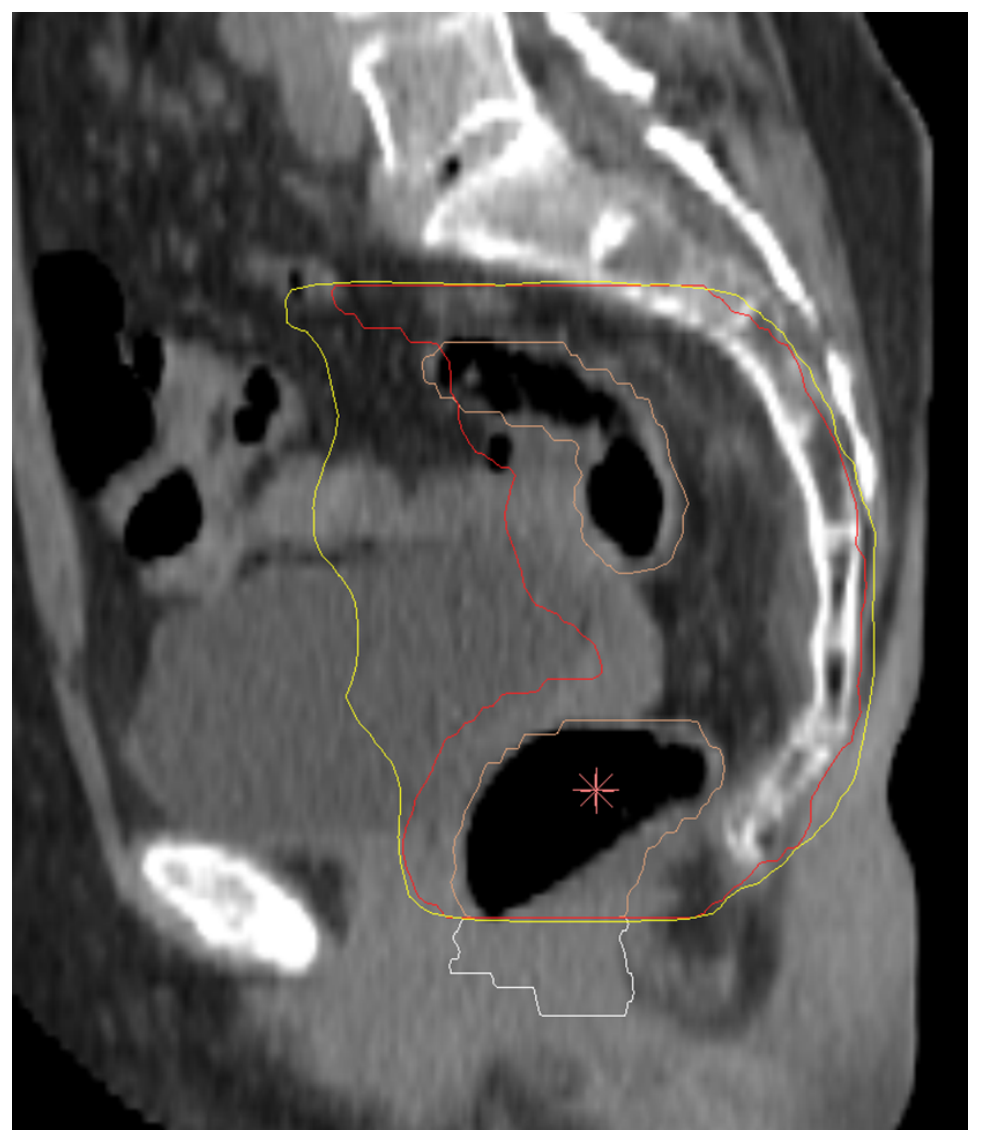

Figure 5.1 - Delineation of anal sphincter complex (white) and rectum (orange) on CT scan. 


\section{Manometry}

Anorectal function was assessed using manometry at one of the routine followup outpatient visits. Anorectal manometry was performed with the patient in the left lateral position with knees and hips bent to $90^{\circ}$. Patients did not receive bowel preparation ${ }^{10}$. A four-channel catheter (Mui Scientific, Mississauga, Canada) with a water perfusion system connected to an electronic polygraph (Synectics Medical, Stockholm, Sweden) was used for the investigation. A $7 \mathrm{~cm}$ inflatable balloon was incorporated at the top of the catheter. The catheter was calibrated outside the patient at study level before introduction. A stationary technique was used and mean anal resting pressure (MRP) and squeeze anal pressures (MRP) were measured ${ }^{11}$. These parameters were calculated as the average of the four radial measuring points. For rectal capacity, first rectal sensation (FS), volume at first urge to defaecate (FUTD) and maximum tolerable volume (MTV) were measured during stepwise balloon inflation. Manometry examinations were performed by two investigators (M.S. and B.H.).

\section{Questionnaires}

Anorectal function was also evaluated using two validated scores send out as questionnaires: the Vaizey score and LARS score.

The Vaizey score was used to assess faecal incontinence ${ }^{12}$. Patients were asked to evaluate their defaecation pattern in the last four weeks, including questions regarding consistency of stool loss, frequency and its effect on lifestyle. Results are reported on a continuous scale from 0-24. Faecal incontinence is defined as a score $>12$ points.

The Dutch version of the LARS score was used to evaluate bowel dysfunction ${ }^{13}$. It consists of five questions regarding incontinence for flatus and liquid stool, frequency, clustering and urgency. The range of this score is $0-42$ and outcome categories are no LARS (score 0-20), minor LARS (score 21-29) and major LARS (score 30-42).

\section{Statistical analysis}

SPSS v22.0 (SPSS Inc, Chicago, IL) was used for statistical analyses. Stochastic regression imputation was used to impute incomplete variables to prevent a loss of statistical precision and to decrease the likelihood of bias. Multiple regression was used to quantify preliminary associations between the dose-volume parameters and the manometry and questionnaire scores and was 
adjusted for sex, tumour height and age. A two-tailed $p$ value $\leq 0.05$ was considered significant in all analyses.

\section{Results}

\section{Patient characteristics and dosimetric data}

Thirty-three patients with a median age of 68 (range 38-85) years, of whom 21 male patients (64\%), were included in this study. Patients' demographics are shown in Table 5.1. Median time from end of CRT to anorectal function assessment was 38 (range 23-117) months. Twenty-three patients (70\%) had low rectal cancer ( $\leq 5 \mathrm{~cm}$ from anorectal junction), 10 patients had mid-high rectal cancer. Mean $( \pm S D)$ distance from distal border of tumour to anorectal junction was $3.9( \pm 3.0) \mathrm{cm}$.

The radiation dose-volume data are shown in Table 5.2. The mean $( \pm S D) D^{\text {mean }}$ and mean $V_{50 G y}$ to the rectum were $50.5 \pm 1.3 \mathrm{~Gy}$ and $90.1 \pm 19.4 \%$, respectively. The mean $( \pm S D) D_{\text {mean }}$ to the anal sphincter complex was $44.7 \pm 9.7 \mathrm{~Gy}$, whereas the $\mathrm{V}_{50 \mathrm{~Gy}}$ was $47.1 \% \pm 37.9 \%$, meaning that on average $47 \%$ of the anal sphincter volume had a planned dose of $\geq 50 \mathrm{~Gy}$.

Table 5.1 - Patients' demographics $(n=33)$.

\begin{tabular}{lc}
\hline Characteristics & \\
\hline Sex & \\
Male & $21(63.6 \%)$ \\
Female & $12(36.4 \%)$ \\
Median age, in years (range) & $67.5(38-85)$ \\
Median follow-up, in months (range) & $38.4(23-117)$ \\
cT stage & \\
CT2 & $8(24.2 \%)$ \\
CT3 & $24(72.8 \%)$ \\
CT4 & $1(3.0 \%)$ \\
CN stage & \\
cN0 & $8(24.2 \%)$ \\
CN1 & $12(36.4 \%)$ \\
cN2 & $13(39.4 \%)$ \\
Tumourheight & \\
$\leq 5 \mathrm{~cm}$ & $23(69.7 \%)$ \\
$>5 \mathrm{~cm}$ & $10(30.3 \%)$ \\
\hline
\end{tabular}


Table 5.2 - Radiation dose-volume data.

\begin{tabular}{lcc}
\hline & Anal sphincter complex & Rectum \\
\hline Volume $\left(\mathrm{cm}^{3}\right)$ & $14.9 \pm 4.7$ & $98.0 \pm 27.7$ \\
$\mathrm{D}_{\max }(\mathrm{Gy})$ & $47 \pm 11$ & $52.0 \pm 1.1$ \\
$\mathrm{D}_{\text {mean }}(\mathrm{Gy})$ & $44.7 \pm 9.7$ & $50.5 \pm 1.3$ \\
$\mathrm{~V}_{30 G y}(\%)$ & $85.4 \pm 25.3$ & $99.2 \pm 2.7$ \\
$\mathrm{~V}_{35 G y}(\%)$ & $85.0 \pm 25.6$ & $98.8 \pm 2.8$ \\
$\mathrm{~V}_{40 G y}(\%)$ & $81.3 \pm 27.2$ & $99.1 \pm 2.7$ \\
$\mathrm{~V}_{45 \mathrm{~Gy}}(\%)$ & $80.3 \pm 28.4$ & $99.0 \pm 3.1$ \\
$\mathrm{~V}_{50 \mathrm{~Gy}}(\%)$ & $47.1 \pm 37.9$ & $90.1 \pm 19.4$ \\
\hline
\end{tabular}

$D_{\max }=$ Maximal dose; $D_{\text {mean }}=$ Mean dose; $V_{30 G y}-V_{50 G y}=$ percentage of volume receiving $>30$ to $>50$ Gy.

\section{Manometry}

Overall, the mean MRP was $30 \pm 12 \mathrm{mmHg}$ and mean MSP was $104 \pm 41 \mathrm{mmHg}$. Mean volume at first sensation (FS) was $47 \pm 26 \mathrm{~mL}, 88 \pm 28 \mathrm{~mL}$ at first urge to defaecate (FUTD), and $136 \pm 36 \mathrm{~mL}$ at maximum threshold (MTV), see Table 5.3.

Table 5.3 - Vaizey score items $(n=33)$

\begin{tabular}{|c|c|c|c|c|c|}
\hline & Never & Rarely & Sometimes & Weekly & Daily \\
\hline Incontinence for solid stool, n (\%) & $28(85)$ & $-(0)$ & $4(12)$ & $-(0)$ & $1(3)$ \\
\hline Incontinence for liquid stool, n (\%) & $21(64)$ & $7(21)$ & $4(12)$ & $1(3)$ & $-(0)$ \\
\hline Incontinence for gas, $\mathrm{n}(\%)$ & $13(40)$ & $11(33)$ & $5(15)$ & $1(3)$ & $3(9)$ \\
\hline \multirow[t]{2}{*}{ Alterations in lifestyle, $n(\%)$} & $27(81)$ & $3(10)$ & $2(6)$ & $-(0)$ & $1(3)$ \\
\hline & No & Yes & & & \\
\hline Need to wear a pad/plug, $n(\%)$ & $32(97)$ & $1(3)$ & & & \\
\hline Use of constipating agents, $\mathrm{n}(\%)$ & $32(97)$ & $1(3)$ & & & \\
\hline $\begin{array}{l}\text { Unable to defer defecation for } 15 \\
\text { minutes, } n(\%)\end{array}$ & $17(54)$ & $15(46)$ & & & \\
\hline
\end{tabular}

\section{Questionnaire outcomes}

The mean Vaizey score was $4.3 \pm 4.1$. Two (6\%) patients had faecal incontinence, based on the Vaizey score (>12 points). One (3\%) patient reported the use of pads/plugs, and one (3.0\%) other patient reported the use of constipating agents.

The mean LARS score was $23.4 \pm 11.3$. Twelve $(36 \%)$ patients had no LARS (score 0-20), 10 (30\%) patients had minor LARS (score 21-29) and 11 (33\%) patients had major LARS (score 30-39). The most reported complaint in the LARS questionnaire was clustering, with nine $(27 \%)$ patients reporting clustering at least once a week and 18 patients (55\%) less than once a week. Urge 
incontinence for faeces at least once a week was reported by $15(46 \%)$ patients and less than once a week by $9(27 \%)$ patients. Occasions of uncontrollable flatus at least once a week were reported in $10(30 \%)$ patients, less than one a week in $8(24 \%)$ patients. Complaints of frequency or accidental leakage of stools were less often reported, see Figure 5.2.

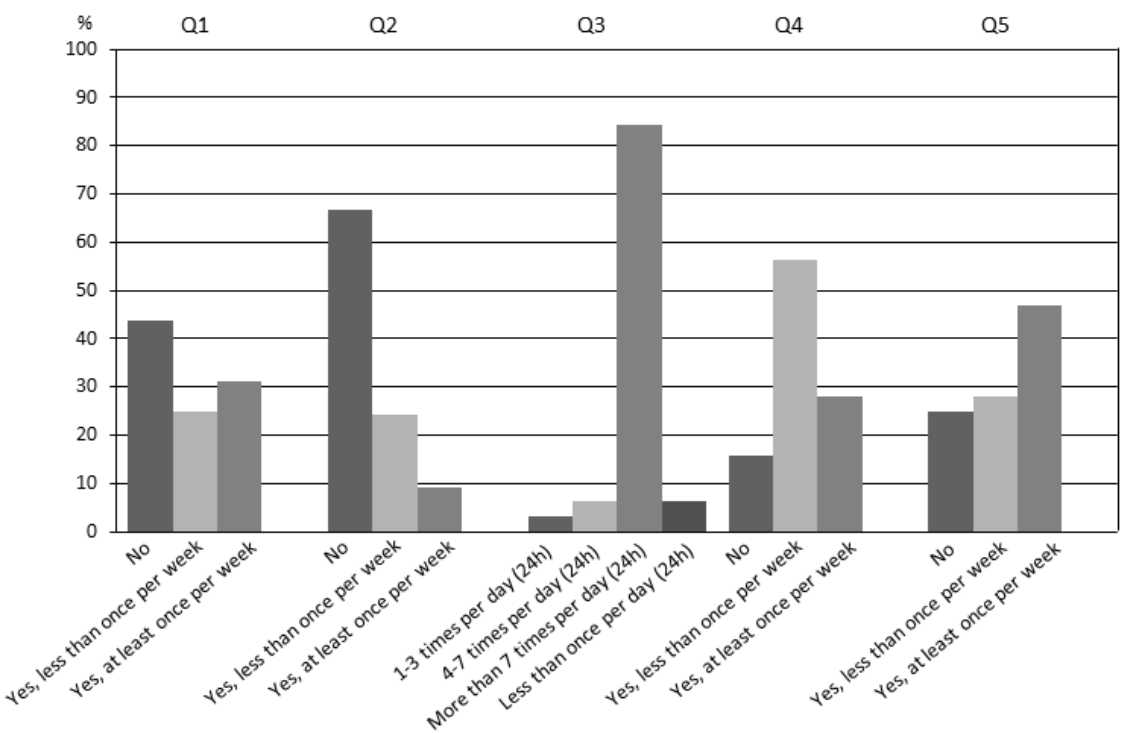

Figure 5.2 - LARS score; answers per question. Q1: Do you ever have occasions when you cannot control your flatus? Q2: Do you ever have any accidental leakage of liquid stool? Q3: How often do you open your bowel? Q4: Do you ever have to open your bowels again within one hour of the last bowel opening? Q5: Do you ever have such a strong urge to open your bowels that you have to rush to the toilet?

\section{Correlation of dosimetric data to anorectal function}

There weren't any statistically significant associations between dose parameters and the LARS or Vaizey score. However, we did observe a trend towards higher Vaizey scores after higher $D_{\max }(\beta=0.341, p=0.211), V_{30 G y}(\beta=0.374, p=0.095)$, $V_{35 G y}(\beta=0.343, p=0.126)$ and $V_{40 G y}(\beta=0.381, p=0.109)$ of the anal sphincter complex. Additionally, a trend towards higher LARS scores after higher Dmean of the anal sphincter complex $(\beta=0.362, p=0.122)$ was observed. Regarding the rectal dose, regression analysis showed trends towards higher Vaizey scores after higher $\mathrm{V}_{35 \mathrm{~Gy}}(\beta=0.353, p=0.066)$ and $\mathrm{V} 40 \mathrm{~Gy}(\beta=0.309, p=0.117)$, although not statistically significant. The results of all regression analyses are presented in Table 5.4. 


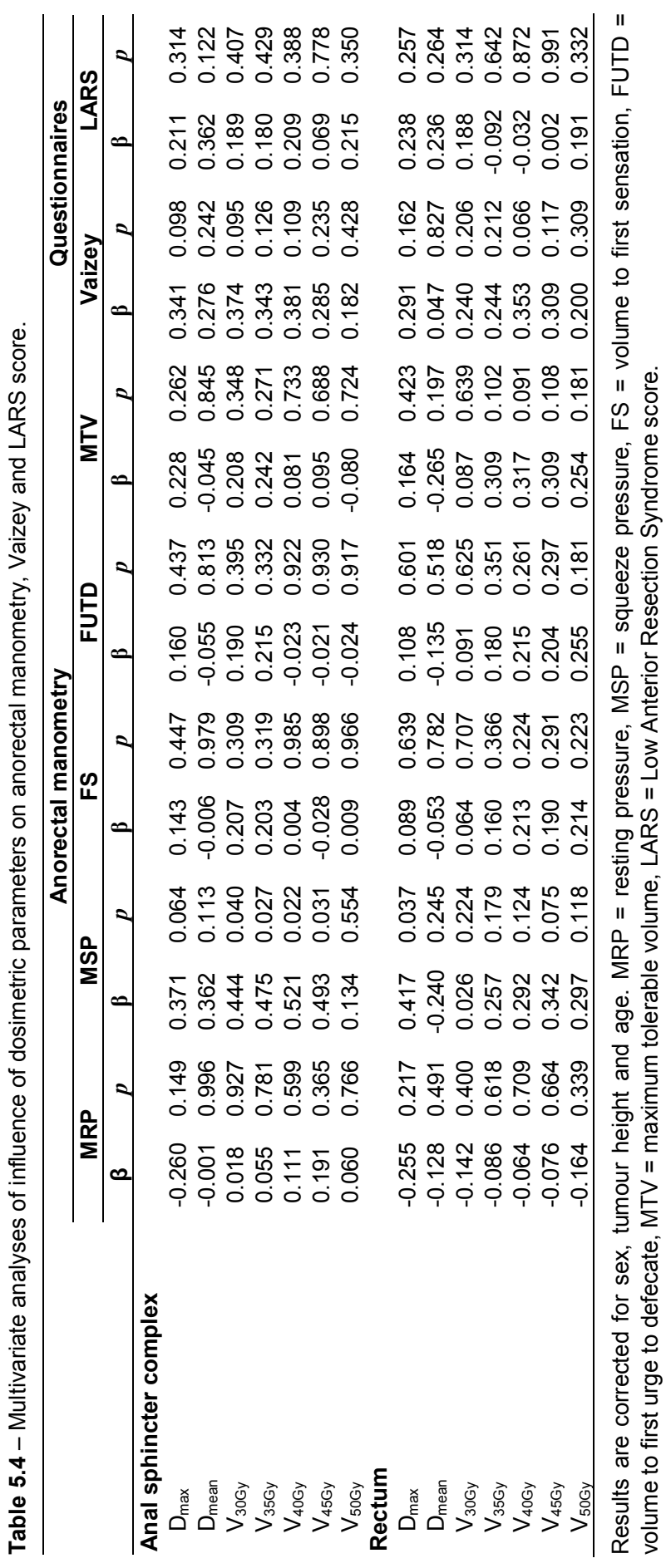


For all dosimetric parameters of the anal sphincter complex, except $\mathrm{V}_{506 \mathrm{y}}$, higher doses were associated with higher squeeze pressure (MSP). No associations were found between the dosimetric parameters and resting pressure (MRP) or anorectal sensory function (FS, FUTD, MTV).

\section{Discussion}

This study assessed the long-term anorectal function and the association between the anorectal function and the radiotherapy dose parameters in rectal cancer patients following a watch-and-wait policy. One-third of the patients has major LARS after a minimal follow-up of two years. The most frequent complaints were clustering of defaecation and faecal urgency. Additionally, we observed trends towards worse long-term anorectal function after higher anal sphincter complex radiotherapy dose.

To date, there have been few studies that assessed the anorectal function in rectal cancer patients treated according to a watch-and-wait policy after CRT. In our previous study by Hupkens et al. ${ }^{6}$, the long-term quality of life and functional outcomes were compared between 41 watch-and-wait patients and 41 patients treated with CRT and TME. In that study, $36 \%$ of the watch-and-wait policy patients experienced major LARS, compared to $67 \%$ of the patients who underwent CRT followed by TME. This showed that although bowel function was generally better after a watch-and-wait policy, there were patients with significant functional impairment after CRT alone.

Habr-Gama et al. on the other hand concluded that the consequences of radiotherapy on the anorectal function may be minimal ${ }^{14}$. The anorectal function of patients undergoing watch-and-wait after CRT to was compared to the function of patients treated with full-thickness local excision after CRT. Fifty-four watch-and-wait patients were assessed with anorectal manometry and validated questionnaires and most outcomes were considered to be within the normal range. However, the Faecal Incontinence Quality of Life (FIQL) Scale and the Vaizey score were used, which both emphasise on faecal incontinence. Although faecal incontinence is a common issue, bowel dysfunction after rectal cancer treatment is more complex and may also involve frequent bowel movements and complaints of clustering and faecal urgency ${ }^{15}$. The scores used in the study of Habr-Gama et al. may not have been sensitive enough to detect 
these complaints adequately and may therefore have underestimated the adverse effects of radiotherapy.

Despite an absence of baseline anorectal function information in the present study, it is likely that neoadjuvant chemotherapy contributed to the observed bowel dysfunction in this study population as it is well known that neoadjuvant radiotherapy is a risk factor for anorectal dysfunction after $\mathrm{TME}^{16-18}$. In other pelvic malignancies, however, it is better established what the effects are of stand-alone radiotherapy on bowel functioning. In anal cancer, approximately $43-54 \%$ of the patients report faecal incontinence after radiation treatment ${ }^{19-21}$. In prostate cancer patients, faecal incontinence is reported in up to $57 \%$ and bowel urgency in $34 \%{ }^{22,23}$.

Faecal continence is a complex system and multiple components fundamental to continence are suggested to be involved in the pathogenesis of radiotherapy induced anorectal dysfunction. Some studies suggest that radiotherapy negatively affects innervation of the anorectum, including the pudendal nerve, the myenteric plexus, and the lumbosacral plexus ${ }^{24-26}$. Furthermore, radiotherapy can induce structural morphologic alterations, such as collagen depositions in the internal and external anal sphincter ${ }^{25,27}$, and fibrosis of the rectal wall ${ }^{28}$. This can compromise sphincter tone, sphincter contractibility, and anorectal sensitivity.

Although we did not find an association between higher planned radiotherapy dose to the anal sphincter complex and lower anal pressures, we did observe low mean anal resting pressures and anal squeeze pressures after CRT in the present study when compared to normal values from literature ${ }^{29}$. This is in accordance with other studies showing reduced anal sphincter tone and squeeze pressures after pelvic irradiation ${ }^{30-32}$. Decreased anal pressures have been related to complaints of urgency and incontinence specifically ${ }^{33,34}$. In prostate cancer, decreased sensory thresholds for defaecation urge have also been reported after irradiation, while in the present study these were in the normal range ${ }^{30,35}$.

While there were no significant associations between the dose parameters and questionnaire outcomes, the results suggest that higher Vaizey and LARS score were associated with a higher $D_{\text {mean }}$ and $D_{\max }$ of the anal sphincter complex, and a higher LARS score with higher $D_{\text {mean }}$ of the rectum. One other study in rectal 
cancer survivors, treated with CRT and TME, investigated the relationship between radiation dose and anorectal function ${ }^{36}$. They showed that the volume of the anal sphincters receiving $>20 \mathrm{~Gy}$ was predictive of poor sphincter control as measured on the Wexner scale. In prostate cancer survivors, it has repeatedly been shown that dosimetric parameters of the anal sphincter and rectum are associated with late gastro-intestinal toxicity and patient reported outcomes $^{37-39}$. Moreover, the dose to different anatomic substrates have been correlated to different symptoms ${ }^{33,40}$. These studies ${ }^{33,37-40}$ suggest that the anorectal region should be avoided whenever possible during radiation treatment planning for prostate cancer. Delineation guidelines and dose constraints for the anal sphincter complex could also facilitate sphincter sparing radiotherapy in rectal cancer, and thereby possibly reduce the impact on functional outcomes.

The following limitations should be taken into consideration when interpreting the results of the present study. Our analyses are based on a relatively small group of patients. As a result, we observed several associations that may be of clinical relevance, but lacked the statistical power to draw firm conclusions. Furthermore, we had no baseline information about the anorectal function, and it remains unclear whether the reported symptoms were present before the diagnosis of rectal cancer and treatment with CRT. However, when baseline measurements are taken in rectal cancer patients, these measurements are likely to be influenced by the rectal tumour and may not represent normal anorectal functioning. In the absence of questionnaires that have been validated specifically for patients undergoing a watch-and-wait policy, we used the LARS score to assess bowel dysfunction.

Despite these limitations, this is the first study to explore the specific dose effects of chemoradiation alone in rectal cancer patients on the long-term anorectal function. Our results may provide support in the rationale for sphincter sparing radiotherapy, however the relation between the dosimetric parameters and the long-term anorectal function in chemoradiation for rectal cancer should be evaluated on a larger scale. Especially with the current interest in radiotherapy to achieve organ preservation in rectal cancer, insights into functional deterioration after radiotherapy are needed, as well as insights into the specific mechanisms that are affected. With these insights, further improvements in radiotherapy delivery could be aided, as to maximise the effect on the tumour while minimising the detrimental impact on the anorectal function. 


\section{Conclusion}

In conclusion, it is often difficult to differentiate between the radiation and surgery induced damage in rectal cancer patients treated with chemoradiotherapy. This study in rectal cancer patients followed in a watch-andwait programme is the first study to investigate the dose effects of radiotherapy specifically on the anorectal function in rectal cancer patients. One third of the patients reported major LARS after a minimal follow-up of two years. The most frequent complaints were clustering of defaecation and faecal urgency. Additionally, we observed trends towards worse long-term anorectal function after higher anal sphincter complex radiotherapy dose. However, this should be evaluated on a larger scale. Future efforts to the minimise the dose to the sphincters could possibly reduce the impact of radiotherapy on the anorectal function. 


\section{References}

1. Sauer R, Becker H, Hohenberger W, Rodel C, Wittekind C, Fietkau R, et al. Preoperative versus postoperative chemoradiotherapy for rectal cancer. N Engl J Med. 2004;351(17): $1731-40$

2. Jayne DG, Brown JM, Thorpe H, Walker J, Quirke P, Guillou PJ. Bladder and sexual function following resection for rectal cancer in a randomized clinical trial of laparoscopic versus open technique. Br J Surg. 2005;92(9):1124-32.

3. Habr-Gama A, Perez RO, Nadalin W, Sabbaga J, Ribeiro U, Jr., Silva e Sousa AH, Jr., et al. Operative versus nonoperative treatment for stage 0 distal rectal cancer following chemoradiation therapy: long-term results. Ann Surg. 2004;240(4):711-7; discussion 7-8.

4. Maas M, Beets-Tan RG, Lambregts DM, Lammering G, Nelemans PJ, Engelen SM, et al. Waitand-see policy for clinical complete responders after chemoradiation for rectal cancer. J Clin Oncol. 2011;29(35):4633-40.

5. Dossa F, Chesney TR, Acuna SA, Baxter NN. A watch-and-wait approach for locally advanced rectal cancer after a clinical complete response following neoadjuvant chemoradiation: a systematic review and meta-analysis. Lancet Gastroenterol Hepatol. 2017;2(7):501-13.

6. Hupkens BJP, Martens MH, Stoot JH, Berbee M, Melenhorst J, Beets-Tan RG, et al. Quality of Life in Rectal Cancer Patients After Chemoradiation: Watch-and-Wait Policy Versus Standard Resection - A Matched-Controlled Study. Dis Colon Rectum. 2017;60(10):1032-40.

7. Petersen S, Jongen J, Petersen C, Sailer M. Radiation-induced sequelae affecting the continence organ: incidence, pathogenesis, and treatment. Dis Colon Rectum. 2007;50(9):1466-74.

8. Martens MH, Maas M., Heijnen, L.A., Lambregts, D.M., Leijtens, J.W., Stassen, L.P., Breukink, S.O., Hoff, C., Belgers, E.J., Melenhorst, J., Jansen, R., Buijsen, J., Hoofwijk, T.G., Beets-Tan, R.G., Beets, G.L. Long-term outcome of an organ preservation program after neoadjuvant treatment for rectal cancer. J Natl Cancer Inst. 2016;108(12).

9. Gay HA, Barthold HJ, O'Meara E, Bosch WR, El Naqa I, Al-Lozi R, et al. Pelvic normal tissue contouring guidelines for radiation therapy: a Radiation Therapy Oncology Group consensus panel atlas. Int J Radiat Oncol Biol Phys. 2012;83(3):e353-62.

10. Eckardt VF, Elmer T. Reliability of anal pressure measurements. Dis Colon Rectum. 1991; 34(1):72-7.

11. Rao C, Sun Myint A, Athanasiou T, Faiz O, Martin AP, Collins B, et al. Avoiding Radical Surgery in Elderly Patients With Rectal Cancer Is Cost-Effective. Dis Colon Rectum. 2017; 60(1):30-42.

12. Vaizey CJ, Carapeti E, Cahill JA, Kamm MA. Prospective comparison of faecal incontinence grading systems. Gut. 1999;44(1):77-80.

13. Emmertsen KJ, Laurberg S. Low anterior resection syndrome score: development and validation of a symptom-based scoring system for bowel dysfunction after low anterior resection for rectal cancer. Ann Surg. 2012;255(5):922-8.

14. Habr-Gama A, Lynn PB, Jorge JM, Sao Juliao GP, Proscurshim I, Gama-Rodrigues J, et al. Impact of Organ-preserving strategies on anorectal function in patients with distal rectal cancer following neoadjuvant chemoradiation. Dis Colon Rectum. 2016;59(4):264-9.

15. Emmertsen KJ, Laurberg S, Rectal Cancer Function Study G. Impact of bowel dysfunction on quality of life after sphincter-preserving resection for rectal cancer. Br J Surg. 2013;100(10): 1377-87.

16. Bregendahl S, Emmertsen KJ, Lous J, Laurberg S. Bowel dysfunction after low anterior resection with and without neoadjuvant therapy for rectal cancer: a population-based crosssectional study. Colorectal Dis. 2013;15(9):1130-9. 
17. Peeters KC, van de Velde CJ, Leer JW, Martijn H, Junggeburt JM, Kranenbarg EK, et al. Late side effects of short-course preoperative radiotherapy combined with total mesorectal excision for rectal cancer: increased bowel dysfunction in irradiated patients--a Dutch colorectal cancer group study. J Clin Oncol. 2005;23(25):6199-206.

18. Beppu N, Kimura H, Matsubara N, Tomita N, Yanagi H, Yamanaka N. Long-term functional outcomes of total mesorectal excision following chemoradiotherapy for lower rectal cancer: Stapled anastomosis versus intersphincteric resection. Dig Surg. 2016;33(1):33-42.

19. Sunesen KG, Norgaard M, Lundby L, Havsteen H, Buntzen S, Thorlacius-Ussing O, et al. Long-term anorectal, urinary and sexual dysfunction causing distress after radiotherapy for anal cancer: a Danish multicentre cross-sectional questionnaire study. Colorectal Dis. 2015; 17(11):O230-9.

20. Bentzen AG, Guren MG, Vonen B, Wanderas EH, Frykholm G, Wilsgaard T, et al. Faecal incontinence after chemoradiotherapy in anal cancer survivors: long-term results of a national cohort. Radiotherapy Oncol. 2013;108(1):55-60.

21. Vordermark D, Sailer M, Flentje M, Thiede A, Kolbl O. Curative-intent radiation therapy in anal carcinoma: quality of life and sphincter function. Radiotherapy Oncol. 1999;52(3):239-43.

22. Maeda $Y$, Hoyer M, Lundby L, Norton C. Faecal incontinence following radiotherapy for prostate cancer: a systematic review. Radiotherapy Oncol. 2011;98(2):145-53.

23. Resnick MJ, Koyama T, Fan KH, Albertsen PC, Goodman M, Hamilton AS, et al. Long-term functional outcomes after treatment for localized prostate cancer. N Engl J Med. 2013; 368(5):436-45.

24. Yeoh EE, Botten R, Di Matteo A, Tippett M, Hutton J, Fraser R, et al. Pudendal nerve injury impairs anorectal function and health related quality of life measures $>/=2$ years after $3 \mathrm{D}$ conformal radiotherapy for prostate cancer. Acta Oncol. 2017:1-9.

25. Da Silva GM, Berho M, Wexner SD, Efron J, Weiss EG, Nogueras JJ, et al. Histologic analysis of the irradiated anal sphincter. Dis Colon Rectum. 2003;46(11):1492-7.

26. Lorenzi B, Brading AF, Martellucci J, Cetta F, Mortensen NJ. Short-term effects of neoadjuvant chemoradiotherapy on internal anal sphincter function: a human in vitro study. Dis Colon Rectum. 2012;55(4):465-72.

27. Zhu X, Lou Z, Gong H, Meng R, Hao L, Zhang W. Influence of neoadjuvant chemoradiotherapy on the anal sphincter: ultrastructural damage may be critical. Int $\mathrm{J}$ Colorectal Dis. 2016;31(8):1427-30.

28. Chen FC, Mackay JR, Woods RJ, Collopy BT, Fink RJ, Guiney MJ. Early experience with postoperative adjuvant chemoradiation for rectal carcinoma: focus on morbidity. Aust $\mathrm{N} \mathrm{Z} \mathrm{J}$ Surg. 1995;65(10):732-6.

29. Gundling F, Seidl H, Scalercio N, Schmidt T, Schepp W, Pehl C. Influence of gender and age on anorectal function: normal values from anorectal manometry in a large caucasian population. Digestion. 2010;81(4):207-13.

30. Berndtsson I, Lennernas B, Hulten L. Anorectal function after modern conformal radiation therapy for prostate cancer: a pilot study. Techn Coloproctol. 2002;6(2):101-4.

31. Yeoh EK, Russo A, Botten R, Fraser R, Roos D, Penniment M, et al. Acute effects of therapeutic irradiation for prostatic carcinoma on anorectal function. Gut. 1998;43(1):123-7.

32. Bregendahl S, Emmertsen KJ, Fassov J, Krogh K, Zhao J, Gregersen H, et al. Neorectal hyposensitivity after neoadjuvant therapy for rectal cancer. Radiotherapy Oncology. 2013; 108(2):331-6.

33. Smeenk RJ, Hopman WP, Hoffmann AL, van Lin EN, Kaanders JH. Differences in radiation dosimetry and anorectal function testing imply that anorectal symptoms may arise from different anatomic substrates. Int J Radiat Oncol Biol Phys. 2012;82(1):145-52.

34. Krol R, Smeenk RJ, van Lin EN, Yeoh EE, Hopman WP. Systematic review: anal and rectal changes after radiotherapy for prostate cancer. Int J Colorectal Dis. 2014;29(3):273-83.

35. Yeoh EE, Holloway RH, Fraser RJ, Botten RJ, Di Matteo AC, Moore JW, et al. Anorectal dysfunction increases with time following radiation therapy for carcinoma of the prostate. Am J Gastroenterol. 2004;99(2):361-9. 
36. Arias F, Eito C, Asin G, Mora I, Cambra K, Maneru F, et al. Fecal incontinence and radiation dose on anal sphincter in patients with locally advanced rectal cancer (LARC) treated with preoperative chemoradiotherapy: a retrospective, single-institutional study. Clin Transl Oncol. 2017;19(8):969-75.

37. Vordermark D, Schwab M, Ness-Dourdoumas R, Sailer M, Flentje M, Koelbl O. Association of anorectal dose-volume histograms and impaired fecal continence after 3D conformal radiotherapy for carcinoma of the prostate. Radiotherapy Oncol. 2003;69(2):209-14.

38. Peeters ST, Lebesque JV, Heemsbergen WD, van Putten WL, Slot A, Dielwart MF, et al. Localized volume effects for late rectal and anal toxicity after radiotherapy for prostate cancer. Int J Radiat Oncol Biol Phys. 2006;64(4):1151-61.

39. Buettner F, Gulliford SL, Webb S, Sydes MR, Dearnaley DP, Partridge M. The dose-response of the anal sphincter region--an analysis of data from the MRC RT01 trial. Radiotherapy Oncol. 2012;103(3):347-52.

40. Smeenk RJ, Hoffmann AL, Hopman WP, van Lin EN, Kaanders JH. Dose-effect relationships for individual pelvic floor muscles and anorectal complaints after prostate radiotherapy. Int $\mathrm{J}$ Radiat Oncol Biol Phys. 2012;83(2):636-44. 



\section{Chapter 6}

Dutch validation of the Low Anterior Resection

Syndrome Score

BJP Hupkens, SO Breukink, C Olde Reuver of Briel, PJ Tanis, ME de Noo, $P$ van Duijvendijk, HL van Westreenen, JWT Dekker, T Chen, T Juul 


\section{Abstract}

Aim: The aim of this study was to validate the Dutch translation of the Low Anterior Resection Syndrome (LARS) score in a population of Dutch rectal cancer patients.

Method: Patients who underwent surgery for rectal cancer received the LARS score questionnaire, a single quality of life category question and the EORTC QLQ-C30 questionnaire. A subgroup of patients received the LARS score twice to assess the test-retest reliability.

Results: A total of 165 patients were included in the analysis, identified in six Dutch centres. The response rate was $62.0 \%$. The percentage of patients who reported 'major LARS' was $59.4 \%$. There was a high proportion of patients with a perfect or moderate fit between the QoL category question and the LARS score, showing a good convergent validity. The LARS score was able to discriminate between patients with or without neoadjuvant radiotherapy $(p=0.003)$, between total and partial mesorectal excision (TME vs. PME) $(p=0.008)$ and between age groups $(p=0.039)$. There was a statistically significant association between a higher LARS score and an impaired function on the global QoL subscale and the physical-, role-, emotional- and social functioning subscales of the EORTC QLQ-C30 questionnaire. The test-retest reliability of the LARS score was good, with an interclass correlation coefficient of 0.79 .

Conclusion: The good psychometric properties of the Dutch version of the LARS score are overall comparable to the earlier validations in other countries. Therefore, the Dutch translation can be considered to be a valid tool for assessing LARS in Dutch rectal cancer patients. 


\section{Introduction}

Colorectal cancer is the second most common cancer in the Netherlands, with an incidence of 15,427 new cases in 2016 , of which $26 \%$ were located in the rectum ${ }^{1}$. Due to earlier detection and improved treatment in the past decades, locoregional control and overall survival have improved substantially in rectal cancer patients. This higher survival comes at a price, and hence in addition to survival, the current focus of rectal cancer treatment has shifted towards treatment-related morbidity, functional outcome and quality of life (QoL). Most patients with rectal cancer are treated with sphincter-sparing surgery, namely a low anterior resection (LAR), without a permanent stoma.

It is known that 50 to $90 \%$ of the patients undergoing a LAR, will have at least some degree of bowel dysfunction ${ }^{2,3}$. These problems consist of incontinence of faeces and/or flatus, constipation, urgency, fragmentation and frequent bowel movements. This combination of symptoms is called the low anterior resection syndrome $(\mathrm{LARS})^{3}$. A decreased $\mathrm{QoL}$ is seen in patients with severe LARS symptoms ${ }^{4}$.

Because of the severity and high prevalence of these problems, and because a good tool was lacking, the LARS score was developed to systematically assess the presence and severity of LARS ${ }^{5}$. The score is already validated in several languages, including English ${ }^{6}$, Chinese ${ }^{7}$, Lithuanian $^{8}$, as well as Swedish, Spanish, German and Danish (as a consolidated international validation) ${ }^{9}$.

The aim of this study was to validate the Dutch version of the LARS score in a cohort of Dutch rectal cancer patients, investigating the convergent and discriminative validity and test-retest reliability of the score.

\section{Materials and methods}

\section{Translation}

The original Danish version of the LARS score was translated to English and subsequently to Dutch. The translation to the Dutch language was performed by two independent professional translators, whose mother tongue was Dutch. The translators discussed discrepancies between their respective translations, until a final consensus was reached. A third translator, with English as the mother tongue, back-translated the agreed Dutch version to English. This third translator 
was not familiar with the original English version. Afterwards, the two English versions were checked for differences and a final version was formed.

\section{Participants and data collection}

Based on the earlier validation studies, around 200 patients were needed for the validation of the LARS score ${ }^{6,9}$. Patients eligible for this study were those who underwent a LAR in the form of a partial or total mesorectal excision (PME or TME) for rectal cancer between January 2009 and December 2013 in one of the six participating Dutch centres. To ensure a minimum of 24 months after surgery, allowing their bowel function to have regained stability, the questionnaires were sent after December $2015^{2}$. In cases where a temporary stoma was created, the bowel continuity should have been restored by stoma reversal. Exclusion criteria were recurrent or metastatic disease, a defunctioning stoma proximal to the anastomosis, dementia or inability to speak Dutch.

Six Dutch centres participated in the patient identification and data collection. The data were collected between July 2016 and January 2017. All patients meeting the study criteria received a postal invitation to complete the LARS score, an extra QoL category question, and the EORTC QLQ-C30 questionnaire. All patients were invited to complete a second LARS score questionnaire about two weeks after their initial response, for the purpose of assessing the test-retest reliability of the LARS score. The clinical data were collected by the Dutch Institute for Clinical Auditing (DICA) and the Medical Research Data Management (MRDM).

\section{Patient-reported outcome measures}

\section{LARS score}

All participants received the LARS score questionnaire (Figure 6.1). This score was originally developed on the basis of patient-reported outcomes in a population of Danish rectal cancer patients. Five items out of 26 candidate items were selected for the score for their high correlation with patients' self-reported impact of bowel dysfunction on QoL. The scores of the five individual items result in a total score ranging from 0 to 42 points. The total score is categorised into three groups: 0-20 points - no LARS; 21-29 points - minor LARS; and 30 - 42 points - major LARS ${ }^{5}$. 
Deze vragenlijst heeft tot doel de darmfunctie van patiënten met endeldarmkanker te meten. Per vraag mag u één antwoord aankruisen. Het kan moeilijk zijn om maar één antwoord te kiezen, aangezien we weten dat bij sommige patiënten de symptomen van dag tot dag variëren. Echter vragen we $u$ het antwoord te kiezen die het beste uw dagelijks leven beschrijft. Als $u$ recent een darminfectie heeft gehad, vragen we u deze symptomen niet mee te nemen in uw antwoorden, maar u te focussen op uw dagelijks leven.

Vraag 1: Komt het wel eens voor dat u geen controle heeft over uw winderigheid?

$\square$ Nee, nooit

Ja, minder dan 1 keer per week

․ Ja, minstens 1 keer per week

Vraag 2: Heeft u wel eens last van ongewenste lekkage van dunne ontlasting?

口 Nee, nooit

$\square \mathrm{Ja}$, wel eens, dat wil zeggen minder dan eenmaal per week

口 Ja, vaak, dat wil zeggen minstens eenmaal per week

Vraag 3: Hoe vaak heeft u ontlasting?

口 Meer dan 7 keer per dag (24 uur)

प 4-7 keer per dag (24 uur)

- 1-3 keer per dag (24 uur)

口 Minder dan 1 keer per dag (24 uur)

Vraag 4: Als u ontlasting heeft gehad, moet $\mathrm{u}$ dan wel eens binnen het uur nog een keer naar het toilet voor ontlasting?

口 Nee, nooit

口 $\mathrm{Ja}$, minder dan 1 keer per week

․ Ja, minstens 1 keer per week

Vraag 5 :Heeft u wel eens zo een sterke aandrang voor ontlasting, dat u zich naar het toilet moet haasten?

$\square$ Nee, nooit

Ja, minder dan 1 keer per week

口 Ja, minstens 1 keer per week

\begin{tabular}{l} 
Tel de scores van de bovenstaande vijf antwoorden bij elkaar op, tot één uiteindelijke score. \\
Interpretatie: $0-20=$ Geen LARS $\quad 21-29=$ Minimale LARS $30-42=$ Ernstige LARS \\
\hline
\end{tabular}

Figure 6.1 - The Dutch translation of the low anterior resection syndrome (LARS) score. An extra question was added for validation purposes only. The Dutch translation of that question is "In hoeverre beïnvloedt uw darmfunctie over het algemeen uw kwaliteit van leven?", and can be answered with "helemaal niet", "een beetje", "nogal" en "heel erg". 


\section{QoL category question}

One single question on QoL was added to the LARS score to investigate measurements that theoretically should be related, are in fact related. The question: "Overall, how much does your bowel function affect your quality of life?" could be answered with "not at all", "very little", "somewhat", or "a lot". This question has previously been used for the development and validation of the LARS score and is shown in Figure 6.1 ${ }^{5,9}$.

\section{EORTC QLQ-C30}

The EORTC-QLQ-C $30^{10}$ questionnaire is a validated cancer-specific instrument to assess QoL. It consists of 30 questions that form one global QoL scale, five functional scales (i.e. physical, role, emotional, cognitive, and social), three symptom scales (fatigue, nausea and vomiting, and pain), and six single items (dyspnoea, insomnia, appetite loss, constipation, diarrhoea, and financial difficulties). The scores of each scale were calculated into a score that ranges from 0 to 100 . Only the functional scales and the global QoL scale were used in this analysis. A high score on a functional scale represents a high level of functioning. Missing data were handled according to the guidelines ${ }^{11,12}$.

\section{Convergent validity}

To investigate the convergent validity, the LARS score was correlated against the single QoL category question and the EORTC-QLQ-C30 questionnaire ${ }^{10}$ to test how the LARS score related to QoL.

\section{Discriminative validity}

To investigate the discriminative validity, we evaluated the ability of the LARS score to differentiate between groups of patients who are known to differ with regard to LARS. Clinically relevant subgroups were based on receipt of preoperative radiotherapy, type of surgery (TME/PME) and age (cut-off at 69 years), in keeping with the earlier validation studies ${ }^{5,9,13}$.

\section{Test-retest reliability}

Test-retest reliability is one of the key measurements of all health measures ${ }^{14}$. To examine the test-retest reliability of the LARS score, all participants received 
by mail the LARS score again 1-2 weeks after they first had completed the score.

\section{Statistical analysis}

Statistical analyses were performed using IBM Statistical Package for the Social Sciences (SPSS version 23.0, Armonk, NY, USA) and STATA 14® (StataCorp, 4905 Lakeway Drive, College Station, Texas, USA). A p-value <0.05 was considered statistically significant. For baseline characteristics, we used descriptive analyses.

For convergent validity, fit between the QoL categories (having no, minor or some/major impact of bowel function on QoL) and the three LARS score categories was assessed. A perfect fit was defined as no LARS and no impact on QoL, minor LARS and minor impact on QoL, and major LARS and some/major impact on QoL. The fit between the two measures was moderate when there was a difference by only one category, and no fit in the case of a difference of two categories.

The data of the LARS score were presented as median (with range) and differences were tested by the Kruskal-Wallis test. The Kruskal-Wallis test was also used to test the null hypothesis in investigating the association between the LARS score and the five functional subscales and the global QoL scale of the EORTC-QLQ-C30 questionnaire ${ }^{12}$. The Wilcoxon rank sum test was applied to investigate the discriminative validity.

Agreement between the two tests when measuring the reliability of the LARS score was presented as proportions with $95 \%$ confidence intervals $(95 \% \mathrm{Cl})$. A Bland-Altman plot with $95 \%$ limits of agreement and the intraclass correlation (ICC) were computed. An ICC of less than 0.50 is indicative of poor reliability, between 0.50 and 0.75 reflects moderate reliability, between $0.75-0.90$ reflects good reliability, and an ICC of over 0.90 indicates excellent reliability ${ }^{15}$.

\section{Ethics}

The study was approved by the Committee on Medical Research Ethics and all patients provided written informed consent. 


\section{Results}

\section{Translation}

The English version was successfully translated to Dutch. The final version is shown in Figure 6.1.

\section{Participants}

The six participating centres identified a total of 407 eligible patients, of whom 99 were excluded because of recurrence, death, colostomy or poor general health. Out of the 308 remaining patients, 191 responded (response rate: 62.0\%). After excluding the patients with missing clinical data and/or missing LARS score items, 165 patients were eventually included in the analysis. The flow chart is shown in Figure 6.2.

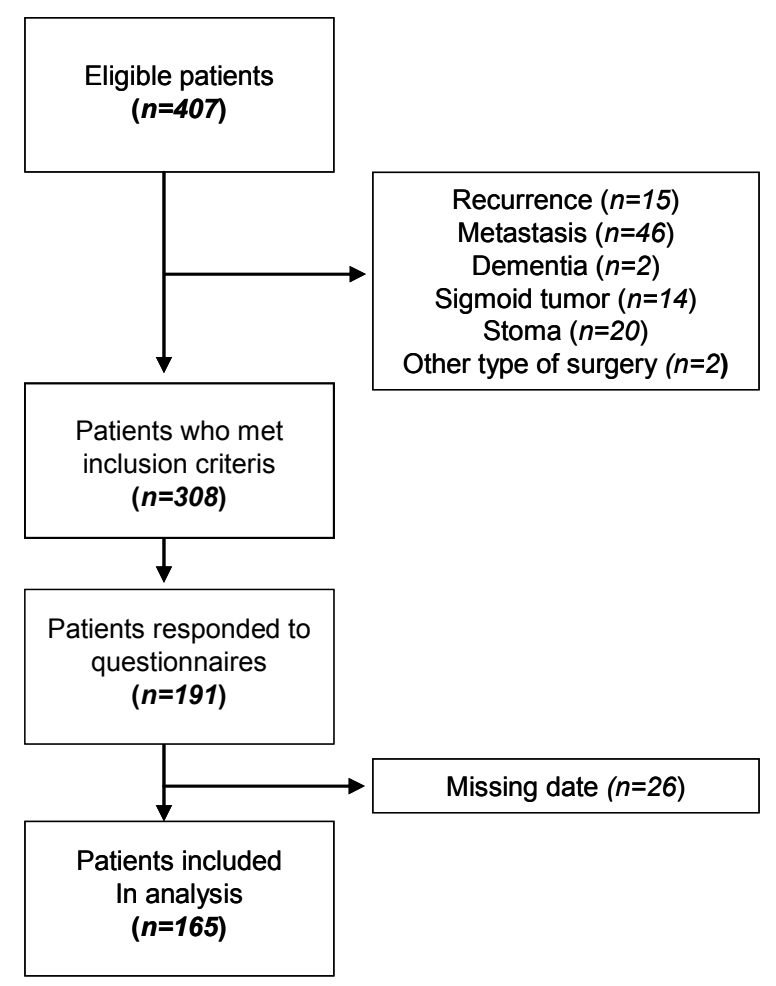

Figure 6.2 - Flow chart of the inclusion of patients. 
All baseline characteristics are shown in Table 6.1. The mean (SD) age of the responders was $62.8( \pm 9.4)$ years at the time of the study, and $74.6 \%$ of the participants were men. The median time from surgery to assessing the LARS score was 4.9 (2.4-8.1) years. Ninety-eight (59.4\%) patients had 'major LARS', 31 (18.8\%) patients had 'minor LARS' and 36 (21.8\%) patients had 'no LARS', according to the LARS score.

Table 6.1 - Baseline characteristics of patients.

\begin{tabular}{lr}
\hline Number of patients $(\boldsymbol{n})$ & $\mathbf{1 6 5}$ \\
\hline Sex $(n(\%))$ & $123(75 \%)$ \\
Male & $42(25 \%)$ \\
Female & $62.8 \mathrm{y}( \pm 9.4)$ \\
Age at surgery (mean (SD)) & $67.5 \mathrm{y}( \pm 9.5)$ \\
Age at test (mean (SD)) & $4.9 \mathrm{y}( \pm 1.3)$ \\
Time since surgery (mean (SD)) & $8.8 \mathrm{~cm}( \pm 3.4)$ \\
Tumour height (mean (SD)) & $133(82 \%)$ \\
Type of surgery $(n(\%))$ & $30(18 \%)$ \\
TME & $16(9.7 \%)$ \\
PME & $79(47.9 \%)$ \\
Neo-adjuvant treatment $(n(\%))$ & $70(42.4 \%)$ \\
No & \\
$5 x 5 G y$ RT & $36(21.8 \%)$ \\
Chemoradiation & $31(18.8 \%)$ \\
LARS score (first) $(n(\%))$ & $98(59.4 \%)$ \\
No & \\
Minor & \\
Major & \\
\hline
\end{tabular}

TME: Total mesorectal excision; PME: partial mesorectal excision; LARS: low anterior resection syndrome.

\section{Convergent validity}

The proportion of participants with a perfect fit between QoL category and LARS score category was $41.8 \%(95 \% \mathrm{Cl} 34.4-49.6)$. A moderate fit was found in $49.7 \%(95 \% \mathrm{Cl} 42.1-57.4)$ and no fit in $8.5 \%$ (95\% Cl 5.1-13.9). Results are shown in Table 6.2. The mean LARS score was $20.5( \pm 10.5)$ in participants reporting no impact of bowel dysfunction on $\mathrm{QoL}(\mathrm{n}=34)$. In participants reporting a minor impact of bowel dysfunction on QoL $(n=81)$, the mean LARS score was 29.3 ( \pm 10.0 ), and for those who reported major impact of bowel dysfunction on QoL $(n=50)$, the mean LARS score was $32.7( \pm 9.9)$. These results are shown in Figure 6.3. The sensitivity of the LARS score was $78.0 \%$ (95\% Cl 64.0-88.5) and specificity was $48.7 \%(95 \% \mathrm{Cl} 39.3-58.2)$. 
Table 6.2 - Fit between LARS category and QoL category.

\begin{tabular}{lccc}
\multicolumn{1}{c}{} & $\begin{array}{c}\text { No impact } \\
\text { on QoL }(\boldsymbol{n}(\%))\end{array}$ & $\begin{array}{c}\text { Minor impact } \\
\text { on QoL }(\boldsymbol{n}(\%))\end{array}$ & $\begin{array}{c}\text { Major impact } \\
\text { on QoL }(\boldsymbol{n}(\%))\end{array}$ \\
\cline { 2 - 4 } No LARS & $15(9.1 \%)$ & $15(9.1 \%)$ & $6(3.6 \%)$ \\
Minor LARS & $11(6.7 \%)$ & $15(9.1 \%)$ & $5(3.0 \%)$ \\
Major LARS & $8(4.9 \%)$ & $51(30.9 \%)$ & $39(23.6 \%)$ \\
\hline
\end{tabular}

Perfect fit $41.8 \%$ Moderate fit $49.7 \%$ No fit $8.5 \%$. LARS: low anterior resection syndrome; QoL: quality of life.

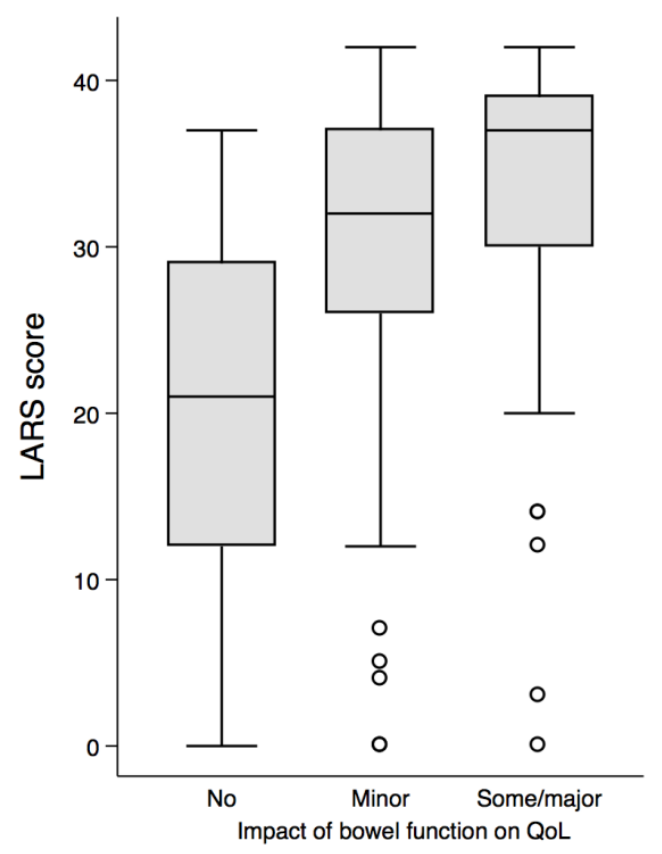

Figure 6.3 - Box plot illustrating the association between low anterior resection syndrome score (LARS) and impact of bowel function on quality of life.

To further investigate convergent validity, the LARS categories (no, minor and major) were also compared with the EORTC QLQ-C30 functional subscales. A higher score in the major LARS category, compared to the no LARS category, was associated with a significantly impaired function in four out of the five functional subscales and in the global QoL scale. The difference in the EORTC QLQ-C30 scores between the 'no LARS' and the 'major LARS' score categories were: 6.6 in global QoL scale $(p=0.0042), 3.8$ in physical functioning $(p=0.0203)$, 6.0 in role functioning $(p=0.0313), 5.5$ in emotional functioning $(p=0.0368)$, and 6.8 in social functioning $(p=0.0023)$. There were no significant differences in 
cognitive functioning (difference: $2.7, \mathrm{p}=0.1076$ ). The results are summarised in Figure 6.4.

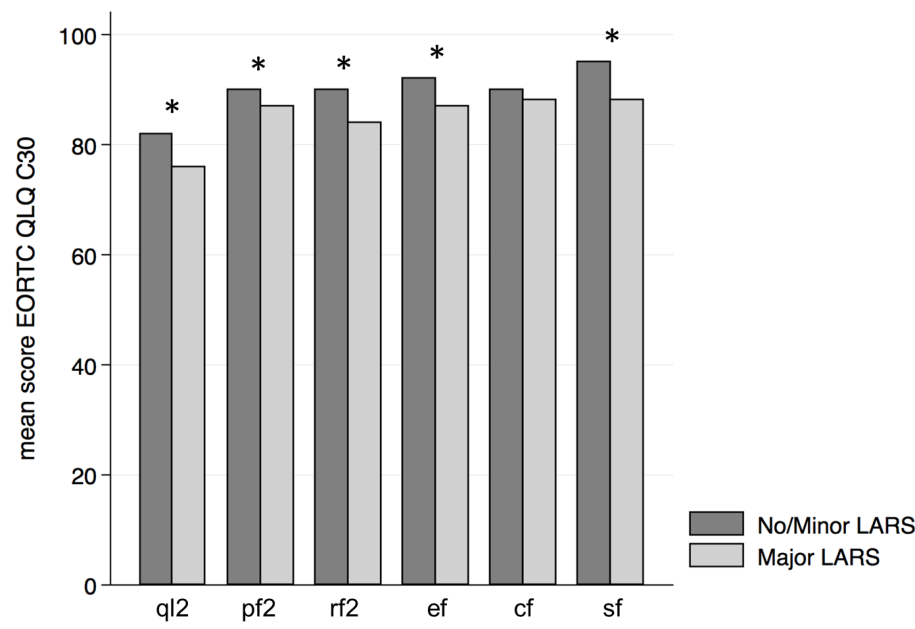

Figure 6.4 - Mean score of the functional scales compared between the LARS categories (no/minor LARS vs. major LARS) $(p=0.0023-0.1076) .{ }^{*}$ results are significantly different. $q l 2=$ global $Q$ oL scale; pf2 = physical functioning; rf2 = role functioning; ef = emotional functioning; $\mathrm{cf}=$ cognitive functioning; sf = social functioning.

\section{Discriminative validity}

The LARS score was able to discriminate between participants treated with preoperative radiotherapy $(n=149$, median $=33$ (range $0-42))$ and those who did not receive preoperative radiotherapy $(n=16$, median $=21$ (range 0-37)) $(p=0.003)$. There was also a significant difference found between participants who underwent a PME $(n=30$, median=26.5 (range 4-39)) and a TME $(n=133$, median=34 (range 0-42)) $(p=0.008)$. The LARS score was also able to discriminate between participants younger than 69 years $(n=112$, median $=34$ (range 0-42)) and participants older than 69 years $(n=53$, median=29 (range $0-42))(p=0.039)$. All results regarding discriminative validity are shown in Figure 6.5 . 

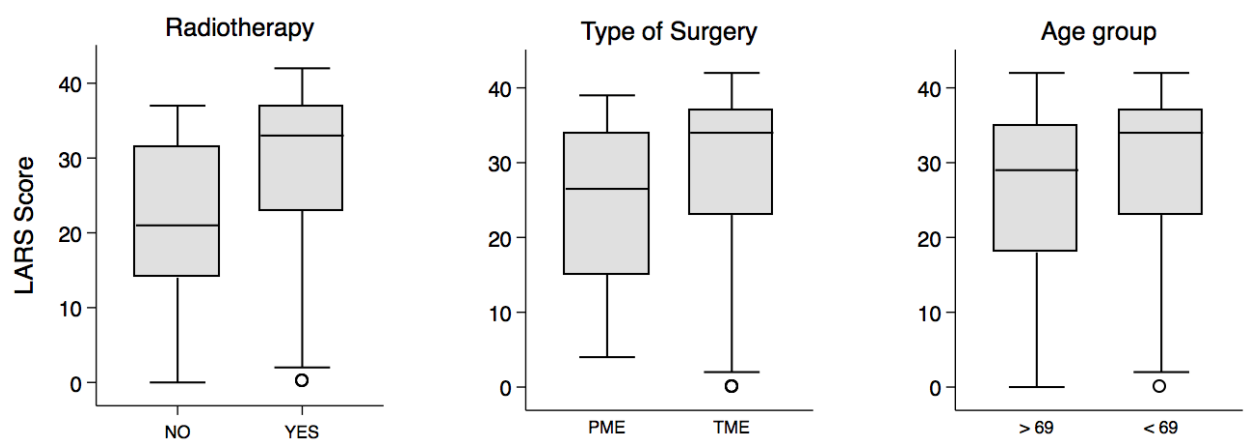

Figure 6.5 - Comparison of the low anterior resection syndrome score (LARS) in groups of patients differing with regards to pre-operative radiotherapy $(p=0.003)$, type of surgery $(p=0.008)$, and age $(p=0.039)$.

\section{Reliability}

The second questionnaire was filled in by 130 out of 165 participants $(78.8 \%)$. The median time between the two tests was 19 days (6-42). There were no significant differences between the LARS scores on the first and second test $(p=0.0985)$. The differences between LARS scores in the first and second test are shown in Figure $\mathbf{6 . 6}$ in the Bland-Altman plot with 95\% limits of agreement at -14.252 to 12.313 . Seventy per cent $(95 \% \mathrm{Cl} 61.5-77.3)$ of the participants remained in the same LARS category in both tests, $26.9 \%(95 \% \mathrm{Cl} 19.9-35.3)$ differed by one category, and $3.1 \%(1.1-8.0)$ differed by two categories. The ICC was 0.79 , showing a good reliability ${ }^{15}$.

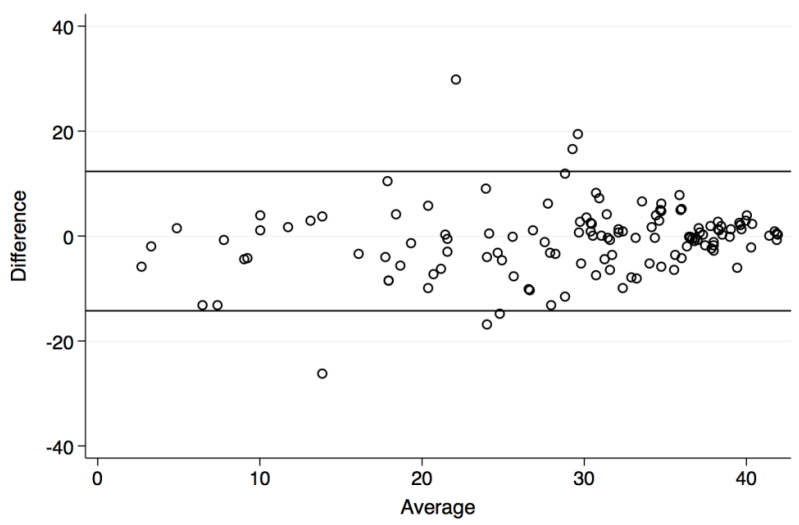

Figure 6.6 - Bland-Altman plot with $95 \%$ limits of agreement (-14.3 to 12.3) showing the difference between low anterior resection syndrome scores (LARS) at first and second test. 


\section{Discussion}

This study validated the Dutch translation of the LARS score in a population of Dutch rectal cancer patients. The results demonstrate that, when applied to a population of Dutch rectal cancer patients, the Dutch version of the LARS score has good psychometric properties and is strongly associated with QoL. The LARS score was able to distinguish between groups of patients who did or did not undergo neoadjuvant radiotherapy, underwent different types of surgery (PME vs. TME), and between patients below 69 years of age or older. Finally, there was good test-retest reliability.

The distribution of the LARS scores of the Dutch patients was very similar to patient cohorts in other countries as shown in the earlier validation studies ${ }^{6-9}$. After TME, $47-59 \%$ of these other patient groups reported major LARS. This is a little lower than the percentage of patients with major LARS in the Dutch population in this study, which could be explained by the higher percentage of patients who had neoadjuvant radiotherapy. This higher percentage is due to the Dutch national colorectal cancer guideline at the time these patients were treated, which was revised in 2014. According to that former guideline, only patients with stage I rectal cancer would be treated without neoadjuvant radiotherapy ${ }^{16,17}$.

Although there was a low percentage of patients who did not receive neoadjuvant radiotherapy, the LARS score was still able to discriminate between patients with and without preoperative radiotherapy in this study, showing a higher LARS score in irradiated patients. This is in accordance to all other validation studies of the LARS score ${ }^{6-9}$. It is already well documented that preoperative (chemo)radiotherapy results in an impaired QoL in patients with rectal cancer ${ }^{18-22}$. The Dutch version of the LARS score was also able to discriminate between types of surgery (PME vs TME), just like in the English and the consolidated international validations $s^{6,9}$. As expected, patients who underwent a TME had more severe LARS compared to those who underwent a PME. An earlier Danish study has already shown the association between a worse QoL due to LARS and a younger age ${ }^{13}$. The Dutch version of the LARS score was able to discriminate between age groups, just like the international validation $^{9}$, showing a higher LARS score in younger patients. However, in the Chinese and Lithuanian validation studies, no differences were found between age groups ${ }^{7,8}$. 
An extra QoL category question was added to validate the LARS score. The convergent validity of the LARS score was tested using this question. The percentage of perfect fit was a little lower and the percentage of no fit was a little higher compared to the English, Lithuanian and international validations ${ }^{6,8,9}$.

The English, international and Chinese validation studies compared the results of the LARS score with the EORTC QLQ-C30 functional scales ${ }^{4,6,7}$. There was a correlation between the results of the EORTC QLQ C30 subscales and the LARS score. Patients reported a higher LARS score if their general QoL was impaired. Just like the Chinese validation study, we did not find an association between the LARS score and the cognitive functioning scale.

The sensitivity of the LARS score in this study was moderate compared to the international validation ${ }^{9}$. Only the Swedish and Danish versions of the LARS score showed a higher sensitivity. The specificity of the LARS score in this study was much lower compared to the international validation ${ }^{9}$. This might be explained by the high percentage of patients with major LARS in the Netherlands. The reliability of the LARS score was comparable to the English and international validations of the LARS score.

This study has some limitations. We obtained a lower response rate in the Netherlands, compared with similar validation studies from other countries ${ }^{6-9}$. This is probably due to a high number of Dutch colorectal cancer studies involving a lot of questionnaires, leading to a smaller sample size than comparable validation studies. Another consequence is that the proportion of patients with major LARS might be overestimated in this study, since we assume that the patients with symptoms were more likely to respond than those without. It should be noted, that since this study is a validation study, it was not designed to measure the true prevalence of LARS in the Dutch rectal cancer population, or to identify risk factors/predictors for LARS. Therefore, we intentionally did not perform detailed analyses of these factors.

\section{Conclusions}

The good psychometric properties of the Dutch version of the LARS score are overall comparable to the earlier validations. Therefore, the Dutch translation can be considered to be a valid tool for measuring LARS in Dutch rectal cancer patients. The LARS score is a clinically relevant tool that is easy to implement in 
routine practice and research (only five questions) for assessing bowel dysfunction after rectal cancer treatment, as well as the effectiveness of therapies that target these adverse symptoms, to achieve the ultimate goal of optimising the QoL of these patients. 


\section{References}

1. Nederland IK. Cijfers over kanker. http://www.cijfersoverkanker.nl/nkr/index 2016

2. Emmertsen KJ, Laurberg S. Bowel dysfunction after treatment for rectal cancer. Acta Oncol. 2008;47:994-1003.

3. Bryant $\mathrm{CL}$, Lunniss $\mathrm{PJ}$, Knowles $\mathrm{CH}$, Thaha MA, Chan CL. Anterior resection syndrome. Lancet Oncol. 2012;13:e403-8.

4. Juul T, Ahlberg M, Biondo S, Espin E, Jimenez LM, Matzel KE, et al. Low anterior resection syndrome and quality of life: an international multicenter study. Dis Colon Rectum 2014;57: 585-91.

5. Emmertsen KJ, Laurberg S. Low anterior resection syndrome score: development and validation of a symptom-based scoring system for bowel dysfunction after low anterior resection for rectal cancer. Ann Surg. 2012;255:922-8.

6. Juul T, Battersby NJ, Christensen P, Janjua AZ, Branagan G, Laurberg S, et al. Validation of the English Translation of the Low Anterior Resection Syndrome Score (The LARS score). Colorectal Dis. 2015;17(10):908-16.

7. Hou XT, Pang D, Lu Q, Yang P, Jin SL, Zhou YJ, et al. Validation of the Chinese version of the low anterior resection syndrome score for measuring bowel dysfunction after sphincterpreserving surgery among rectal cancer patients. Eur J Oncol Nurs. 2015;19(5):495-501

8. Samalavicius NE, Dulskas A, Lasinskas M, Smailyte G. Validity and reliability of a Lithuanian version of low anterior resection syndrome score. Techn Coloproctol. 2016;20:215-20.

9. Juul T, Ahlberg M, Biondo S, Emmertsen KJ, Espin E, Jimenez LM, et al. International validation of the low anterior resection syndrome score. Ann Surg. 2014;259:728-34.

10. Aaronson NK, Ahmedzai S, Bergman B, Bullinger M, Cull A, Duez NJ, et al. The European Organization for Research and Treatment of Cancer QLQ-C30: a quality-of-life instrument for use in international clinical trials in oncology. J Natl Cancer Inst. 1993;85:365-76.

11. Fayers PM. Interpreting quality of life data: population-based reference data for the EORTC QLQ-C30. Eur J Cancer. 2001;37:1331-4.

12. Klee M, Groenvold M, Machin D. Using data from studies of health-related quality of life to describe clinical issues - Examples from a longitudinal study of patients with advanced stages of cervical cancer. Qual Life Res. 1999;8:733-42.

13. Bregendahl S, Emmertsen KJ, Lous J, Laurberg S. Bowel dysfunction after low anterior resection with and without neoadjuvant therapy for rectal cancer: a population-based crosssectional study. Colorectal Dis. 2013;15:1130-9.

14. Polit DF. Getting serious about test-retest reliability: a critique of retest research and some recommendations. Qual Life Res. 2014;23:1713-20.

15. Landis JR, Koch GG. The measurement of observer agreement for categorical data. Biometrics 1977;33:159-74.

16. Peeters KC, Marijnen CA, Nagtegaal ID, Kranenbarg EK, Putter H, Wiggers T, et al. The TME trial after a median follow-up of 6 years: increased local control but no survival benefit in irradiated patients with resectable rectal carcinoma. Ann Surg. 2007;246:693-701.

17. van Gijn W, Marijnen CA, Nagtegaal ID, Kranenbarg EM, Putter H, Wiggers T, et al. Preoperative radiotherapy combined with total mesorectal excision for resectable rectal cancer: 12-year follow-up of the multicentre, randomised controlled TME trial. Lancet Oncol. 2011;12: 575-82.

18. Ozgen Z, Ozden S, Atasoy BM, Ozyurt H, Gencosmanoglu R, Imeryuz N. Long-term effects of neoadjuvant chemoradiotherapy followed by sphincter-preserving resection on anal sphincter function in relation to quality of life among locally advanced rectal cancer patients: a crosssectional analysis. Radiation Oncol. 2015;10:168.

19. Maris A, Penninckx F, Devreese AM, Staes F, Moons P, Van Cutsem E, et al. Persisting anorectal dysfunction after rectal cancer surgery. Colorectal Dis. 2013;15:e672-9. 
20. Ekkarat $\mathrm{P}$, Boonpipattanapong $\mathrm{T}$, Tantiphlachiva K, Sangkhathat S. Factors determining low anterior resection syndrome after rectal cancer resection: A study in Thai patients. Asian $\mathrm{J}$ Surg 2016;39(4):225-31.

21. Andreyev HJ, Wotherspoon A, Denham JW, Hauer-Jensen M. Defining pelvic-radiation disease for the survivorship era. Lancet Oncol. 2010;11:310-2.

22. Emmertsen KJ, Laurberg S, Rectal Cancer Function Study G. Impact of bowel dysfunction on quality of life after sphincter-preserving resection for rectal cancer. Br J Surg. 2013;100: 1377-87. 




\section{Chapter 7}

Oncological outcomes and hospital costs of the treatment in rectal cancer patients: watch-and-wait policy and standard surgical treatment

BJP Hupkens, SO Breukink, JHMB Stoot, RE Toebes, ME van der Sande, J Melenhorst, GL Beets, CD Dirksen 


\section{Abstract}

Background: Little is known about the costs of the current treatment strategy in locally advanced rectal cancer, in which patients with a clinical complete response after chemoradiotherapy are treated in a watch-and-wait-policy.

Objective: The aim of this study is to present the oncological outcome and hospital costs of patients with a complete response after chemoradiotherapy (watch-and-wait-policy) and patients with an incomplete response after chemoradiotherapy (total mesorectal excision).

Methods: Cohort study. Academic and non-academic hospital setting. Patients with locally advanced rectal cancer received either a watch-and-wait-policy or TME depending on their clinical response to chemoradiotherapy. Interventions: Watch-and-wait-policy, total mesorectal excision.

Main outcome measures: Overall-, local recurrence free-, distant metastasis free survival and hospital costs over a two-years follow-up period.

Results: 292 patients with locally advanced rectal cancer were included. Mean age was 65.1 years and $64,7 \%$ were men. 105 patients were included in the watch-and-wait subgroup, and 187 in the total mesorectal excision subgroup. Both subgroups showed good oncological outcomes. Hospital costs consisted of five categories: costs of primary surgery; costs of adjuvant chemotherapy; costs of examinations; costs of additional surgery; and costs of treatment of regrowth/metastasis. The mean costs per patient were $€ 6.713$ (watch-and-wait subgroup) and $€ 17.108$ (total mesorectal excision subgroup) over the first two years.

Limitations: Only costs from a hospital perspective, follow-up was two years, partly retrospective study, no comparative study.

Conclusions: Overall survival was good in both subgroups and comparable to literature. The mean costs per patient differ between the watch-and-wait subgroup (€6.713) and the total mesorectal excision subgroup (€17.108). No comparison between the groups could be made. Based on the results of this study, the current strategy, where patient with a clinical complete response are treated in a watch-and-wait policy, and patients with an incomplete response were treated with total mesorectal excision, is likely to be (cost)saving. 


\section{Introduction}

Patients with locally advanced rectal cancer are normally treated with neoadjuvant chemoradiotherapy (CRT) followed by a total mesorectal excision $(\mathrm{TME})^{1}$. In $10-20 \%$ of these patients, a pathological complete response (pCR) is seen in the resected specimen ${ }^{2,3}$. In recent literature there is growing evidence that a stringent follow-up instead of TME, like the watch-and-wait (W\&W) policy, is a safe option with good oncological results in patients with a clinical complete response $(\mathrm{CCR})$ after $\mathrm{CRT}^{4-10}$. This organ preserving treatment eliminates perioperative morbidity and mortality associated with TME, preserves bowel continuity and enhances a good quality of life $e^{7,11,12}$. Despite these favourable results, some patients develop a regrowth. Limited evidence suggests that subsequent surgery can be performed in these patients, with equivalent oncological outcome compared to patients treated initially with CRT and TME ${ }^{8,13}$. These outcomes justify the current triage strategy: if patients with locally advanced rectal cancer have no complete response after CRT they will undergo additional TME, and, in case of a complete response after CRT, a W\&W-policy can be followed.

Little is known about the costs of this current treatment strategy in locally advanced rectal cancer. Many clinicians fear high costs in the W\&W subgroup because of the stringent follow-up programme with endoscopic evaluations, MRI scans and outpatients visits. However, surgery and its associated costs are avoided in the majority of patients entering a watch-and-wait programme. Only one study so far, with a hypothetical study population, reported that a W\&Wpolicy is likely to be more cost-effective compared to treatment of patients with CRT and TME ${ }^{14}$.

The aim of this study is to present the oncological results and to calculate the hospital costs of this current triage strategy in which patients with a complete response following CRT are followed up according to W\&W-policy and patients with incomplete response are treated with additional TME.

\section{Materials and methods}

\section{Study design}

This is a cohort study, in which patients with locally advanced rectal cancer received either a W\&W-policy (in case of $\mathrm{CCR}$ ) or TME surgery (in case an 
incomplete response) following CRT. Data of patients in the W\&W-policy were collected prospectively, whereas data of patients who underwent TME surgery were collected retrospectively.

\section{Patient selection}

Patients with locally advanced rectal cancer with a clinical complete response (cCR) after CRT had been included in two prospective studies (METC 09-2-034 and METC14-2-032; clinicaltrials.gov: NCT02278653), running from 2004-2014 in Maastricht University Medical Centre (the Netherlands). In both prospective studies, patients were included in the W\&W-policy for rectal cancer. Patients with locally advanced rectal cancer and no complete response following CRT, who were treated with TME surgery in the same period (2004-2014) in two hospitals (Maastricht University Medical Centre and Zuyderland Medical Centre) were additionally and retrospectively selected for the purpose of this study. Exclusion criteria were: surgery during the neoadjuvant treatment; neoadjuvant treatment other than CRT; palliative treatment of rectal cancer; synchronous metastases; no adenocarcinoma; death during neoadjuvant treatment or within 48 hours after surgery; brachytherapy instead of or in combination with external beam radiotherapy; acute surgery; second malignancy of colon/rectum; and other malignancy in same treatment period.

\section{Data collection}

The study was approved by the Committee on Medical Research Ethics. Due to the retrospective collection of extra data, no informed consent was needed. For the purpose of this study all patient data were collected with a follow-up of two years. All baseline data and data concerning treatment and follow-up of the rectal cancer was collected, including types of treatment, complications (complications were scored, based on the registry of the complications in the two hospitals. All complications which needed extra treatment were included in the costs), treatment of complications, regrowths and distant metastases, treatment of regrowths and distant metastases. All hospital resource use (e.g. outpatient visits, diagnostic imaging tests, surgeries, inpatient days) associated with treatment and follow-up of rectal cancer was registered as well. The costs of the treatment of regrowths, recurrences and distant metastases were based on the purpose of the treatment. These costs include costs for chemotherapy, radiotherapy, surgery, hospitalization, etc. As all patients had started with the 
same neoadjuvant treatment (chemoradiation), data before TME or inclusion in the W\&W-policy were not evaluated in this study.

\section{Treatment and follow-up}

All patients were treated with neoadjuvant chemoradiotherapy. Six to twelve weeks after the end of the neoadjuvant treatment patients underwent MRI and endoscopy. After these examinations and based on their clinical response, patients where either treated in the TME subgroup or the W\&W subgroup. The TME surgery was performed by an experienced colorectal surgeon, or by a surgeon in training, but always together with an experienced colorectal surgeon. Postoperative patients were treated by the ERAS protocol. The follow-up of patients in the TME subgroup is according to the national guidelines. Patients in the W\&W subgroup had follow-up according to the watch-and-wait protocol, with 5 more MRIs and 6 more endoscopies in the first two years. The total follow-up of W\&W patients is described in previous papers ${ }^{6,7}$.

\section{Statistical analysis}

To analyse the data, IBM SPSS Statistics (version 23.0, Armonk, NY, USA) was used. Two-year non-regrowth disease-free survival (nrDFS), local regrowth-free survival (LRFS), and overall survival (OS) were analysed using Kaplan-Meier survival methods. nrDFS was defined as absence of loco regional recurrence, distant metastases and death; LRFS was defined as absence of loco regional recurrence; and OS was defined as absence of death ${ }^{15}$.

A hospital perspective was applied for the cost analysis. Costs were calculated by multiplying hospital resource use with the integral cost price per unit. We used reference prices of 2014 , published in the Dutch guideline ${ }^{16}$. As not all cost prices are included in this guideline, some were provided by the hospitals. All costs are shown in Table 7.1. To calculate the costs of the current strategy we used a proportional strategy of $20 \%$ of the patients in the W\&W-subgroup and $80 \%$ of the patients in the TME-subgroup. 


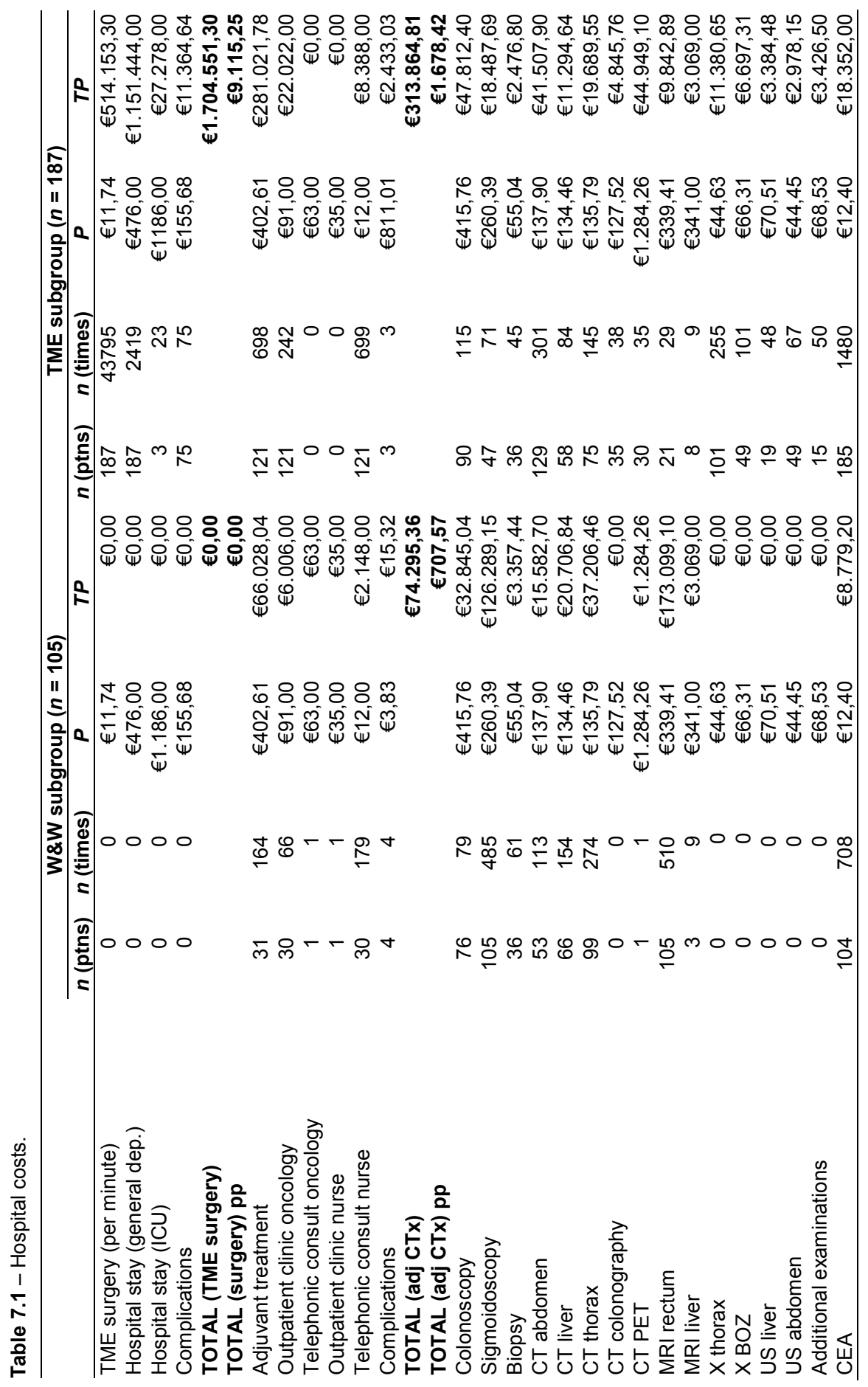




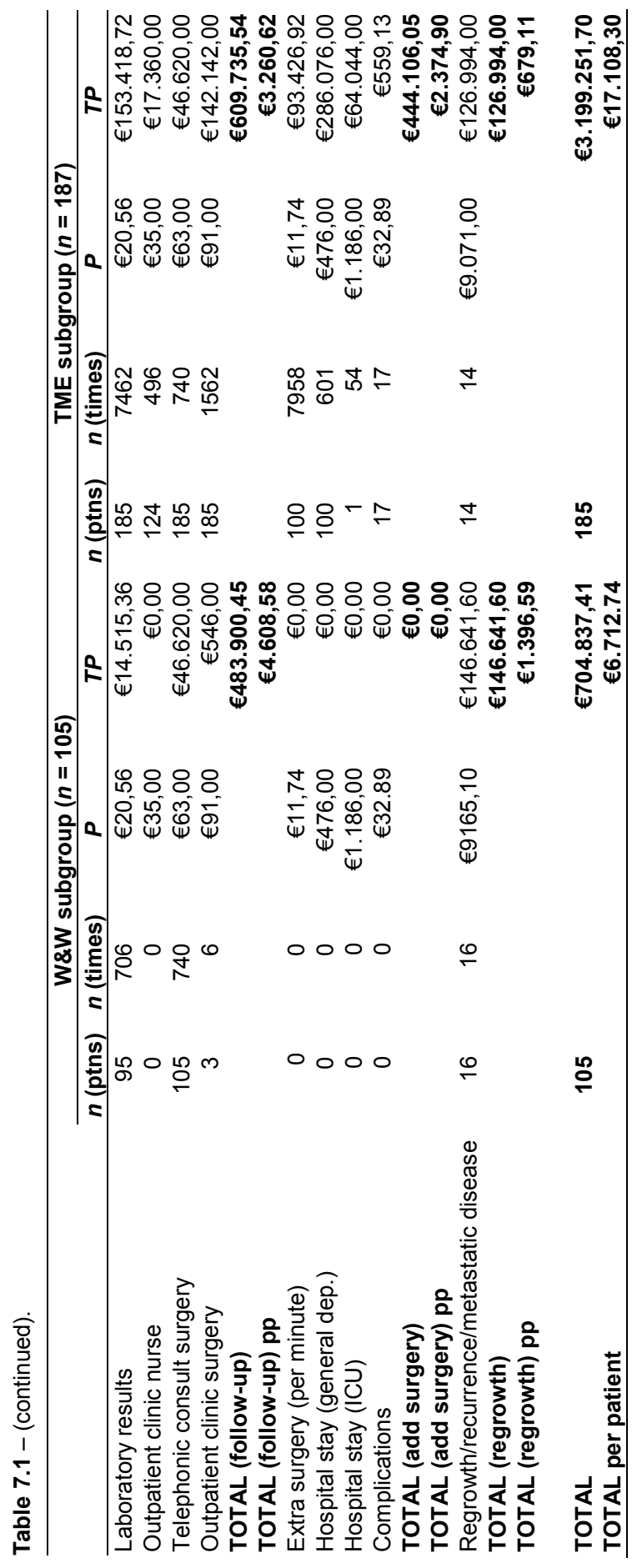




\section{Results}

\section{Patient characteristics}

Of the 369 patients potentially eligible for this study, 292 patients met the inclusion criteria. Figure 7.1 shows a flow chart of the inclusion. The mean age (SD) was $65.1(9,9)$ years and $64,7 \%$ were male patients. All baseline characteristics are shown in Table 7.2.

In the TME subgroup, 187 patients were included in the analysis, with a mean age (SD) of $66,1(9,6)$ years. In the W\&W subgroup 105 patients were included, with a mean age $(S D)$ of $63,4(10,2)$ years.

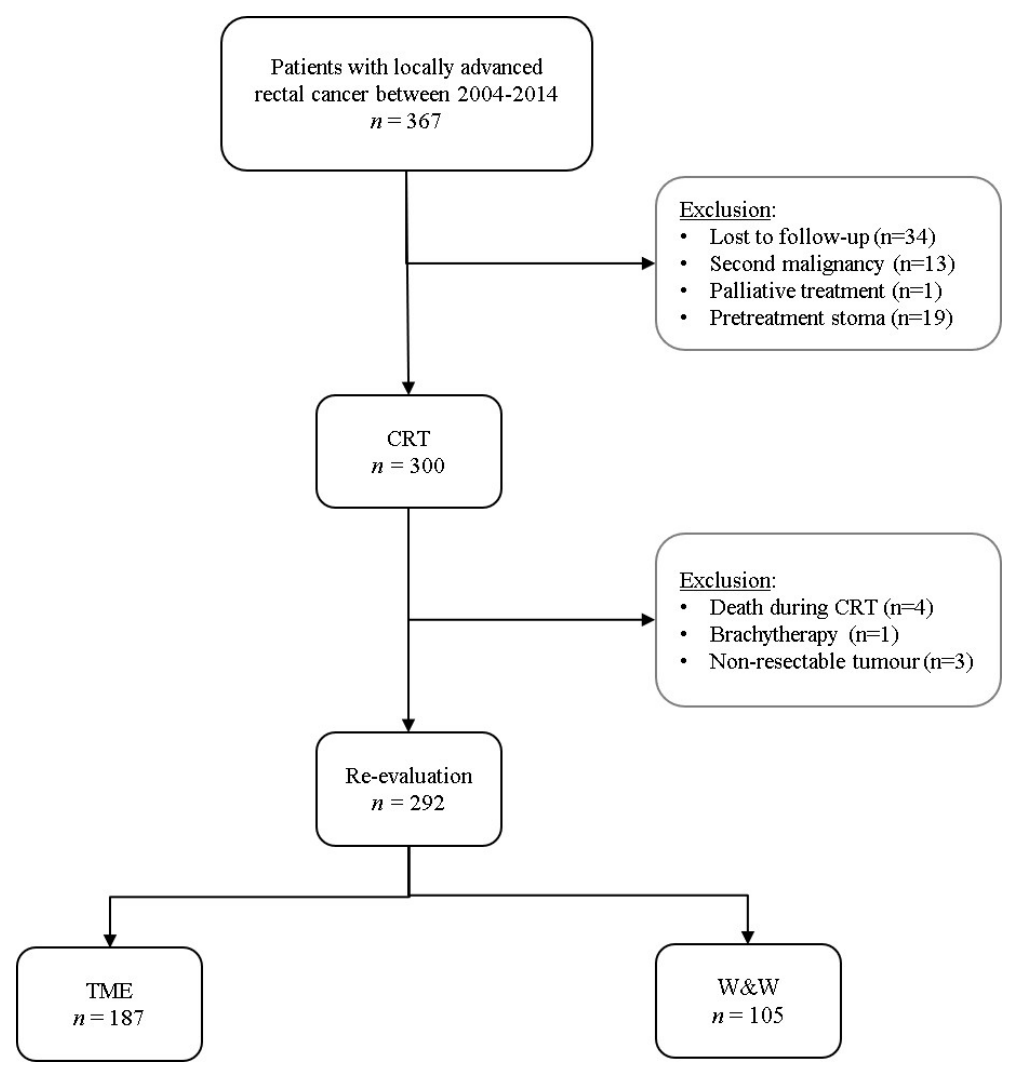

Figure 7.1 - Flow chart. 
Table 7.2 - Patient characteristics.

$\left.\begin{array}{lcc}\hline & \text { TME subgroup } & \text { W\&W subgroup } \\ \mathbf{n = 1 8 7} & 105\end{array}\right)$

\section{Oncological results}

The median follow-up time of the patients in the TME subgroup was 58 months (range 0-141) and 44 months (range 6-135) in the W\&W subgroup. The two-year LRFS of patients in the TME subgroup is $98,3 \%$ and $85,6 \%$ in the W\&W subgroup. All patients in the W\&W subgroup with recurrent local disease $(n=15)$ underwent salvage surgery, this is in $24,4 \%$ of the W\&W patients. Three patients in the TME subgroup who had recurrent disease underwent extended salvage surgery. This was in $1,7 \%$ of the TME patients. The two-year DMFS of patients in the TME subgroup is $93,4 \%$ and $98,0 \%$ in the W\&W subgroup. In the current triage strategy, which is based on $20 \%$ in the W\&W subgroup and $80 \%$ in the TME subgroup, the two-year LRFS is $95,8 \%$, and the two-year DMFS is $94,3 \%$.

The OS of patients in the TME- and W\&W subgroups are similar, respectively $96,8 \%$ and $98,1 \%$ (current triage strategy: $97,1 \%$ ). All results are shown in

\section{Table 7.3.}

\section{Hospital costs}

Hospital costs consisted of costs of primary TME surgery; costs of adjuvant chemotherapy; costs of follow-up; costs of additional surgery; and costs of treatment of a regrowth and/or metastasis. All costs are shown in Table 7.1. The costs were calculated for the TME surgery subgroup, the W\&W-policy subgroup and for the new triage strategy (based on $20 \%$ W\&W subgroup and $80 \%$ TME subgroup).

First, the hospital costs for the TME subgroup were calculated. All patients in the TME subgroup underwent TME surgery. These 187 patients had a total of 
43.795 minutes of surgery, 2.419 days at the regular care unit, and eleven days at the intensive care unit (ICU). Seventy-five out of 187 patients $(40,1 \%)$ had some sort of complications. The mean costs per patient of the TME-surgery, including complications (and treatment), were $€ 9.115,25$ (SD $€ 5.474,16$ ). Patients in the TME subgroup had a mean costs per patient for adjuvant treatment of $€ 1.678,42$ (SD $€ 1.273,24$ ). Table 7.1 shows all costs included in the follow-up for the subgroups. For the patients in the TME subgroup the mean costs per patient for follow-up were $€ 3.260,62$. During the follow-up, a total of 100 out of 187 patients in the TME subgroup $(53,8 \%)$ underwent additional surgery (e.g. anastomosis repair after temporary ileo- or colostoma). For this additional surgery TME patients were 601 days at the regular care unit and 54 days at the ICU. Seventeen patients in this group had complications. The mean costs per patient for this additional surgery were $€ 2.374,90$ (SD 6.982,57) in the TME subgroup. As shown in the oncological paragraph of this paper and Table 7.3, fourteen patients in the TME subgroup had a recurrence or metastasis in the first two years of follow-up. The mean costs per patients of diagnosis and treatment of a recurrence in the TME subgroup were $€ 679,11$ (SD $€ 3.040,06$ ). All hospital costs combined for patients in the TME subgroup resulted in a mean total costs per patients of $€ 17.108,30$ (SD $€ 10.450,35$ ).

Table 7.3 - Oncological outcomes.

\begin{tabular}{lccc}
\hline & W\&W subgroup & TME subgroup & Current triage strategy* $^{*}$ \\
\hline 2-year LRFS & $85,6 \%(n=15)$ & $98,3 \%(n=3)$ & $95,8 \%$ \\
2-year DMFS & $98,0 \%(n=2)$ & $93,4 \%(n=12)$ & $94,3 \%$ \\
2-year OS & $98,1 \%(n=2)$ & $96,8 \%(n=6)$ & $97,1 \%$ \\
\hline
\end{tabular}

LRFS = local recurrence free survival; DMFS = distant metastasis free survival; OS = overall survival; TME = total mesorectal excision; W\&W = watch and wait; ${ }^{*}$ based on $20 \% \mathrm{~W} \& \mathrm{~W}$ and $80 \%$ TME.

Secondly, the hospital costs for the W\&W subgroup were calculated. In the W\&W subgroup no patients underwent primary TME-surgery or additional surgery. Thirty-one patients in the W\&W subgroup underwent adjuvant treatment. The mean costs per patient for adjuvant treatment in the W\&W subgroup were $€ 707,57$ ( $S D € 1.151,76$ ). Patients in the W\&W subgroup had a more frequent follow-up compared with patients who underwent TME surgery. The mean costs per patient for follow-up in the W\&W subgroup were $€ 4.608,58$ (SD $€ 1.170,29$ ). Sixteen patients in the W\&W subgroup were diagnosed with regrowth of the local tumour and/or distant metastases. The mean costs per patient associated with regrowths in the W\&W subgroup were $€ 1.396,59$ (SD 
$3.331,96)$. For the $\mathrm{W} \& \mathrm{~W}$ subgroup the mean total hospital costs per patient were $€ 6.712,74$ (SD €2.963,58).

The costs of the TME- and W\&W subgroups combined, based on $20 \%$ of the patients in the W\&W subgroup and $80 \%$ of the patients in the TME subgroup, resulted in the costs of the current triage policy. In the current triage policy the mean costs per patient for primary TME surgery were $€ 7.292,20$, and $€ 1.899,92$ for additional surgery. The mean costs per patient for adjuvant chemotherapy were $€ 1.484,25$. The mean costs per patient for follow-up were $€ 3.530,21$. For diagnostics and treatment of recurrences, regrowths or distant metastasis, the mean costs per patient were $€ 822,61$. All hospital costs combined, the mean costs per patient for the current triage policy were $€ 15.029,19$.

\section{Discussion}

The aim of this study was to present the oncological results and to calculate the hospital costs of the current triage strategy in which patients with a complete response following CRT are followed up according to W\&W-policy and patients with incomplete response are treated with additional TME. Our study showed a two-year local regrowth free survival of $98.3 \%$ in the TME subgroup and $85.6 \%$ in the W\&W subgroup. Distant metastasis were more common in the TME subgroup, but overall survival was similar in both subgroups. The oncological results of the W\&W subgroup are similar to those written in literature ${ }^{4-9,17,18}$.

This study also showed the overall hospital costs of the current triage policy in patients with locally advanced rectal cancer. Total hospital costs were calculated over a two years follow-up period and included costs for primary surgery, additional surgery, adjuvant treatment, follow-up and recurrences/distant metastasis. The overall mean hospital costs per patient in the current triage policy were $€ 15.029,19$. For the $W \& W$ subgroup the mean costs per patient were $€ 6.712,74$, and for the TME subgroup $€ 17.108,30$.

To our knowledge, this is the first study presenting real-time data of hospital costs in patients with rectal cancer followed in the current triage policy, including a W\&W subgroup. Only two other groups presented results of costs in a W\&Wpolicy, however these results were based on a hypothetical group of patients ${ }^{10,14}$. The paper of Gani et al. ${ }^{10}$ states that the costs of extra MRI and 
rectoscopy were around $€ 6.344$,- in five years of follow-up. Our study showed a difference in follow-up costs of approximately $€ 1.300$,- in two years. In our study all costs for diagnostics (including the costs in the hospital, as well as the costs during outpatient clinic) were combined, this is leading to a smaller differences in follow-up costs. Gani et al. showed costs for immediate radical surgery (including additional surgery costs) were $€ 14.511$,- per patient ${ }^{10}$. Our study showed a total of around $€ 11.500$,- per patient for TME- and additional surgery. In their study they used a local regrowth rate of $25 \%$ for patients in a W\&Wpolicy. This is comparable to the current literature where we see regrowth rates around $16-25 \%{ }^{17,18}$. In our data we had a lower percentage of local regrowth $(14.4 \%)$. Their study concluded that an organ preservation strategy, like the W\&W-strategy has an intensive surveillance using extra MRI and endoscopy, but this will produce costs that are expected to remain below the costs of immediate salvage surgery. This conclusion is in accordance to the results of our study.

The paper of Rao et al. ${ }^{14}$, used a cost-effectiveness model on a hypothetical group of patients. They studied the results in a 60 - and 80 -year-old man cohort with and without significant comorbidities. They concluded that a strategy of the W\&W subgroup is more effective and less costly independent of patient cohort age and comorbidity in patients with a clinical complete response. In our study we could not compare the groups of patients, as we had no comparable baseline characteristics at the moment of decision for W\&W- versus a TME-policy.

\section{Limitations}

This study had some limitations. First of all, we only calculated the costs from a hospital perspective. We did not include the costs outside the healthcare system, like costs for patients and family (in cases of informal care), and costs incurred in other sectors of society, like productivity losses ${ }^{16,19}$. Secondly, we calculated the costs of the first two years of follow-up, while the usual follow-up is five years. However, as most regrowths or recurrent disease occurs in the first two years of follow-up, we assume we included the majority of the events and associated $\operatorname{costs}^{18}$. More research is needed to calculate the costs of the total follow-up of five years. However, we expect that the hospital costs of extra follow-up in the W\&W subgroup remain lower than the costs of TME surgery. Also, we did collect the data of the TME subgroup retrospectively, and we were not able to compare both subgroups as - logically - their characteristics were not 
comparable at the moment of triage. A model-based study is needed in which the cost and effects of the new triage strategy in which patients receive either TME or W\&W based on their clinical response to chemoradiotherapy, is compared to costs and effects of TME in all patients irrespective of clinical response to chemoradiotherapy.

\section{Conclusions}

This study is the first study showing oncological results and hospital costs of the new policy with real-time data over a two-year follow-up period. Oncological results were comparable with literature, with a good overall survival in the W\&Wand TME subgroup. The mean costs per patient in the W\&W subgroup and TME group were $€ 6.713$ and $€ 17.108$ respectively for the first two years. As this was a cohort study where no randomisation could be performed between the two subgroups at time of treatment choice, no actual comparison between the groups could be made. The current strategy, where patient with a CCR are treated with a W\&W-policy, and patients with an incomplete response with TME surgery, is likely to be cost-saving. Besides, the higher costs of follow-up in the W\&W subgroup are far outweighed by the costs of surgery in the TME subgroup. 


\section{References}

1. Sauer R, Becker H, Hohenberger W, Rodel C, Wittekind C, Fietkau R, et al. Preoperative versus postoperative chemoradiotherapy for rectal cancer. N Engl J Med. 2004;351(17): 1731-40.

2. Maas M, Nelemans PJ, Valentini V, Das P, Rodel C, Kuo LJ, et al. Long-term outcome in patients with a pathological complete response after chemoradiation for rectal cancer: a pooled analysis of individual patient data. Lancet Oncol. 2010;11(9):835-44.

3. Martin ST, Heneghan HM, Winter DC. Systematic review and meta-analysis of outcomes following pathological complete response to neoadjuvant chemoradiotherapy for rectal cancer. Br J Surg. 2012;99(7):918-28.

4. Glynne-Jones R, Wallace M, Livingstone JI, Meyrick-Thomas J. Complete clinical response after preoperative chemoradiation in rectal cancer: is a "wait and see" policy justified? Dis Colon Rectum. 2008;51(1):10-9; discussion 9-20.

5. Habr-Gama A, Perez RO, Nadalin W, Sabbaga J, Ribeiro U, Jr., Silva e Sousa AH, Jr., et al. Operative versus nonoperative treatment for stage 0 distal rectal cancer following chemoradiation therapy: long-term results. Ann Surg. 2004;240(4):711-7; discussion 7-8.

6. Maas M, Beets-Tan RG, Lambregts DM, Lammering G, Nelemans PJ, Engelen SM, et al. Waitand-see policy for clinical complete responders after chemoradiation for rectal cancer. J Clin Oncol. 2011;29(35):4633-40.

7. Martens MH, Maas M, Heijnen LA, Lambregts DM, Leijtens JW, Stassen LP, et al. Long-term outcome of an organ preservation program after neoadjuvant treatment for rectal cancer. J Natl Cancer Inst. 2016;108(12).

8. Renehan AG, Malcomson L, Emsley R, Gollins S, Maw A, Myint AS, et al. Watch-and-wait approach versus surgical resection after chemoradiotherapy for patients with rectal cancer (the OnCoRe project): a propensity-score matched cohort analysis. Lancet Oncol. 2016;17(2): 174-83.

9. Smith JD, Ruby JA, Goodman KA, Saltz LB, Guillem JG, Weiser MR, et al. Nonoperative management of rectal cancer with complete clinical response after neoadjuvant therapy. Ann Surg. 2012;256(6):965-72.

10. Gani C, Grosse U, Clasen S, Kirschniak A, Goetz M, Rodel C, et al. Cost analysis of a waitand-see strategy after radiochemotherapy in distal rectal cancer. Strahlentherapie und Onkologie : Organ der Deutschen Rontgengesellschaft [et al]. 2018.

11. Habr-Gama A, Lynn PB, Jorge JM, Sao Juliao GP, Proscurshim I, Gama-Rodrigues J, et al. Impact of organ-preserving strategies on anorectal function in patients with distal rectal cancer Following neoadjuvant chemoradiation. Dis Colon Rectum. 2016;59(4):264-9.

12. Hupkens BJP, Martens MH, Stoot JH, Berbee M, Melenhorst J, Beets-Tan RG, et al. Quality of life in rectal cancer patients after chemoradiation: Watch-and-wait policy versus standard resection - A matched-controlled study. Dis Colon Rectum. 2017;60(10):1032-40.

13. Smith FM, Rao C, Oliva Perez R, Bujko K, Athanasiou T, Habr-Gama A, et al. Avoiding radical surgery improves early survival in elderly patients with rectal cancer, demonstrating complete clinical response after neoadjuvant therapy: results of a decision-analytic model. Dis Colon Rectum. 2015;58(2):159-71.

14. Rao C, Sun Myint A, Athanasiou T, Faiz O, Martin AP, Collins B, et al. Avoiding radical surgery in elderly patients with rectal cancer is cost-effective. Dis Colon Rectum. 2017;60(1):30-42.

15. Punt CJ, Buyse M, Kohne $\mathrm{CH}$, Hohenberger P, Labianca R, Schmoll HJ, et al. Endpoints in adjuvant treatment trials: a systematic review of the literature in colon cancer and proposed definitions for future trials. J Natl Cancer Inst. 2007;99(13):998-1003.

16. Zorginstituut N. Richtlijn voor het uitvoeren van economische evaluaties in de gezondheidszorg. 2016 
17. Dossa F, Chesney TR, Acuna SA, Baxter NN. A watch-and-wait approach for locally advanced rectal cancer after a clinical complete response following neoadjuvant chemoradiation: a systematic review and meta-analysis. Lancet Gastroenterol Hepatol. 2017;2(7):501-13.

18. van der Valk MJM, Hilling DE, Bastiaannet E, Meershoek-Klein Kranenbarg E, Beets GL, Figueiredo NL, et al. Long-term outcomes of clinical complete responders after neoadjuvant treatment for rectal cancer in the International Watch \& Wait Database (IWWD): an international multicentre registry study. Lancet. 2018;391(10139):2537-45.

19. Cihan Gani, Ulrich Grosse, Stephan Clasen, Andreas Kirschniak, Martin Goetz, Claus Rödel, Daniel Zips. Cost analysis of a wait-and-see strategy after radiochemotherapy in distal rectal cancer. Strahlentherapie und Onkology, July 2018 



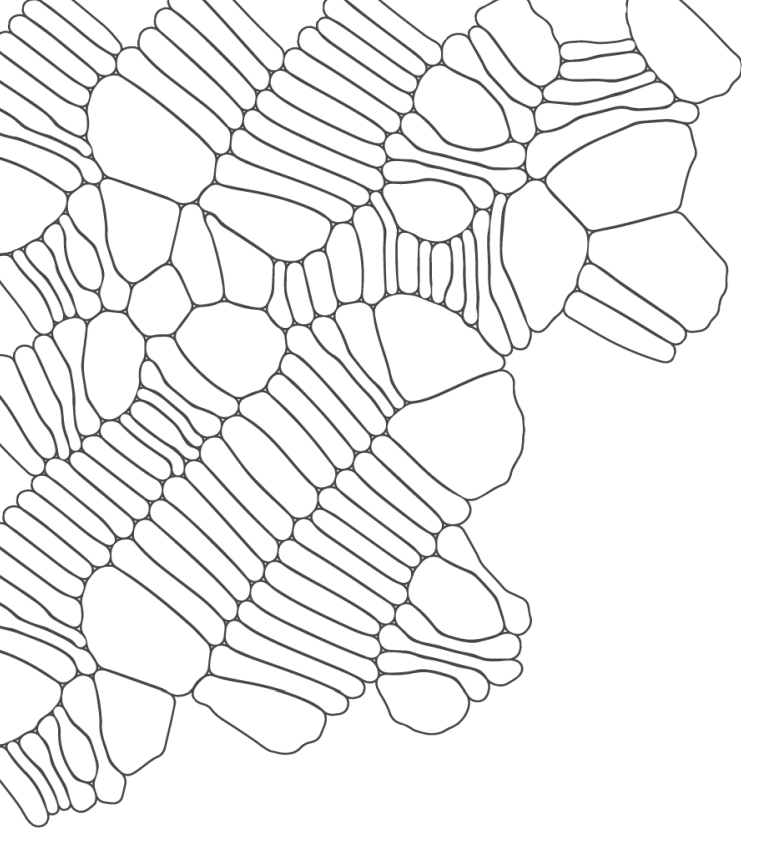

\section{Chapter 8}

General discussion

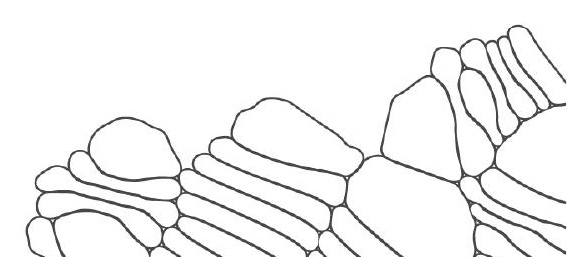


Chapter 8 


\section{General discussion}

Patients with locally advanced rectal cancer are usually treated with neoadjuvant chemoradiation therapy (CRT) and a total mesorectal excision (TME). In approximately $15-20 \%$ of these patients no residual tumour is found after standard resection: a pathologic complete response (pCR: ypTON0) ${ }^{1,2}$. Based on this phenomenon the watch-and-wait policy (W\&W) has been developed, in which patients with a suspected complete response are followed with a stringent follow up instead of surgery ${ }^{3,4}$. One of the prerequisites to offer this organ preserving policy is an accurate selection of patients with a clinical complete response (CCR) after CRT.

Previous studies showed promising oncological results for patients included in the W\&W-policy. Two-year disease-free survival rates of these patients range between $81 \%$ and $92 \%$, and two-year overall survival rates between $97 \%$ and $100 \%^{3-8}$. Given this promising oncological outcome, the research focus has shifted towards answering additional questions relevant to the W\&W-policy regarding selection, follow-up, functional outcome and cost-effectiveness.

This thesis has addressed the following issues: (1) Is it oncologically safe to extend the observation period after CRT to increase the number of patients who can be included in the W\&W-policy? (2) What is the diagnostic performance of MRI to detect recurrences during the follow-up of rectal cancer patient who underwent transanal endoscopic microsurgery (TEM)? (3) What is the quality of life (QoL) in patients in a W\&W-policy? (4) What is the correlation between QoL, anorectal manometric results and radiotherapy doses and fields in W\&W patients? (5) Can we use the low anterior resection syndrome (LARS) score in Dutch rectal cancer patients? And finally, (6) what are the hospital costs if a W\&W-policy becomes part of the clinical management of rectal cancer next to the traditional TME versus a TME resection for all patients after CRT?

\section{Part I - Timing of inclusion and follow-up}

Selection of patients with a cCR was initially performed with very strict selection criteria. Patients could only be included when all diagnostic procedures showed an unequivocal complete response. This resulted in a very small risk of missing residual tumour ${ }^{4,9}$. The downside of this selection strategy was the low sensitivity to detect complete responders of only $50 \%$. Due to the increased interest in the W\&W-policy, this very strict selection strategy that included only patients when 
all diagnostic procedures showed an unequivocal complete response, was gradually adapted to a less strict approach in which a W\&W-policy is also considered in the so called clinical near complete responders (near cCR). For these patients there are two options: (1) extending the observation period with another 6-12 weeks, or (2) a local excision as an 'excision biopsy'.

The first option was evaluated in chapter 2. This study showed that extending the observation period in rectal cancer patients with a near cCR resulted in an increased inclusion of patients in the W\&W-policy, without an apparent impact on overall survival. The 'test of time concept' increased the number of patients eligible for a W\&W policy by $43 \%$. This 'test of time' selection approach was also proposed by Smith et al. ${ }^{10}$, Habr-Gama et al. ${ }^{3}$ and the Royal Marsden UK trial ${ }^{11}$. Adding an additional waiting interval overcomes the issue that current diagnostic techniques are insufficiently accurate to show a true complete response because the rectal mucosa and rectal wall can still be in the healing phase, resulting in a near $\mathrm{CCR}$ on different diagnostic modalities ${ }^{10,12-16}$. From a practical point of view, the traditional assessment 6-8 weeks after completion of CRT is a good starting point. Most patients will have obvious residual tumour that requires surgery. The limitations of the study are that due to the rather short follow-up time in this study it is difficult to estimate the long-term disease free and overall survival. Besides, the small sample size makes it impossible to draw definite conclusions about a difference in the potential risk for distant metastasis between both groups.

The second option, TEM showed good oncological results, but comes with morbidity associated with this procedure, particularly after $\mathrm{CRT}^{17-21}$. Traditionally, TEM was only used for the treatment of early rectal cancer $^{22,23}$. However, it can also be considered as an alternative for TME in small residual tumours after neoadjuvant treatment ${ }^{24,25}$, which provides the advantage of obtaining histopathology. Recurrence rates are lower in patients treated with TEM for early rectal cancer than in patients treated with TEM after neoadjuvant $\mathrm{CRT}^{25-32}$, which stresses the need for an accurate follow-up tool to assess local status and to identify luminal and/or nodal recurrences. In chapter 3 we evaluated the diagnostic performance and interobserver agreement of MRI in the follow-up after TEM for detection of luminal or nodal recurrence. We concluded that postoperative changes can be confusing and difficult to interpret at the first postoperative MRI, with a heterogeneous signal at the TEM location, massive fibrosis and substantial edema in the rectal wall and mesorectal fat. During follow-up the diagnostic performance and reproducibility increased. The most 
important factors that helped both readers in identifying luminal recurrences were the appearance of intermediate signal in the scar and the appearance of diffusion restriction. Diffusion weighted imaging (DWI) can help in identifying recurrences earlier, as shown in earlier literature ${ }^{33-35}$. Detection of a nodal recurrence remains a challenge - just as in primary staging of rectal cancer. Given the very few nodal recurrences in this population it is difficult to draw any robust conclusions on nodal evaluation after TEM. Literature shows an agreement between MRI and histologic assessment of lymph nodes of around $80 \%{ }^{36}$. The first postoperative scan after TEM is difficult to interpret because of a heterogeneous signal at the TEM location, massive fibrosis and substantial edema in the rectal wall and mesorectal fat, which leads to uncertainty in readers. Strikingly, at the first postoperative MRI at 3 months after TEM five recurrences were already found. This finding suggests the need for early imaging of the TEM scar in order not to miss early recurrences and to provide a baseline scan to compare with during further follow-up.

\section{Part II - Quality of life and functional outcome}

In literature, TME has been shown to have negative effects on quality of life in patients with rectal cancer. The most common long-term sequelae are anorectal, sexual and urinary dysfunction ${ }^{37-39}$. Adding radiotherapy can increase these long-term risks for functional problems, most likely because of fibrosis of the rectal wall, the anal sphincter and the urogenital organs ${ }^{40}$. Based on these facts, it is expected that patients who undergo (chemo)radiotherapy and are followed in a W\&W programme, have better functional outcomes and a better QoL than patients treated with CRT and surgery. Until now, only a limited number of studies evaluated QoL and functional outcome in W\&W-patients ${ }^{1,4,6,12}$.

In chapter 4, we compared quality of life between patients who underwent CRT and surgery, and patients who underwent CRT and W\&W. We concluded that patients who remained in a W\&W-approach and did not have a regrowth, had a better quality of life than patients treated with chemoradiation and surgery on several domains. W\&W-patients had fewer defecation problems compared to TME-patients after CRT. Sixty-seven percent of the patients in the TME-group had major LARS symptoms. These findings are in line with the literature showing a relatively high incidence of defecation problems after neoadjuvant CRT followed by TME, compared to TME only ${ }^{40-44}$. This can be explained by the 
pathophysiology of functional problems after surgery. One of the mechanisms is damage to the autonomic nervous system. Even optimal autonomic nerve preserving surgical techniques can lead to sexual dysfunction due to intraoperative stretching or neuropraxia rather than to nerve transection ${ }^{45-47}$. Pelvic radiotherapy induces long term gastro-intestinal morbidity additional to the surgical morbidity. Studies have shown that up to half of all patients undergoing pelvic radiotherapy for various tumours will develop late radiation-induced gastro-intestinal changes which impairs their QoL ${ }^{48,49}$. Conversely, W\&Wpatients showed only mild symptoms, with $36 \%$ major LARS. Patients in a W\&W-strategy only underwent CRT and are not exposed to the risk of surgery and are expected to have fewer of these functional problems. The exact mechanism behind radiation-induced genitourinary dysfunction remains unknown. However, inflammation, fibrosis and vascular changes all appear to be of importance ${ }^{50-52}$, but apparently lead to relatively minor functional problems. Even though sexual dysfunction is a common problem after rectal cancer surgery, we did not find this in our population, probably due to a low response rate to the questionnaires and underreporting due to embarrassment of these symptoms ${ }^{38,50,53-56}$. Rectal cancer surgery is also associated with long-term urinary dysfunction, like incontinence and difficulty in bladder emptying, which was confirmed in our study ${ }^{53-57}$.

Chapter 5 assessed long-term anorectal function and the relationship between the anorectal function and the radiotherapy dose parameters in rectal cancer patients following a W\&W policy. Thirty-three patients were included and underwent anorectal manometry and completed questionnaires (Vaizey and LARS score). Dose-volume histograms for the rectum and anal sphincter complex were calculated and associations between the dose-volume parameters and anorectal function were assessed. This study showed, just like the study in chapter 4 , that one-third of the patients had major LARS, with the most frequent reported complaints of clustering and faecal urgency. Secondly, we observed a trend towards worse long-term anorectal function after a higher radiotherapy dose on the anal sphincter complex. Although we did not find an association between higher planned radiotherapy dose to the anal sphincter complex and lower anal pressures, we did observe low mean anal resting pressures and anal squeeze pressures after CRT when compared to normal values from literature ${ }^{58}$. This is in accordance with other studies showing reduced anal sphincter tone and squeeze pressures after pelvic irradiation ${ }^{59-61}$. Decreased anal pressures have been related to complaints of urgency and 
incontinence specifically ${ }^{62,63}$. Our results may provide support in the rationale for sphincter sparing radiotherapy, however the relation between the dosimetric parameters and the long-term anorectal function in chemoradiation for rectal cancer should be evaluated on a larger scale. Especially with the current interest in radiotherapy to achieve organ preservation in rectal cancer, insights into functional deterioration after radiotherapy are needed, as well as insights into the specific mechanisms of injury. These insights could be of help in further improving radiotherapy delivery and maximize the effect of the tumour while minimizing the detrimental impact on the anorectal function.

Although there is not yet a specific, validated questionnaire to assess anorectal function in W\&W patients, it is generally agreed that the LARS score, developed for patients who underwent a low anterior resection, is a reasonable tool to use. Before using the score in a Dutch population, the in Dutch translated version of the LARS score should be validated and chapter 6 reports on this validation. The results demonstrate that, when applied to a population of Dutch rectal cancer patients, the Dutch version of the LARS score has good psychometric properties and is strongly associated with QoL. The LARS score was able to distinguish between groups of patients who did or did not undergo neoadjuvant radiotherapy, underwent different types of surgery (PME vs. TME), and between patients below 69 years of age or older. There was also a good test-retest reliability. The good psychometric properties of the Dutch version of the LARS score are comparable to the earlier validations in other countries ${ }^{64-67}$. Therefore, the Dutch translation can be considered to be a valid tool for assessing LARS in Dutch rectal cancer patients. It is a clinically relevant tool that is easy to implement in routine practice and research, using only five questions, for assessing bowel dysfunction after rectal cancer treatment.

\section{Part III - Costs}

In chapter 7 we discussed the hospital costs and oncological outcome of the new treatment strategy in locally advanced rectal cancer, in which patients with a clinical complete response after chemoradiotherapy are treated by a watchand-wait-policy. The hospital costs were categorized in five groups: costs of primary TME surgery; costs of adjuvant chemotherapy; costs of examinations; costs of additional surgery; and costs of treatment of regrowth/metastasis. The mean costs per patient were $€ 6.713$ (W\&W) and $€ 17.294$ (TME) over the first 
two years. Only two other studies presented costs of a W\&W policy in patients with locally advanced rectal cancer. The study of Gani et al. ${ }^{68}$ concluded that an organ preservation strategy, like the W\&W-strategy has an intensive surveillance using extra MRI and endoscopy, but this will lead to costs that are expected to remain below the costs of TME surgery after chemoradiotherapy. This conclusion is in accordance to the results of our study. The paper of Rao et al. ${ }^{69}$ concluded that a strategy of the W\&W subgroup is more effective and less costly independent of patient cohort age and comorbidity. In our study, overall survival was good in both the W\&W- and TME subgroup, concordant with findings of other studies ${ }^{3-8,10,70}$. Moreover, the new treatment strategy, where patient with a CCR are treated in a W\&W-policy, and patients with an incomplete response were treated with TME surgery, is likely to be (cost)saving.

\section{Future perspectives}

Major progress has been achieved regarding the evidence synthesis of the W\&W policy since the first publication of Habr-Gama in 2004. However, many questions in organ preservation of rectal cancer have to be answered. The most important current issues are: (1) Is it possible to predict which patients will respond to chemoradiotherapy?; (2) How can we optimize the response assessment to select patients with a $\mathrm{CCR}$, and select non-responders for early surgery; (3) Can the W\&W-approach in advanced tumours be applied in smaller tumours, and what are the differences?; (4) How can we optimize chemoradiotherapy to reduce side effects and to increase the complete response rate?; and (5) What can we learn more about the quality of life?

\section{Prediction of response}

Ideally, the knowledge before CRT about the expected response of tumour could be used to predict which patients are suitable for an organ preservation treatment modality while avoiding futile overtreatment in patients who will not respond. Current modalities are not yet able to accurately predict response before the start of (chemo)radiation. A new approach based on imaging is radiomics. Radiomics is rapidly gaining interest in current cancer research. With radiomics imaging data is used to evaluate tumoral features that are not detectable by visual evaluation, such as heterogeneity, shape and texture. The hypothesis of radiomics is that the microscopic heterogeneity, which is 
associated with cellular biology and molecular markers of the tumour can be captured in the macroscopic heterogeneity of quantitative features on medical imaging $^{71-74}$. Radiomics models predicting the outcome while using clinical and imaging variables, could adjust treatment strategies and lead to more personalized cancer treatment. Main advantages of radiomics are that the data is readily available (standard clinical imaging is used) and that the obtained information is based on the whole tumour volume, which is a clear advantage over biopsies for example ${ }^{71}$. In rectal cancer, recent studies have evaluated the potential of radiomics (but also deep learning) to distinguish responders from non-responders, by selecting radiomics features on pre-CRT MRI ${ }^{75-77}$. Bibault et al. shows that a combination of clinical characteristics and radiomics features has potential to predict patients who will have a $\mathrm{pCR}^{78}$. Additionally, Cui et al. showed that by combining MRI data from T2, T1 and ADC in one radiomics signature even yielded a AUC of 0.94 to predict pathologic $\mathrm{CR}^{79}$. Even though, promising results are found, development and clinical validation of radiomics is still an ongoing process and practical implementation is difficult, as many papers lack data on reproducibility. Therefore, more studies are needed to establish the clinical value of radiomics.

\section{Assessment of response}

At present there are still patients who do not have a clinical complete response on restaging with MRI and endoscopy, while they have a pathological complete response in the surgical TME specimen. This raise the question how to improve the accuracy of the response assessment. Overstaging of residual tumour after (chemo)radiotherapy is mainly due to residual mucosal abnormalities at endoscopy, mixed signal intensity or irregular fibrosis at T2-MRI, diffusion restriction at DWI and residual suspicious lymph nodes. Presence of these features is not definitely associated with residual tumour ${ }^{80}$. Better methods to distinguish tumour from fibrosis after CRT should be developed, and radiologists need to be aware of the current state of the art, as shown in a recent pictorial review of Lambregts et al. ${ }^{81}$. Equally important is to improve the assessment and interpretation of the endoscopy features. A retrospective study of van der Sande et al. evaluated the features of endoscopy. They stated that only a flat scar had a good predictive value for a $\mathrm{CCR}$, and small flat ulcers as possible good responders who could benefit from an extended observation period ${ }^{82}$. 


\section{W\&W in small tumours}

The results of organ preservation in locally advanced rectal cancer are promising. However, smaller tumours, generally treated with surgery alone, are more likely to show a very good response to radiotherapy. The CARTS study showed that in early-stage rectal cancer, CRT with additional TEM surgery enables organ preservation in $64 \%$ of patients with good long-term oncological outcomes and health-related $\mathrm{QoL}^{83}$. In an ongoing multicentre international randomized study, the STAR-TREC trial, early-stage rectal cancer patients ( $\leq \mathrm{CT} 3 \mathrm{~b}, \mathrm{NO}, \mathrm{MO})$ are randomized to either standard TME surgery, organ preserving treatment with long-course concurrent chemoradiation, or organ preserving treatment using short-course radiotherapy. The aim of this phase II study is to demonstrate sufficient recruitment, to sustain a phase III study with pelvic failure as its primary outcome ${ }^{84}$. The question of the phase III trial is if the price that patients pay regarding functional outcome when they still require major TME surgery after radiotherapy is in balance with the improved functional outcome of the other patients in whom organ preservation is successful. In patients with even smaller rectal tumours (high risk T1 and low risk T2) who underwent a local excision, the ongoing TESAR trial is randomizing between direct TME surgery and adjuvant chemoradiotherapy ${ }^{85}$.

\section{Radiotherapy}

The current two main questions regarding radiotherapy are: (1) How can we increase the complete response rate, and (2) How can we minimize the side effects to improve quality of life. Dose escalation most likely will increase the response rates. Increasing response rates can be obtained by increasing the radiotherapy dose, as shown in a modelling review study by Appelt et al. ${ }^{84}$. So far, the results of external beam boosting (EBRT) have been inconsistent. Though EBRT boosting has been shown to be possible from a technical perspective, the obtained increase in CCR rates are not yet convincing. This is probably a result of the limited increase in radiation dose in these studies. Endoluminal irradiation is more selective than EBRT and hence higher tumour radiation doses can be applied to the tumour with the same or even lower doses to the surrounding normal tissues. The results of endoluminal boosting using brachytherapy are very promising: a cCR rate of $78 \%$, with a one-year local recurrence rate of $15,5 \%$ in the CCR group is reported by Appelt et al. Sphincter function was excellent ${ }^{87-89}$. The exact timing of the boosts is still unclear. Is it better to use it at sequential treatment in patients with a near complete 
response, or should it be given as concurrent treatment in patients with predicted good responses? The ideal boost would be highly selective on the tumour with a limited dose to normal tissue, and would lead to a high cCR rate while maintaining good functional outcome.

\section{Functional outcome and QoL}

Although organ preserving treatment showed good results of quality of life in small preliminary studies, the long-term effects are not well documented. The follow-up of previous Dutch watch and wait cohorts and the ongoing Dutch prospective multicentre implementation study will provide more detailed information about the QoL with a longer follow up. In addition to the current QoL assessing tools, a specific, validated questionnaire for organ preserving treatment in rectal cancer should be developed. 


\section{References}

1. Maas M, Nelemans PJ, Valentini V, et al. Long-term outcome in patients with a pathological complete response after chemoradiation for rectal cancer: a pooled analysis of individual patient data. Lancet. Oncol. 2010;11(9):835-44.

2. Martin ST, Heneghan HM, Winter DC. Systematic review and meta-analysis of outcomes following pathological complete response to neoadjuvant chemoradiotherapy for rectal cancer. Br J Surg. 2012;99(7):918-28.

3. Habr-Gama A, Perez RO, Nadalin W, et al. Operative versus nonoperative treatment for stage 0 distal rectal cancer following chemoradiation therapy: long-term results. Ann Surg. 2004;240(4):711-7; discussion 717-8.

4. Maas M, Beets-Tan RG, Lambregts DM, et al. Wait-and-see policy for clinical complete responders after chemoradiation for rectal cancer. J Clin Oncol. 2011;29(35):4633-40.

5. Glynne-Jones R, Wallace M, Livingstone JI, Meyrick-Thomas J. Complete clinical response after preoperative chemoradiation in rectal cancer: is a "wait and see" policy justified? Dis Colon Rectum. 2008;51(1):10-9; discussion 19-20.

6. Martens MH, Maas M., Heijnen, L.A., Lambregts, D.M., Leijtens, J.W., Stassen, L.P., Breukink, S.O., Hoff, C., Belgers, E.J., Melenhorst, J., Jansen, R., Buijsen, J., Hoofwijk, T.G., Beets-Tan, R.G., Beets, G.L. Long-term outcome of an organ preservation program after neoadjuvant treatment for rectal cancer. J Natl Cancer Inst. 2016;108(12).

7. Renehan AG, Malcomson L, Emsley R, et al. Watch-and-wait approach versus surgical resection after chemoradiotherapy for patients with rectal cancer (the OnCoRe project): a propensity-score matched cohort analysis. Lancet. Oncol. 2016;17(2):174-83.

8. van der Valk MJM, Hilling DE, Bastiaannet $E$ et al. Long-term outcomes of clinical complete responders after neoadjuvant treatment for rectal cancer in the International Watch \& Wait Database (IWWD): an international multicentre registry study. Lancet. 2018;391(10139): 2537-45.

9. Maas M, Lambregts DM, Nelemans PJ, et al. Assessment of Clinical Complete Response After Chemoradiation for Rectal Cancer with Digital Rectal Examination, Endoscopy, and MRI: Selection for Organ-Saving Treatment. Ann Surg Oncol. 2015;22(12):3873-80.

10. Smith JD, Ruby JA, Goodman KA, et al. Nonoperative management of rectal cancer with complete clinical response after neoadjuvant therapy. Ann Surg. 2012;256(6):965-72.

11. West MA, Dimitrov BD, Moyses HE, et al. Timing of surgery following neoadjuvant chemoradiotherapy in locally advanced rectal cancer - A comparison of magnetic resonance imaging at two time points and histopathological responses. Eur J Surg Oncol. 2016;42(9): 1350-8.

12. Habr-Gama A, Lynn PB, Jorge JM, et al. Impact of Organ-Preserving Strategies on Anorectal Function in Patients with Distal Rectal Cancer Following Neoadjuvant Chemoradiation. Dis Colon Rectum. 2016;59(4):264-9.

13. Hughes R, Harrison M, Glynne-Jones R. Could a wait and see policy be justified in T3/4 rectal cancers after chemo-radiotherapy? Acta Oncol. 2010;49(3):378-81.

14. Lim L, Chao M, Shapiro J, et al. Long-term outcomes of patients with localized rectal cancer treated with chemoradiation or radiotherapy alone because of medical inoperability or patient refusal. Dis Colon Rectum. 2007;50(12):2032-9.

15. Nahas SC, Rizkallah Nahas CS, Sparapan Marques CF, et al. Pathologic complete response in rectal cancer: Can we detect it? Lessons learned from a proposed randomized trial of watchand-wait treatment of rectal cancer. Dis Colon Rectum. 2016;59(4):255-63.

16. Nakagawa WT, Rossi BM, de OFF, et al. Chemoradiation instead of surgery to treat mid and low rectal tumours: is it safe? Ann Surg Oncol. 2002;9(6):568-73.

17. Coco C, Rizzo G, Mattana C, et al. Transanal endoscopic microsurgery after neoadjuvant radiochemotherapy for locally advanced extraperitoneal rectal cancer: short-term morbidity and functional outcome. Surg Endosc. 2013;27(8):2860-7. 
18. Garcia-Aguilar J, Renfro LA, Chow OS, et al. Organ preservation for clinical T2NO distal rectal cancer using neoadjuvant chemoradiotherapy and local excision (ACOSOG Z6041): results of an open-label, single-arm, multi-institutional, phase 2 trial. Lancet. Oncol. 2015;16(15): 1537-46.

19. Lezoche G, Baldarelli M, Guerrieri M, et al. A prospective randomized study with a 5-year minimum follow-up evaluation of transanal endoscopic microsurgery versus laparoscopic total mesorectal excision after neoadjuvant therapy. Surg Endosc. 2008;22(2):352-8.

20. Perez RO, Habr-Gama A, Sao Juliao GP, et al. Transanal Endoscopic Microsurgery (TEM) Following Neoadjuvant Chemoradiation for Rectal Cancer: Outcomes of Salvage Resection for Local Recurrence. Ann Surg Oncol. 2016;23(4):1143-8.

21. Perez RO, Habr-Gama A, Sao Juliao GP, Proscurshim I, Scanavini Neto A, Gama-Rodrigues J. Transanal endoscopic microsurgery for residual rectal cancer after neoadjuvant chemoradiation therapy is associated with significant immediate pain and hospital readmission rates. Dis Colon Rectum. 2011;54(5):545-51.

22. Tytherleigh MG, Warren BF, Mortensen NJ. Management of early rectal cancer. Br J Surg. 2008;95(4):409-23.

23. Borschitz T, Gockel I, Kiesslich R, Junginger T. Oncological outcome after local excision of rectal carcinomas. Ann Surg Oncol. 2008;15(11):3101-8.

24. Verseveld $\mathrm{M}$, de Graaf EJ, Verhoef $\mathrm{C}$, et al. Chemoradiation therapy for rectal cancer in the distal rectum followed by organ-sparing transanal endoscopic microsurgery (CARTS study). $\mathrm{Br}$ J Surg. 2015;102(7):853-60.

25. Lezoche E, Guerrieri M, Paganini AM, et al. Transanal endoscopic versus total mesorectal laparoscopic resections of T2-NO low rectal cancers after neoadjuvant treatment: a prospective randomized trial with a 3-years minimum follow-up period. Surg Endosc. 2005;19(6):751-6.

26. Restivo A, Zorcolo L, D'Alia G, et al. Risk of complications and long-term functional alterations after local excision of rectal tumours with transanal endoscopic microsurgery (TEM). Int $J$ Colorectal Dis. 2016;31(2):257-66.

27. Serra-Aracil X, Vallverdu $H$, Bombardo-Junca J, Pericay-Pijaume C, Urgelles-Bosch J, Navarro-Soto S. Long-term follow-up of local rectal cancer surgery by transanal endoscopic microsurgery. World J Surg. 2008;32(6):1162-7.

28. Steinhagen E, Chang G, Guillem JG. Initial experience with transanal endoscopic microsurgery: the need for understanding the limitations. J Gastrointest Surg. 2011;15(6): 958-62.

29. Allaix ME, Arezzo A, Caldart M, Festa F, Morino M. Transanal endoscopic microsurgery for rectal neoplasms: experience of 300 consecutive cases. Dis Colon Rectum. 2009;52(11): 1831-6.

30. Buess G. Review: transanal endoscopic microsurgery (TEM). J R Coll Surg Edinb. 1993;38(4):239-45.

31. De Graaf EJ, Doornebosch PG, Tollenaar RA, et al. Transanal endoscopic microsurgery versus total mesorectal excision of T1 rectal adenocarcinomas with curative intention. Eur $\mathrm{J}$ Surg Oncol. 2009;35(12):1280-5.

32. Lebedyev A, Tulchinsky H, Rabau M, Klausner JM, Krausz M, Duek SD. Long-term results of local excision for T1 rectal carcinoma: the experience of two colorectal units. Techn Coloproctol. 2009;13(3):231-6.

33. Lambregts DM, Maas M, Bakers FC, et al. Long-term follow-up features on rectal MRI during a wait-and-see approach after a clinical complete response in patients with rectal cancer treated with chemoradiotherapy. Dis Colon Rectum. 2011;54(12):1521-8.

34. Lambregts DM, Vandecaveye $V$, Barbaro $B$, et al. Diffusion-weighted MRI for selection of complete responders after chemoradiation for locally advanced rectal cancer: a multicenter study. Ann Surg Oncol. 2011;18(8):2224-31. 
35. van der Paardt MP, Zagers MB, Beets-Tan RG, Stoker J, Bipat S. Patients who undergo preoperative chemoradiotherapy for locally advanced rectal cancer restaged by using diagnostic MR imaging: a systematic review and meta-analysis. Radiology. 2013;269(1): 101-12.

36. Park JS, Jang YJ, Choi GS et al. Accuracy of preoperative MRI in predicting pathology stage in rectal cancers: node-for-node matched histopathology validation of MRI features. Dis Colon Rectum 2014;57(1):32-8.

37. Harji DP, Griffiths B, Velikova G, Sagar PM, Brown J. Systematic review of health-related quality of life in patients undergoing pelvic exenteration. Eur J Surg Oncol. 2016;42(8):1132-45.

38. Sun V, Grant M, Wendel CS, et al. Sexual function and health-related quality of life in long-term rectal cancer survivors. J Sex Med. 2016;13(7):1071-9.

39. Wiltink LM, Nout RA, van der Voort van Zyp JR, et al. Long-term health-related quality of life in patients with rectal cancer after preoperative short-course and long-course (Chemo) radiotherapy. Clin Colorectal Cancer. 2016;15(3):e93-9.

40. Bregendahl S, Emmertsen KJ, Lous J, Laurberg S. Bowel dysfunction after low anterior resection with and without neoadjuvant therapy for rectal cancer: a population-based crosssectional study. Colorectal Dis. 2013;15(9):1130-9.

41. Ozgen Z, Ozden S, Atasoy BM, Ozyurt H, Gencosmanoglu R, Imeryuz N. Long-term effects of neoadjuvant chemoradiotherapy followed by sphincter-preserving resection on anal sphincter function in relation to quality of life among locally advanced rectal cancer patients: a crosssectional analysis. Radiation Oncol. 2015;10:168.

42. Maris A, Penninckx F, Devreese AM, et al. Persisting anorectal dysfunction after rectal cancer surgery. Colorectal Dis. 2013;15(11):e672-9.

43. Ekkarat $\mathrm{P}$, Boonpipattanapong $\mathrm{T}$, Tantiphlachiva $\mathrm{K}$, Sangkhathat $\mathrm{S}$. Factors determining low anterior resection syndrome after rectal cancer resection: A study in Thai patients. Asian J Surg. 2016;39(4):225-31.

44. Horisberger K, Rothenhoefer S, Kripp M, Hofheinz RD, Post S, Kienle P. Impaired continence function five years after intensified chemoradiation in patients with locally advanced rectal cancer. Eur J Surg Oncol. 2014;40(2):227-33.

45. Zedan A, Salah T. Total mesorectal excision for the treatment of rectal cancer. Electron Physician. 2015;7(8):1666-72.

46. Duran E, Tanriseven M, Ersoz N, et al. Urinary and sexual dysfunction rates and risk factors following rectal cancer surgery. Int J Colorectal Dis. 2015;30(11):1547-55.

47. Beraldo FB, Yusuf SA, Palma RT, Kharmandayan S, Goncalves JE, Waisberg J. Urinary Dysfunction after Surgical Treatment for Rectal Cancer. Arquivos Gstroenterol. 2015;52(3): 180-5.

48. Olopade FA, Norman A, Blake P, et al. A modified Inflammatory Bowel Disease questionnaire and the Vaizey Incontinence questionnaire are simple ways to identify patients with significant gastrointestinal symptoms after pelvic radiotherapy. Br J Cancer. 2005;92(9):1663-70.

49. Andreyev HJ, Wotherspoon A, Denham JW, Hauer-Jensen M. Defining pelvic-radiation disease for the survivorship era. Lancet. Oncol. 2010;11(4):310-2.

50. Bregendahl S, Emmertsen KJ, Lindegaard JC, Laurberg S. Urinary and sexual dysfunction in women after resection with and without preoperative radiotherapy for rectal cancer: a population-based cross-sectional study. Colorectal Dis. 2015;17(1):26-37.

51. Havenga K, Maas CP, DeRuiter MC, Welvaart K, Trimbos JB. Avoiding long-term disturbance to bladder and sexual function in pelvic surgery, particularly with rectal cancer. Semin Surg Oncol. 2000;18(3):235-43.

52. Jensen PT, Froeding LP. Pelvic radiotherapy and sexual function in women. Transl Androl Urol. 2015;4(2):186-205.

53. Lange MM, van de Velde CJ. Urinary and sexual dysfunction after rectal cancer treatment. Nat Rev Urol. 2011;8(1):51-7. 
54. Breukink SO, van der Zaag-Loonen HJ, Bouma EM, et al. Prospective evaluation of quality of life and sexual functioning after laparoscopic total mesorectal excision. Dis Colon Rectum. 2007;50(2):147-55.

55. Eveno C, Lamblin A, Mariette C, Pocard M. Sexual and urinary dysfunction after proctectomy for rectal cancer. J Visceral Surg. 2010;147(1):e21-30.

56. Lange MM, Maas CP, Marijnen CA, et al. Urinary dysfunction after rectal cancer treatment is mainly caused by surgery. Br J Surg. 2008;95(8):1020-8.

57. Benoist S, Panis $Y$, Denet C, Mauvais F, Mariani P, Valleur P. Optimal duration of urinary drainage after rectal resection: a randomized controlled trial. Surgery. 1999;125(2):135-41.

58. Gundling $\mathrm{F}$, Seidl $\mathrm{H}$, Scalercio $\mathrm{N}$ et al. Influence of gender and age on anorectal function: normal values from anorectal manometry in a large caucasian population. Digestion. 2010;81(4):207-13.

59. Berndtsson I, Lennernas B, Hulten L. Anorectal function after modern conformal radiation therapy for prostate cancer: a pilot study. Techn Coloproctol. 2002;6(2):101-4.

60. Yeoh EK, Russo A, Botten R et al. Acute effects of therapeutic irradiation for prostatic carcinoma on anorectal function. Gut. 1998;43(1):123-7.

61. Bregendahl $\mathrm{S}$, Emmertsen $\mathrm{KJ}$, Fassov $\mathrm{J}$ et al. Neorectal hyposensitivity after neoadjuvant therapy for rectal cancer. Radiotherapy Oncol. 2013;108(2):331-6.

62. Smeenk RJ, Hopman WP, Hoffmann AL et al. Differences in radiation dosimetry and anorectal function testing imply that anorectal symptoms may arise from different anatomic substrates. Int J Radiat Oncol Biol Phys. 2012;82(1):145-52.

63. Krol R, Smeenk RJ, van Lin EN et al. Systematic review: anal and rectal changes after radiotherapy for prostate cancer. Int J Colorectal Dis. 2014;29(3):273-83.

64. Juul T, Battersby NJ, Christensen $P$ et al. Validation of the English Translation of the Low Anterior Resection Syndrome Score (The LARS score). Colorectal Dis. 2015;17(10):908-16

65. Hou XT, Pang D, Lu Q et al. Validation of the Chinese version of the low anterior resection syndrome score for measuring bowel dysfunction after sphincter-preserving surgery among rectal cancer patients. Eur J Oncol Nurs 2015;19(5):495-501

66. Samalavicius NE, Dulskas A, Lasinskas $M$ et al. Validity and reliability of a Lithuanian version of low anterior resection syndrome score. Techn Coloproctoly 2016;20:215-20.

67. Juul $\mathrm{T}$, Ahlberg $\mathrm{M}$, Biondo $\mathrm{S}$ et al. International validation of the low anterior resection syndrome score. Ann Surg. 2014;259:728-34.

68. Gani C, Grosse U, Clasen S et al. Cost analysis of a wait-and-see strategy after radiochemotherapy in distal rectal cancer. Strahlentherapie und Onkologie. 2018.

69. Rao C, Sun Myint A, Athanasiou $T$ et al. Avoiding radical surgery in elderly patients with rectal cancer is cost-effective. Dis Colon Rectum. 2017;60(1):30-42.

70. Dossa F, Chesney TR, Acuna SA et al. A watch-and-wait approach for locally advanced rectal cancer after a clinical complete response following neoadjuvant chemoradiation: a systematic review and meta-analysis. Lancet Gastroenterol Hepatol. 2017;2(7):501-13.

71. Morin $\mathrm{O}$, Valliéres $\mathrm{M}$, Jochems $\mathrm{A}$ et al. A deep look into the future of quantitative imaging in oncology: a statement of working principles and proposal for change. Int J Radiation Oncol Biol Phys. 2018;102:1074-82.

72. Segal $\mathrm{E}$, Sirlin $\mathrm{CB}$, Ooi $\mathrm{C}$, et al. Decoding global gene expression programs in liver cancer by noninvasive imaging. Nat Biotechnol. 2007;25:675-80.

73. El Naqa I, Grigsby P, Apte A, et al. Exploring feature-based approaches in PET images for predicting cancer treatment outcomes. Pattern Recognit. 2009;42:1162-71.

74. Lambin P, Rios-Velazquez E. Leijenaar R, et al. Radiomics: Extracting more information from medical images using advanced feature analysis. Eur J Cancer. 2012;48:441-6.

75. Liu Z, Zhang X-Y, Shi Y-J et al. Radiomics analysis for evaluation of pathological complete response to neoadjuvant chemoradiotherapy in locally advanced rectal cancer. Clin Cancer Res. 2017;23(23):7253-62. 
76. Cui $Y$, Yang $X$, Shi Z, et al. Radiomics analysis of multiparametric MRI for prediction of pathological complete response to neoadjuvant chemoradiotherapy in locally advanced rectal cancer. Eur Radiol. 2019;29(3):1211-20.

77. Cusumano D, Dinapoli N, Luca Boldrini et al. Fractal-based radiomic approach to predict complete pathological response after chemo-radiotherapy in rectal cancer. Radiol Med. 2018;123:286-95.

78. Bibault JE, Giraud $P$, Housset $M$ et al. Deep Learning and Radiomics predict complete response after neo-adjuvant chemoradiation for locally advanced rectal cancer. Sci Rep. 2018;8(1):12611.

79. Cui $Y$, Yang $X$, Shi $Z$ et al. Radiomics analysis of multiparametric MRI for prediction of pathological complete response to neoadjuvant chemoradiotherapy in locally advanced rectal cancer. Eur Radiol. 2019;29(3):1211-20.

80. van der Sande ME, Beets GL, Hupkens BJP et al. Response assessment after (chemo)radiotherapy for rectal cancer: Why are we missing complete responses with MRI and endoscopy? Eur J Surg Oncol. 2019;45(6):1011-7.

81. Lambregts DMJ, Boellaard TN and Beets-Tan RGH. Response evaluation after neoadjuvant treatment for rectal cancer using modern MR imaging: a pictorial review. Insights Imaging. 2019;10(1):15.

82. van der Sande ME, Maas M, Melenhorst et al. Predictive value of endoscopic features for a complete response after chemoradiotherapy for rectal cancer. Unplubished data.

83. Stijns RCH, de Graaf EJR, Punt CJA et al. Long-term oncological and functional outcomes of chemoradiotherapy followed by organ-sparing transanal endoscopic microsurgery for distal rectal cancer: The CARTS Study. JAMA Surg. 2019154(1):47-54.

84. Rombouts AJM, Al-Najami I, Abbott NL et al. Can we Save the rectum by watchful waiting or TransAnal microsurgery following (chemo) Radiotherapy versus Total mesorectal excision for early REctal Cancer (STAR-TREC study)?: protocol for a multicentre, randomised feasibility study. BMJ Open. 2017;7(12):e019474.

85. Borstlap WA, Tanis PJ, Koedam TW et al. A multi-centred randomised trial of radical surgery versus adjuvant chemoradiotherapy after local excision for early rectal cancer. BMC Cancer. 2016;16:513.

86. Appelt AL, Pløen J, Vogelius IR et al. Radiation dose-response model for locally advanced rectal cancer after preoperative chemoradiation therapy. Int J Radiat Oncol Biol Phys. 2013; 85(1):74-80).

87. Appelt AL, Pløen J, Harling $\mathrm{H}$ et al. High-dose chemoradiotherapy and watchful waiting for distal rectal cancer: a prospective observational study. Lancet Oncol. 2015;16(8):919-27.

88. Gerard JP, Chapet $\mathrm{O}, \mathrm{Nemoz} \mathrm{C}$ et al. Improved sphincter preservation in low rectal cancer with high-dose preoperative radiotherapy: the lyon R96-02 randomized trial. J Clin Oncol. 2004; 22(12):2404-9

89. Verrijssen AS, Opbroek T, Bellezzo M et al. A systematic review comparing radiation toxicity after various endorectal techniques. Brachytherapy. 2019;18(1):71-86.e5. 


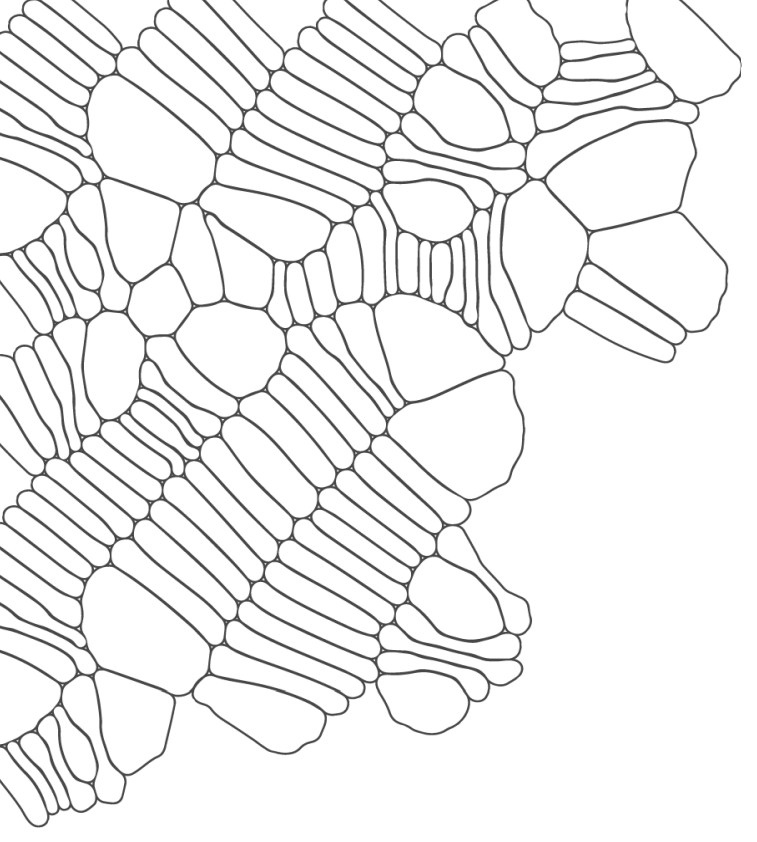

Chapter

Summary

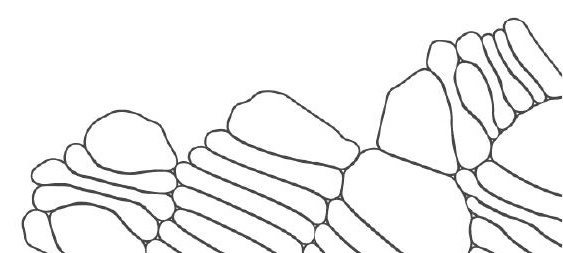


Chapter 9 


\section{Summary}

Patients with locally advanced and distal rectal cancer are often treated with long course chemoradiation (CRT), followed by a waiting period prior to surgery. In $10-20 \%$ of the patients treated with CRT, the definitive histology shows a pathological complete response ( $p C R$ ). These patients can be treated with an organ saving policy, the so-called watch-and-wait policy (W\&W). These patients enter a stringent follow-up protocol instead of surgery. Several reported series show good oncological results for these patients. However, there are still several remaining questions regarding the W\&W policy.

The aims of this thesis are: (chapter 2) to evaluate if it is oncologically safe to extend the observation period after CRT to increase the number of patients who can be included in the W\&W group; (chapter 3) to evaluate the diagnostic performance of follow-up MRI for the detection of local recurrences of rectal cancer after transanal endoscopic microsurgery (TEM); (chapter 4) to compare quality of life between patients following a W\&W policy to patients treated with standard treatment (CRT and surgery); (chapter 5) to assess the impact of chemoradiotherapy on anorectal function in patients included in the W\&W-group; (chapter 6) to validate the Dutch translation of the Low Anterior Resection Syndrome (LARS) score in Dutch rectal cancer patients, and (chapter 7) to assess the hospital costs and oncological outcome of the rectal cancer treatment between W\&W patients and standard care (CRT and surgery).

\section{Part I - patient selection and follow-up}

Due to an increased interest in the W\&W-policy, more patients have a reevaluation with MRI and endoscopy after chemoradiation. Some patients have a very good response, with however still some minor or equivocal findings on endoscopy and MRI, a so-called 'clinical near complete response (near cCR)'. Because of the favourable experience with typical complete responders, patients with a near CCR are increasingly considered for organ preservation as well. Patients with a near cCR can be treated either with a local excision, or an extended observation period, or surgical treatment. With a second assessment after 6-12 weeks, patients with a near cCR can develop a clinical complete response (cCR). 
In chapter 2 we assessed whether patients with a near complete response that progresses to a complete response have an impaired oncological outcome with a W\&W-policy when compared to complete responders at the first restaging.

We followed 170 patients, of which 102 patients had a CCR after CRT and entered the W\&W immediately (W\&W1). Of the 68 patients with a near cCR, 19 patients underwent TEM-surgery and 49 patients opted for second restaging after 6-12 weeks. $44 / 49$ (90\%) of these patients showed a CCR at the second restaging and entered the W\&W2. Patients in the W\&W2 showed a nonsignificant increase in local regrowth rate, without impact on the overall survival after two years. Therefore, it seems fair to extend the observation period rather than to proceed to surgery in patients with a near complete response.

Transanal endoscopic surgery (TEM) is used for the treatment of adenomas and some early rectal cancers. Recently, TEM has also been proposed as an alternative for total mesorectal excision (TME) in small residual tumours after neoadjuvant treatment, in line with the increasing interest for organ preservation after neoadjuvant treatment. This increased indication to use TEM stresses the need for an accurate follow-up tool to assess local status and to identify both luminal and nodal recurrences. Therefore, the aim of chapter 3 was to evaluate the diagnostic performance of follow-up MRI for detection of local recurrence of rectal cancer after TEM.

Two expert readers evaluated 293 MRIs of 81 patients who underwent TEM. 18 patients developed a local recurrence. Areas under the curve (AUC) and reproducibility were moderate too good for recurrence detection and increased during follow-up. We concluded that follow-up with MRI after TEM for rectal cancer is feasible.

\section{Part II - quality of life and functional outcome}

In chapter 4 quality of life (QoL) of the W\&W-policy is compared to the standard treatment of locally advanced rectal cancer (chemoradiation and surgery). The main goal of the W\&W-policy is an anticipated improved quality of life and functional outcome compared to a TME, while maintaining a good oncological outcome.

The study population of the matched controlled multicentre study consisted of two groups: 41 patients were included in a W\&W-policy and 41 were included patients after chemoradiation and TME. Patients were matched on sex, age, 
tumour stage and tumour height. Patients were disease-free at moment of recruitment and had at least two years of follow-up. The QoL was measured by validated questionnaires. The SF-36 and EORTC QLQ-C30 were used to measure general QoL, the EORTC QLQ-CR38 for disease specific QoL, the Vaizey- and LARS-score for defecation problems, IIEF and FSFI for sexual problems and the IPSS for urinary dysfunction. Patients who were followed in a W\&W-policy had a better QoL on almost all domains, compared to patients treated with CRT and TME. However, chemoradiation therapy on its own is not without long term side-effects, as one third of the watch-and-wait-patients suffered from major LARS symptoms.

It is known that CRT in rectal cancer patients may impair the bowel function. In patients treated with CRT and surgery it is not possible to distinguish if the dysfunction is caused by radiation from that caused by surgery. Also, we don't know whether there is a relationship between the severity of anorectal dysfunction and the radiotherapy dose. W\&W-patients have only undergone CRT and are therefore the ideal group to assess the morbidity of CRT alone. In chapter $\mathbf{5}$ we assessed whether there is a relation between the long-term anorectal function and the radiotherapy doses.

The long-term anorectal function was assessed by using the LARS score, Vaizey questionnaire and manometry. The radiotherapy dose was assessed using radiotherapy dose-volume histogram parameters of the rectum and anal sphincter complex.

Thirty-three patients were included in this analysis, with a median follow-up of 37 months. There was a trend for an association of a higher dose to the sphincter complex $\left(D_{\max }, V_{30 G y}, V_{35 G y}, V_{40 G y}\right)$ and a worse Vaizey incontinence score and for the association of a high $D_{\text {mean }}$ of the anal sphincter complex and a worse LARS outcome. The most frequent complaints were clustering and faecal urgency. Regarding the radiotherapy dose on the rectum, the $V_{35 G y}$ and $V_{40 G y}$ were related to higher Vaizey scores. There were no relations found between the dosimetric parameters and anorectal sensory function (first sensation (FS), first urge to defecate (FUTD), and maximal tolerable volume (MTV)). All dosimetric parameters of the anal sphincter complex, except for $V_{50 G y}$, were positively correlated with mean squeeze pressure (MSP), showing that a higher dosis of radiotherapy leads to an impaired functional outcome. The outcomes of the present study should be interpreted with care. The analyses were based on a relatively small group of patients, which made it impossible to do subgroup analyses. There is only information at one single time point and there is no 
validated questionnaire available assessing functional outcome in W\&W patients.

Despite these limitations, this is the first study to explore the specific effects of (chemo)radiation in W\&W patients on the anorectal function. It is important to understand these mechanisms as it will be anticipated that more and more patients will be offered an organ preserving treatment in the future. Together with the oncological data, it is important to discuss functional outcome with patients as well. This information may help patients to cope better with post treatment recovery.

Nowadays, still the majority of patients with rectal cancer is treated with sphincter-sparing surgery, a low anterior resection (LAR). It is known that $50-90 \%$ of these patients had at least some degree of bowel dysfunction after surgery. This is called the Low Anterior Resection Syndrome (LARS), including incontinence for faeces and/or flatus, constipation, urgency, fragmentation and frequent bowel movements. Because of the severity and high incidence of these problems, the LARS score was developed. The aim of the study in chapter 6 was to validate the Dutch translation of the LARS score in a population of Dutch rectal cancer patients who underwent a low anterior resection.

The original Danish version of the LARS score was translated to English and subsequently to Dutch. Dutch patients who underwent a low anterior resection for rectal cancer received the LARS score questionnaire, an extra single QoL question and the EORTC QLQ-C30 questionnaire. A subgroup of patients received the LARS score twice to assess the test-retest reliability. In this study 165 patients were included in the analyses, identified in six participating centres. The response rate was $62.0 \%$. The percentage of patients who reported 'major LARS' was $59.4 \%$. There was a high proportion of patients with a perfect or moderate fit between QoL category and LARS score, which makes the LARS score a good tool to assess bowel dysfunction. The LARS score was able to discriminate between patient with(out) neoadjuvant radiotherapy, between total and partial mesorectal excision (TME vs. PME) and between age groups. Besides, the reliability of the LARS score was good, with an interclass correlation coefficient of 0.79 . This study showed that the Dutch version of the LARS score has good psychometric properties and is therefore considered to be a valid tool for assessing LARS in Dutch rectal cancer patients. 


\section{Part III - costs}

In chapter 7 we discussed the hospital costs and oncological outcome of the new treatment strategy in locally advanced rectal cancer, in which patients with a clinical complete response after chemoradiotherapy are treated by a watchand-wait-policy and patients with no clinical complete response are treated with surgery.

Hospital costs were divided in five groups: costs of primary TME surgery; costs of adjuvant chemotherapy; costs of examinations; costs of additional surgery; and costs of treatment of regrowth/metastasis. The mean costs per patients in the first two years were $€ 6.713$ in the W\&W subgroup and $€ 17.294$ in the TMEsubgroup. The overall survival was good in both groups, the W\&W- and TME group respectively. Moreover, the new treatment strategy, where patient with a CCR are treated in a W\&W-policy, and patients with an incomplete response were treated with TME surgery, is likely to be (cost)saving. 

Chapter 10 


\section{Nederlandse samenvatting}

Patiënten met een stadium III rectumcarcinoom worden voorbehandeld met langdurige chemoradiatie (CRT) gevolgd door een wachtperiode en vervolgens chirurgie. $\mathrm{Bij} 10$ tot $20 \%$ van de rectumcarcinoompatiënten die behandeld worden met CRT, zorgt dit voor een pathologisch complete respons in het operatiepreparaat. Patiënten met een klinisch complete respons (cCR) kunnen behandeld worden met een orgaansparende behandeling in plaats van chirurgie. In zo'n orgaansparende behandeling, het watch-and-wait beleid (W\&W), worden patiënten frequent gecontroleerd in plaats van een operatie. In de huidige literatuur laten diverse onderzoeken zien dat de oncologische resultaten van dit W\&W-beleid goed zijn. Echter zijn er nog meerdere vragen rondom de W\&Wbehandeling onbeantwoord. In dit proefschrift zullende verschillende van deze vragen beantwoord worden.

De doelen van deze thesis zijn: (hoofdstuk 2) evalueren of het oncologisch veilig is de wachtperiode te verlengen na CRT om zo het aantal patiënten dat geïncludeerd kan worden in een W\&W beleid te vergroten; (hoofdstuk 3) het evalueren van de diagnostische waarde van follow-up MRI voor het herkennen van lokale recidieven van het rectumcarcinoom na behandeling met transanale endoscopische microchirurgie (TEM); (hoofdstuk 4) het vergelijken van de kwaliteit van leven tussen W\&W patiënten en patiënten die behandeld zijn met CRT en chirurgie; (hoofdstuk 5) het bepalen van de impact van CRT op de anorectale functie van W\&W patiënten; (hoofdstuk 6) het valideren van de Nederlandse vertaling van de LARS-score in een groep van Nederlandse patiënten met een rectumcarcinoom, en (hoofdstuk 7) het bepalen van de ziekenhuiskosten en de oncologische uitkomsten van de behandeling van het rectumcarcinoom in een W\&W en een TME subgroep (standaard behandeling).

\section{Deel I - patiëntselectie en follow-up}

Door de toenemende kennis over de W\&W-behandeling en de daarbij behorende goede oncologische resultaten, is er steeds meer interesse in een orgaansparende optie. Hierdoor zijn er steeds meer patiënten die na de behandeling met CRT in aanmerking willen komen voor een W\&W-behandeling, onafhankelijk van de respons. Waarbij eerder alleen patiënten met een cCR in aanmerking kwamen voor een W\&W-behandeling, wordt er nu ook gekeken of er bij patiënten die nog geen volledig complete respons hebben (in het Engels, 
near complete response ( $\mathrm{nCR})$ ) een mogelijkheid bestaat tot het ondergaan van een W\&W-behandeling. Patiënten met een nCR hebben drie opties: (1) een chirurgische ingreep (TME); (2) behandeling met een lokale excisie (bijvoorbeeld een TEM); of (3) het verlengen van de observatieperiode. Door het verlengen van de standaard wachttijd (8-10 weken) met nog een extra 6 tot 12 weken, kunnen patiënten met een nCR een cCR ontwikkelen. In hoofdstuk 2 hebben we onderzocht of het verlengen van de observatieperiode bij patiënten met een near cCR leidt tot een verslechterde oncologische uitkomst. We volgden 170 patiënten, waarvan er 102 een CCR hadden na het eerste herbeoordelingsmoment na CRT. Deze patiënten werden direct geïncludeerd in de W\&Wbehandeling (W\&W1). Van de 68 patiënten met een $\mathrm{nCR}$, waren er 19 patiënten die een TEM-operatie ondergingen en 49 patiënten die kozen voor een tweede herbeoordeling na 6 tot 12 weken. 44/49 (90\%) van deze patiënten hadden een cCR bij de tweede herbeoordeling en werden geïncludeerd in de W\&Wbehandeling (W\&W2). De patiënten in de W\&W2 hadden een niet-significante stijging van de kans op lokale teruggroei van de tumor zonder dat dit invloed had op de overleving. Concluderend lijkt het veilig om de observatieperiode na CRT te verlengen bij patiënten met een $\mathrm{nCR}$, in plaats van direct over te gaan op een chirurgische behandeling.

Een transanale endorectale microchirurgische procedure (TEM-operatie) wordt gebruikt bij patiënten met benigne adenomen of een vroeg stadium rectumcarcinoom, zoals bijvoorbeeld een T1sm1 tumor. De afgelopen jaren wordt TEM ook gebruikt als een alternatief voor een TME bij patiënten die nog een kleine resttumor hebben na behandeling met neoadjuvante CRT. Dit is in lijn met de groeiende interesse voor orgaansparende behandeling na neoadjuvante behandeling voor het rectumcarcinoom. Door deze nieuwe indicatie voor TEM, is het belangrijk dat we de patiënten goed kunnen opvolgen om te bepalen wat de lokale status is na de TEM procedure. Met name het opsporen van luminale en klierrecidieven is hierbij van belang. Daarom werd er in hoofdstuk $\mathbf{3}$ gekeken naar de diagnostische waarde van MRI in de follow-up van rectumcarcinoom patiënten die behandeld zijn met een TEM. Twee ervaren radiologen evalueerden 293 MRl's van 81 patiënten die TEM ondergingen. Achttien patiënten ontwikkelden een lokaal recidief. Areas under the curve (AUC) en reproduceerbaarheid waren gemiddeld tot goed voor het identificeren van recidieven. Daarnaast wordt deze identificatie steeds beter tijdens de follow-up. We concludeerden dat follow-up door middel van MRI na behandeling met TEM voor patiënten met een rectumcarcinoom een goede uitvoerbare optie is. 


\section{Deel II - kwaliteit van leven en functionele uitkomsten}

Behalve oncologische uitkomsten is ook de kwaliteit van leven van patiënten belangrijk voor een nieuwe behandeling. In hoofdstuk 4 werd de kwaliteit van leven van $W \& W$-patiënten vergeleken met de kwaliteit van leven van patiënten die de standaard behandeling hadden ondergaan (chemoradiatie en chirurgie). Belangrijk bij een W\&W-behandeling is het verbeteren van de kwaliteit van leven, vergeleken met de standaard behandeling, met tevens het behoud van een goede oncologische uitkomst. In de studie in hoofdstuk 4 worden twee groepen met elkaar vergeleken: 41 patiënten volgen een W\&W-beleid en 41 patiënten waren behandeld met CRT en TME. Patiënten werden gematched op basis van geslacht, leeftijd, tumorstadium en tumorhoogte. Voor inclusie in deze studie moesten patiënten ziektevrij zijn en minimaal 2 jaar in follow-up van de W\&W-behandeling zitten. De kwaliteit van leven werd gemeten aan de hand van gevalideerde vragenlijsten. Algemene gezondheid werd getest door middel van de SF-36 en EORTC-QLQ-C30. Ziekte-specifieke kwaliteit van leven werd bepaald door middel van de EORTC-QLQ-CR38 vragenlijst. De Vaizey- en LARS-score werden gebruikt om defecatieproblemen vast te stellen. De IIEF en FSFI werden gebruikt om seksuele problemen op te sporen en de IPSS voor het bepalen van urinaire dysfunctie. Patiënten in de W\&W-behandeling hadden een betere kwaliteit van leven op bijna alle domeinen, vergeleken met patiënten die behandeld werden met CRT en TME. Echter zorgt CRT alleen, zoals in het geval van een W\&W-behandeling, ook voor bijwerkingen op de lange termijn, want een derde van de patiënten in de W\&W-behandeling geeft ernstige LARSsymptomen aan.

Nu we uit hoofdstuk 4 weten dat chemoradiotherapie bij een rectumcarcinoom kan leiden tot defecatieproblemen, is de vraag of er een relatie is tussen de incidentie en ernst deze anorectale dysfunctie en de dosis van de radiotherapie op het rectum of de anus. Bij patiënten met een rectumcarcinoom is het normaliter moeilijk te bepalen of de klachten die optreden na de behandeling worden veroorzaakt door de neoadjuvante behandeling (chemoradiatie) of de chirurgische behandeling. In hoofdstuk 5 werd onderzocht wat de lange termijn anorectale functie is van patiënten in het watch-and-wait beleid. Dit is onderzocht door de anorectale functie te meten aan de hand van anorectale manometrie en vragenlijsten (LARS en Vaizey). Tevens hebben we gekeken naar de relatie tussen de anorectale functie en de radiotherapeutische dosis op het rectum of op het anale sfincter complex. Drieëndertig patiënten werden 
geïncludeerd in deze studie met een mediane follow-up duur van 37 maanden. De resultaten van deze studie lieten zien dat er een relatie lijkt te zijn tussen de $D_{\max }, V_{30 G y}, V_{35 G y}, V_{40 G y}$ van het anale sfincter complex en de Vaizey score, al zijn ze deze niet statistisch significant. Ook is er een relatie tussen $D_{\text {mean }}$ van het anale sfincter complex en de LARS score. De meest frequent genoemde klachten bij W\&W-patiënten zijn clustering van defecatie en fecale urgentie. Er werd geen relaties gevonden tussen de dosimetrische parameters en de anorectale sensorische functies via de manometrie (first sensation (FS), first urge to defecate (FUTD), en maximal tolerable volume (MTV)). Alle dosimetrische parameters van het anale sphincter complex, behalve de $V_{50 G y}$ zijn positief gecorreleerd met mean squeeze pressure (MSP). Echter moeten de resultaten van deze studie voorzichtig geïnterpreteerd worden. De analyses zijn gebaseerd op een kleine groep patiënten, waardoor het onmogelijk was om subgroep analyses uit te voeren. Er was alleen data bekend van één enkel tijdspunt en er is nog geen specifieke vragenlijst voor patiënten in een W\&Wbeleid. Maar ondanks deze limitaties, is dit de eerste studie die kijkt naar de specifieke effecten van chemoradiatie op de anorectale functie van patiënten met een rectumcarcinoom. Zeker met de huidige verandering in beleid naar het geven van (chemo)radiatie of een radiotherapie boost met de intentie om orgaansparend te behandelen, is het belangrijk om meer inzicht te krijgen in het mechanisme van anorectale functie vermindering na radiotherapie. Dit zou kunnen leiden tot het minimaliseren van de impact van radiotherapie op de anorectale functie, door bijvoorbeeld dosisreductie of het aanpassen van bestralingsvelden.

Patiënten met een rectumcarcinoom hebben minder recidieven en een betere oncologische uitkomst, doordat we eerder de ziekte kunnen diagnosticeren en door de verbetering van de behandeling in de afgelopen decennia. Maar deze betere overleving heeft ook nadelen. De meeste patiënten worden behandeld met sfincter besparende chirurgie, de low anterior resectie (LAR). 50 tot 90\% van de patiënten die een LAR ondergaan hebben een zekere vorm van darmproblematiek. We noemen dit het Low Anterior Resectie Syndroom (LARS). Door de ernst en de hoge incidentie van deze problemen, werd de LARS score ontwikkeld. Het doel van de studie in hoofdstuk 6 was het ontwikkelen en valideren van de Nederlandse vertaling van de LARS score in een populatie van Nederlandse patiënten met een rectumcarcinoom. De originele Deense versie van de LARS score werd eerst vertaald in het Engels en vervolgens in het Nederlands. Patiënten die een LAR ondergingen ontvingen de LARS score, een 
extra kwaliteit van leven vraag en de EORTC QLQ-C30 vragenlijst. Een subgroep van de patiënten ontving de vragenlijst tweemaal, om de test-retest betrouwbaarheid te bepalen. In deze studie werden 165 patiënten geïncludeerd, geïdentificeerd in zes deelnemende centra. De responsratio was 62\%. 59.4\% van de patiënten had 'major' LARS. Een groot deel van de patiënten had een perfect of een moderate fit tussen de LARS score en de kwaliteit van leven categorie. De LARS score kon daarnaast ook een onderscheid maken tussen groepen patiënten die verschilde in neoadjuvante behandeling met radiotherapie, die verschilde in type operatie of verschilde in leeftijd. Daarnaast bleek de LARS score ook betrouwbaar te zijn met een interclass correlatie coëfficiënt van 0.79. Samenvattend liet deze studie dus zien dat de Nederlandse versie van de LARS score een valide instrument is om LARS te beoordelen van Nederlandse patiënten met een rectumcarcinoom.

\section{Deel III - kosten}

In het laatste hoofdstuk, hoofdstuk 7, bespreken we de ziekenhuiskosten en oncologische uitkomsten van deze nieuwe behandelstrategie bij patiënten met een lokaal uitgebreid rectumcarcinoom, waarbij patiënten met een klinisch complete respons na chemoradiotherapie worden behandeld in een watch-andwait beleid, en patiënten met residuale tumor worden behandeld met chirurgie. De ziekenhuiskosten werden ingedeeld in vijf groepen: kosten voor de primaire chirurgie; kosten voor adjuvante chemotherapie; kosten voor diagnostiek; kosten voor extra chirurgie en kosten voor de behandeling van een recidief of metastasen. De gemiddelde kosten per patiënt zijn in de eerste twee jaar $€ 6.713$ voor patiënten in de W\&W subgroep en $€ 17.108$ voor patiënten in de TME subgroep. Tevens was de overleving in beide subgroepen goed en vergelijkbaar met de huidige literatuur. Concluderend kunnen we dan ook zeggen dat deze behandelstrategie waarin patiënten met een klinisch complete respons worden behandeld volgens de W\&W strategie en patiënten met resttumor worden behandeld met chirurgie, kostenbesparend lijkt te zijn. 



\section{Valorisation}


Appendix 1 


\section{Valorisation}

According to Appendix 4 of the Regulation Governing the Attainment of Doctoral Degrees (Maastricht University 2013), knowledge valorisation refers to the "process of creating value from knowledge, by making knowledge suitable and/or available for social and economic use and by making knowledge suitable for translation into competitive products, services, processes and new commercial activities". Five questions must be answered in this valorisation addendum: (1) what is the socio-economic relevance of the research results? (relevance); (2) for whom, outside the peer researchers, are the results relevant? (target population); (3) which concrete services/products can be obtained? (products); (4) what is the innovation value of the results? (innovation); and (5) what are the marketing strategies that can be applied? (planning and realisations).

\section{Socio-economic relevance}

The results of this thesis show that (1) patients with a near complete response (ncCR) after CRT can develop a clinical complete response (cCR) after another 6-12 weeks waiting, with no impact on the oncological outcome; (2) follow-up with MRI after Transanal Endoscopic Microsurgery (TEM) for rectal cancer is feasible; (3) patients in a W\&W-strategy show a better QoL, compared to patients treated with CRT and TME, and show less functional problems; (4) the validation of the Dutch version of the Low Anterior Resection Syndrome (LARS) score, and (5) the W\&W-strategy is a cost-saving strategy compared to CRT and TME.

Because of the feasibility of MRI as an follow-up technique for patients who underwent TEM for rectal cancer, an extra modality can be added in the followup of these patients. Studies have to show if the combination of endoscopy and MRI are the best practice in follow-up for TEM patients. The results of point 1, 3 and 5 are all based on patients with locally advanced rectal cancer who were treated with neoadjuvant CRT as part of the national guidelines. Maybe this organ-preservation could also be feasible for patients with an earlier stage of rectal cancer. Studies (TESAR and STARTREC) have to show the results in this group of patients. Since the W\&W-strategy is a cost-effective strategy, health insurance companies can accept the W\&W-treatment. The Dutch version of the 
LARS-score ensures a good and short scoring system for bowel dysfunction after low anterior resection (LAR).

\section{Target population}

National guidelines state that all patients with locally advanced rectal cancer are treated with neo-adjuvant CRT followed by a surgical resection. 15-20\% of these patients develop a cCR after CRT and could be considered for an organpreserving treatment, the so called watch-and-wait policy. As mentioned before, organ-preservation could also be feasible for patients with an earlier stage of rectal cancer. Studies (TESAR and STARTREC) have to show the results in this group of patients. The Dutch version of the LARS-score can be used in all rectal cancer patients with Dutch as mother tongue. The questionnaire was developed as a scoring system for bowel dysfunction after LAR for rectal cancer, on the basis of symptoms and impact on QoL.

\section{Products}

There are no new products that have been developed with the results of this thesis.

\section{Innovation and future}

The W\&W-policy, an organ preserving strategy for a selected group of rectal cancer patients has proven to be feasible and oncologically safe. More data and longer follow-up are necessary to confirm these results. In 2014 a multicentre collaboration has started to obtain these results. This international watch-andwait database centralizes the data of all main organ-preservation pioneers. The first results will be published soon. A recent multicentre study is started to obtain more data of Dutch W\&W-patients.

Data on functional outcome and quality of life is scarce. A prospective study has started to the quality of life and functional outcome of these patients at several time-points during a 5-year follow-up. In the recently started Dutch multicentre study, these results will also be obtained. The Dutch version of the LARS-score 
has been validated, as shown in this thesis. This questionnaire shall be translated and validated in more languages.

Cost-effectiveness has to be studied in an Markov simulation with a combination of data on costs and QoL. 

Appendix 2 


\section{Dankwoord}

$\mathrm{Na}$ een hele tijd is het dan eindelijk zo ver. Het schrijven van dit proefschrift komt tot een einde. Het heeft even op zich laten wachten, maar toch is het gelukt. Ik had dit natuurlijk niet kunnen doen zonder hulp van velen. In dit laatste, en misschien wel belangrijkste, hoofdstuk wil ik een aantal mensen graag bedanken.

Ten eerste wil ik mijn dank uiten aan alle patiënten die ik de afgelopen jaren heb mogen volgen tijdens hun behandeling voor endeldarmkanker. Het is fijn dat velen van hen bereid waren om deel te nemen aan diverse onderzoeken. Hun bijdrage aan deze onderzoeken zal helpen tot een verbetering van de gezondheidszorg, waarvoor grote dank.

Prof. dr. Beets, beste Geerard. Tijdens mijn wetenschappelijke stage bij de chirurgie wilde ik solliciteren voor een PhD plek bij de radiologie, bij Regina, toen ik al snel kreeg te horen dat jij iets veel leukers voor mij in petto had. Wat fijn dat je deze kans toen aan mij toevertrouwde, wat resulteerde in dit proefschrift. Ondanks je drukke agenda en de verhuizing naar het Amsterdamse, maakte je altijd tijd om te zorgen voor je promovendi in Maastricht. Je feedback op abstracts, presentaties en papers zorgde voor nieuwe aanvullingen en onderzoeksvoorstellen. Wat heb ik veel van je geleerd. Ik ben blij dat ik deel mocht uitmaken van het wait-and-see team, waar jij als Nederlandse kartrekker, veel aanzien mee hebt verworven.

Prof. dr. Beets-Tan, beste Regina. Zoals je zelf al omschreef, je hebt de ontwikkeling van mijn thesis goed mee kunnen volgen en af en toe, naast Geerard op de bank, input kunnen geven. Dankjewel dat ik onderdeel mocht uitmaken van het promotieteam van de familie Beets. Ik heb veel van je geleerd en ondanks de voornamelijk chirurgische insteek van dit proefschrift, was je altijd oprecht geïnteresseerd.

Dr. Breukink, beste Stéphanie. Door jouw enthousiasme startte ik mijn wetenschappelijke stage bij de chirurgie in het MUMC+, wat uiteindelijk leidde tot dit proefschrift. Je oprechte interesse in het onderzoek en mij als persoon waardeer ik enorm. Je dagelijkse begeleiding heeft ervoor gezorgd dat dit proefschrift tot stand is gekomen. Ik wil je bedanken voor je steun, goede ideeën, gezelligheid tijdens congressen en altijd aanwezige enthousiasme. 
Beste Monique, wat fijn dat je me zoveel geholpen hebt bij het schrijven van dit proefschrift. En wat fijn dat ook jij mijn copromotor wilde zijn. Ik vind het een hele eer om als eerste op je copromotorlijst te komen staan in functie als copromotor. Maar behalve onderzoek, hebben we ook veel gezellige momenten gehad, dankjewel hiervoor.

Beste leden van de leescommissie, prof. dr. Stassen, prof. dr. de Wilt, prof. dr. Lange, prof. dr. Boersma en dr. Mihl en alle leden van de corona, bedankt voor de kritische beoordeling van dit proefschrift. Beste dr. Buijsen, dankjewel voor je feedback op mijn proefschrift.

Natuurlijk wil ik ook alle coauteurs van de diverse papers bedanken. Zonder de fijne samenwerking was het onmogelijk geweest deze onderzoeken uit te voeren en de papers tot stand te laten komen. Dankjewel hiervoor.

Lieve kamergenootjes, wat hebben we een fijne tijd samen gehad. Het doen van promotieonderzoek zou nooit gelukt zijn als we dat niet samen hadden gedaan. Wat hebben we veel lol gehad, maar ook nog serieuze zaken kunnen bespreken. Lieve Rianne, dankjewel voor je fijne samenwerking de afgelopen jaren. Wat was het fijn om je weer tegen te komen in het Zuyderland en nu gelukkig ook weer veel erbuiten. Dankjewel voor je steun en adviezen bij het maken van mijn keuzes. Lieve Miriam, zelf zei je het ook al in je dankwoord, wat zaten we vaak op één lijn. Onze gedeelde, soms misschien rare obsessies, hebben ons veel plezier opgeleverd tijdens onze promotietijd. Bedankt voor je fijne samenwerking en fijne vriendschap in de afgelopen jaren. Nu we allemaal een andere kant zijn opgegaan, kunnen we bijna een compleet MDO-team vormen.

Lief Recteam, wat fijn dat ik aan dit mooie lijstje mensen mag aansluiten. Er zullen zeker mensen zijn die ik vergeet te benoemen, gezien het lijstje al behoorlijk lang begint te worden. Max en Doenja, ook al deed ik geen onderzoek samen met jullie, en hadden jullie misschien geen flauw idee wat ik allemaal uitvoerde, toch was het altijd gezellig bij elk recteamuitje, van spontane Disney bezoekjes tot aan concerten van niet nader te noemen artiesten (laten we er een traditie van maken;)). Lieve Milou, wat fijn dat ik als WESP-student bij jou aan de slag mocht, om vervolgens nog veel langer in het team te blijven. Maar nog meer bedankt voor alle leuke momenten in Maastricht, maar ook op 
congressen in Barcelona, Dublin en Berlijn. Joost en Rebecca dankjulliewel voor de fijne tijd samen tijdens deze periode. Lieve Hester, wat leuk dat jij de wait-and-see projecten gaat voortzetten. Heel veel succes hiermee.

Lieve Marit, ik ben je heus niet vergeten in het bovenstaande rijtje. Wat fijn dat jij als WESP-student onderzoek kwam doen in ons team en dit hebt kunnen voortzetten in een eigen promotietraject. Het is fijn om zo'n goede opvolger te hebben. Maar behalve een goede opvolger ben je ook een ontzettend fijne vriendin geworden. Dankjewel voor alle gezelligheid en leuke momenten. Wat ben ik blij dat je vandaag naast me wil staan als paranimf.

Het mooie van onderzoek doen op twee afdelingen, is dat je ook veel mensen leert kennen. De afdeling chirurgie, met in het bijzonder Jarno Melenhorst, wil ik graag bedanken voor de prettige samenwerking. Een bijzonder woord van dank gaat naar Christel Gielen, voor de goede begeleiding van alle wait-andsee patiënten. Dames van het oncologiecentrum, dankjewel voor het overnemen van alle klinische taken. De afdeling radiologie, met in het bijzonder Janneke Houwers en Frans Bakers, wil ik bedanken voor de fijne samenwerking en voor de vele kennis die jullie me hebben bijgebracht (tenminste, ik denk dat ik nu een idee heb wat ik ongeveer zie op een MRI rectum). Dames van het secretariaat, met in het bijzonder Christianne, Elfie en Monique en dames en heren van de radiologiebalie, dankjewel voor de fijne samenwerking. Doordat de behandeling van het rectumcarcinoom multidisciplinair is, heb ik naast vele collega's bij de radiologie en chirurgie ook mogen samenwerken met andere afdelingen, zoals de medische oncologie, MDL en radiotherapie. Tevens wil ik GROW, met in het bijzonder prof. dr. Ramaekers en Brigitte Custers, en de dames en heer van het DataCenter Maastro bedanken voor hun samenwerking. Tevens wil ik natuurlijk ook alle verwijzers van wait-and-see kandidaten bedanken voor hun fijne samenwerking.

Beste collega-onderzoekers van de radiologie en chirurgie, bedankt voor alle gezellige momenten in de afgelopen jaren, niet alleen op het werk, maar ook in de Thembi, op (kerst)borrels, feestjes, et cetera. Een paar mensen wil ik toch graag nog even benoemen. Thiemo, wat leuk dat we beiden in een chirurgisch/radiologisch promotietraject kwamen na onze semi-artsperiode. We zullen elkaar nu weer wat vaker gaan tegenkomen. Bedankt Babs en Nienke voor de gezelligheid één kamer verderop, en dankjewel Jeroen voor alle gezelligheid aan de andere kant. Lieve Briete, wat ben ik blij met jou als collega 
en vriendin. Lieve Paul, Ilse en Marit, wat goed dat we als 'harde kern' overbleven in de pub in Dublin, wat geleid heeft tot deze leuke groep. Ik weet zeker dat promoveren niet zo leuk was geweest en nooit zo snel (nou ja, snel) zou zijn gegaan zonder jullie. Wat waren al die drankjes, koffietjes, congressen, weekendjes weg of late stapavonden een goede afwisseling tussen al het onderzoek. Natuurlijk wil ik alle andere GE-onderzoekers bedanken voor de gezelligheid tijdens het jaarlijkse ESCP congres. Naast mijn mede-onderzoekers wil ik ook graag alle studenten die een bijdrage hebben geleverd aan de papers bedanken voor hun inzet, met speciale dank aan Renee.

Lieve oud-collega's van de chirurgie in het Zuyderland, dankjewel dat ik bijna een jaar deel hebben mogen uitmaken van dit team. Dankjewel voor alle leerzame momenten en nieuwe inzichten. Eén van deze inzichten resulteerde in een AIOS plek radiotherapie bij de Maastro Clinic. Dankjewel nieuwe collega's dat ik mijn eerste maanden van mijn opleiding de tijd kreeg om dit proefschrift af te ronden. Ik hoop nog veel te leren van jullie.

Natuurlijk zijn er ook mensen buiten mijn onderzoek en werk die ik graag wil bedanken voor hun bijdrage, op welke manier dan ook, aan dit boekje. Lieve '1. FC Feuerschweine', lieve Bjorn, Christian, Cyriel, Dennis, Dinah, Erwin, Femke, Ilse, Lars, Laurie, Luc, Marja, Max, Mike, Nadine, Natalia, Noël, Ramon, Rebecca, Rens, Roel, Romy, Ronald, Saskia, Tim en Tom, wat moet ik toch zonder zulke goede vrienden?! De gezellige momenten van de afgelopen jaren, en dit zijn er té veel om op te noemen, zorgden voor een goede afleiding tijdens mijn promotietraject. Een speciaal woord van dank gaat naar Lars, als mede PhD'er. Altijd fijn om met iemand promotieperikelen te kunnen bespreken. Speciaal hiervoor heb ik een heel hoofdstuk naar jou vernoemd (zie hoofdstuk 6).

Lieve Ivy, wat vind ik het fijn dat jij vandaag, als paranimf, hier naast me staat. Beste vriendinnetjes sinds groep 1 van de basisschool en nog steeds een hele fijne vriendschap. Wat hebben we in al die jaren toch veel mooie dingen samen meegemaakt. Wat fijn dat we, ondanks de afstand, elkaar nog vaak zien en spreken. Lieve Simone, ook wij zijn al heel lang vriendinnen. Wat fijn dat je er altijd voor me bent. Lieve Tirza, wat ben ik blij met zo'n lief vriendinnetje als jij.

Lieve meisjes 2.0, Femke, Iris, Lotte, Myrna en Renske en mannen, wat ben ik blij met jullie als vriendinnetjes. Sinds jaar 1 van de geneeskundeopleiding kennen we elkaar en hebben we samen al veel mooie momenten meegemaakt. Ons jaarlijks terugkerende weekendje weg (met of zonder geheime bestemming) moeten we blijven voortzetten. Dankjewel voor jullie fijne vriendschap. Een 
speciaal woord van dank gaat naar Luuk voor het ontwerpen van dit proefschrift.

Lieve Bram, wat fijn dat je er al 10 jaar voor me bent met je al je steun en vertrouwen. Je zegt zelf altijd dat je nauwelijks een bijdrage hebt geleverd aan dit proefschrift, maar zonder jou was het er nooit van gekomen. CTRL + F Bram, mocht je je naam zoeken in dit proefschrift. Beste schoonfamilie, ook jullie wil ik natuurlijk bedanken.

Lieve papa, mama en Kai. Dankjewel voor alles wat jullie voor me doen en voor me betekenen. Zonder jullie onvoorwaardelijke steun, hulp en motivatie was ik niet de persoon geworden die ik nu ben. 

Curriculum vitae 
Appendix 3 


\section{Curriculum vitae}

Britt Hupkens was born on the $1^{\text {st }}$ of September 1990 in Meerssen. After graduating secondary school (Stella Maris College, Meerssen), she started her medical study at the Faculty of health, medicine and life sciences of Maastricht University. She completed her medicine study at the department of Surgery of Maastricht University Medical Centre, under supervision of dr. Stéphanie Breukink. Her research, during her study Medicine, focused on 'the quality of life of patients in a watchand-wait policy in rectal cancer', resulted in a

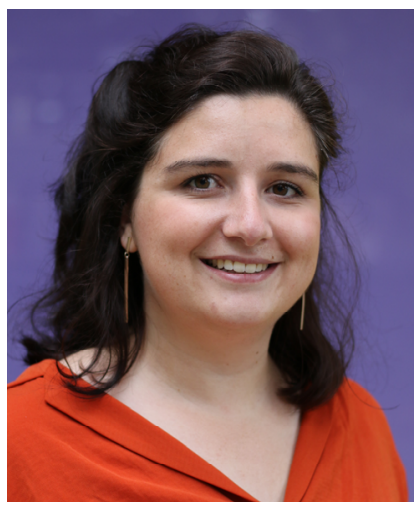
publication in an international peer-reviewed journal (as part of this thesis) and was awarded 'the best-student abstract' during the national meeting of the "Nederlandse Vereniging voor Gastro-Enterologie" in 2014.

In 2014, immediately after obtaining her medical doctor degree, she started working as a PhD student at the GROW School for Oncology and Developmental Biology under supervision of prof. dr. Geerard Beets, prof. dr. Regina Beets-Tan, dr. Stéphanie Breukink and dr. Monique Maas, focussing on the watch-and-wait policy in patients with rectal cancer. This resulted in several conference contributions including oral and poster presentations at the "Nederlandse Vereniging voor Heelkunde" (2015, 2016 - Veldhoven), "Nederlandse Vereniging voor Gastro-Enterologie" (2014, 2016, 2017 in Veldhoven), and the Annual meeting of the "European Society of Coloproctology" (2014 in Barcelona, 2015 in Dublin, 2016 in Milano, 2017 in Berlin, and 2018 in Nice). More importantly, this research resulted in a number of publications which form the basis of this thesis. In February 2018 she started working as a surgical resident at the Zuyderland Medical Center in Sittard/Heerlen under the supervision of dr. Meindert Sosef and drs. Erik de Loos. In January 2019 she started working as radiotherapist in training at the Maastro Clinic in Maastricht under the supervision of dr. Angela van Baardwijk and dr. Rinus Wanders. 



\section{List of publications}


Appendix 4 


\section{List of publications}

\section{This thesis}

BJP Hupkens, GL Beets. How and when to practice a wait and see policy taking care of the patient safety? Multidisciplinary Management of Rectal Cancer 2nd ed; Chapter 64, 2016

BJP Hupkens, M Maas, MH Martens, ME van der Sande, DMJ Lambregts, SO Breukink, J Melenhorst, JB Houwers, C Hoff, MN Sosef, JWA Leijtens, M Berbee, RGH Beets-Tan, G Beets. Organ preservation in rectal cancer after chemoradiation: should we extend the observation period in patients with a clinical near complete response? Ann Surg Oncol. 2018 Jan;25(1):197-203

BJP Hupkens, M Maas, MH Martens, WMLLG Deserno, JWA Leijtens, PJ Nelemans, FCH Bakers, DMJ Lambregts, GL Beets, RGH Beets-Tan. MRI surveillance for the detection of local recurrence in rectal cancer after Transanal Endoscopic Microsurgery. Eur Radiol. 2017 Dec;27(12):4960-4969

BJP Hupkens, MH Martens, JH Stoot, M Berbee, J Melenhorst, RG Beets-Tan, GL Beets, SO Breukink. Quality of life in rectal cancer patients after chemoradiation: watch-and-wait policy versus standard resection - a matched controlled study. Dis Colon Rectum 2017 Oct;60(10):1032-1040

ME van der Sande, BJP Hupkens, M Maas, SMJ van Kuijk, M Berbee, J Melenhorst, GL Beets, SO Breukink. Impact of radiotherapy on anorectal function in patients with rectal cancer following a watch and wait programme. Radiother Oncol 2019 Mar;132:79-84

BJP Hupkens, SO Breukink, PJ Tanis, ME de Noo, P van Duijvendijk, HL van Westreenen, JWT Dekker, T Chen, T Juul. Dutch validation of the Low Anterior Resection Syndrome Score. Colorectal Dis. 2018 Oct;20(10):881-887

BJP Hupkens, SO Breukink, JHMB Stoot, RE Toebes, ME van der Sande, J Melenhorst, GL Beets, CD Dirksen. Oncological outcomes and hospital costs of the new triage policy in locally advanced rectal cancer: watch and wait policy and standard surgical treatment. Submitted in Dis Colon Rectum, 2019 


\section{Other}

BJP Hupkens, GL Beets, SO Breukink. Quality of Life in Rectal Cancer Patients After Chemoradiation: Watch-and-Wait Policy Versus Standard Resection - Are we comparing apples to oranges? - the Author's reply. Dis Colon Rectum. 2018 Mar;61(3):e22

MJM van der Valk, DE Hilling, E Bastiaannet, E Meershoek-Klein Kranenbarg, GL Beets, NL Figueiredo, A Habr-Gama, RO Perez, AG Renehan, GL Beets, $\mathrm{CJH}$ van de Velde, and the IWWD Consortium. Long-term outcomes of clinical complete responders after neoadjuvant treatment for rectal cancer in the International Watch \& Wait Database (IWWD): an international multicentre registry study. Lancet. 2018 Jun 23;391(10139):2537-2545

BJP Hupkens, M Maas. ASO Author Reflections: Decision Timing for Organ Preservation in Rectal Cancer After Chemoradiation. Ann Surg Oncol. 2018 Dec;25(Suppl 3):854-855

ME van der Sande, GL Beets, BJP Hupkens, SO Breukink, J Melenhorst, FCH Bakers, DMJ Lambregts, HI Grabsch, RGH Beets-Tan, M Maas. Response assessment after (chemo)radiotherapy for rectal cancer: why are we missing complete responses with MRI and endoscopy? European Journal of Surgical Oncology, 2019 Jun;45(6):1011-1017

DMJ Lambregts, M Maas, T Boellaard, A Delli Pizzi, ME van der Sande, BJP Hupkens, MJ Lahaye, FCH Bakers, RGH Beets-Tan, GL Beets. Long-term imaging characteristics of clinical complete responders during watch-and-wait for rectal cancer - an evaluation of $>1500$ MRIs. Accepted in European Radiology, 2019

\section{Work in progress}

BJP Hupkens, ME van der Sande, SO Breukink, J Buijsen, J de Vos-Geelen, GL Beets, J Melenhorst. Synchronous metastases in patients in a watch-andwait strategy for rectal cancer. 